Cochrane Database of Systematic Reviews

\title{
Immunonutrition for patients undergoing surgery for head and neck cancer (Review)
}

Howes N, Atkinson C, Thomas S, Lewis SJ

Howes N, Atkinson C, Thomas S, Lewis SJ.

Immunonutrition for patients undergoing surgery for head and neck cancer.

Cochrane Database of Systematic Reviews 2018, Issue 8. Art. No.: CD010954.

DOI: 10.1002/14651858.CD010954.pub2.

www.cochranelibrary.com 
TABLE OF CONTENTS

ABSTRACT 1

PLAIN LANGUAGE SUMMARY

SUMMARY OF FINDINGS

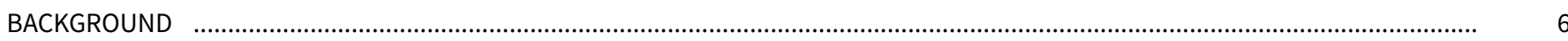

OBJECTIVES

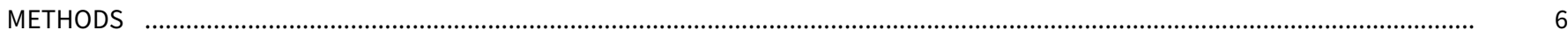

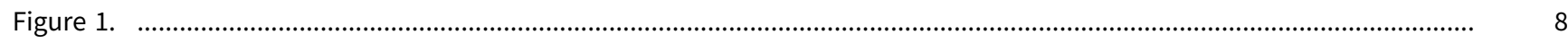

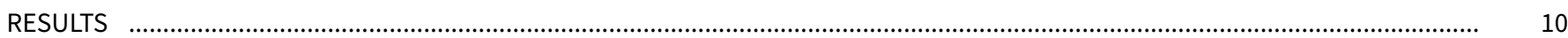

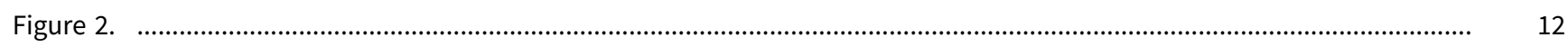

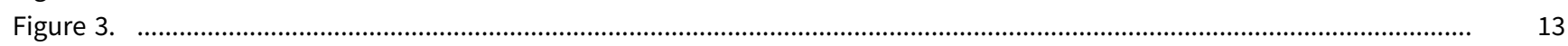

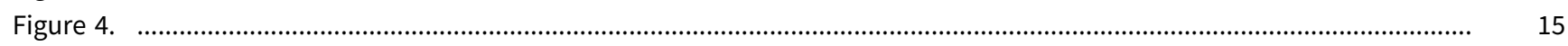

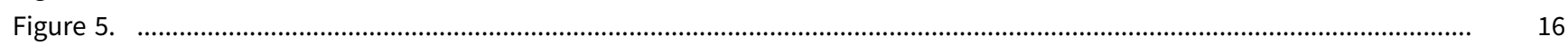

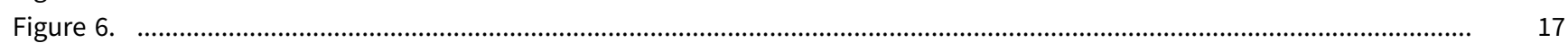

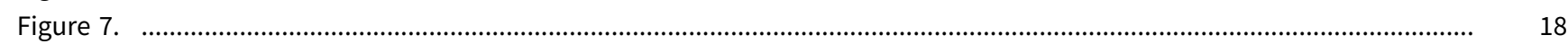

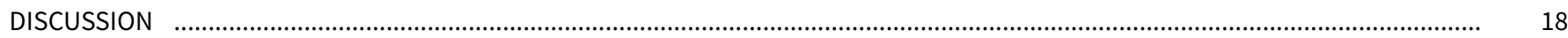

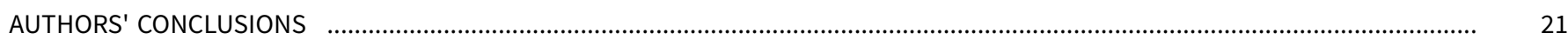

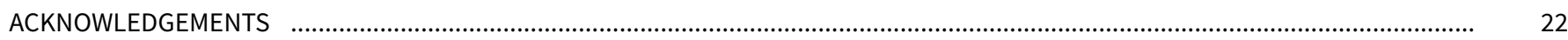

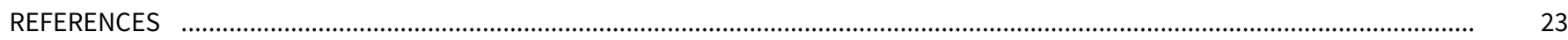

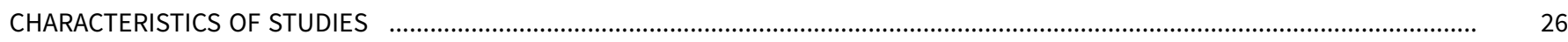

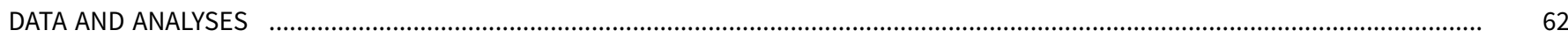

Analysis 1.1. Comparison 1 Immunonutrition versus standard care, Outcome 1 Postoperative length of hospital stay. ............ 62

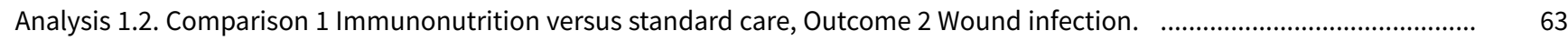

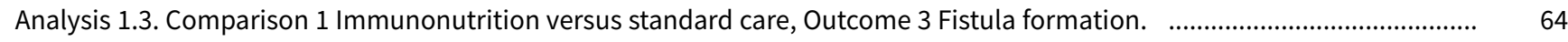

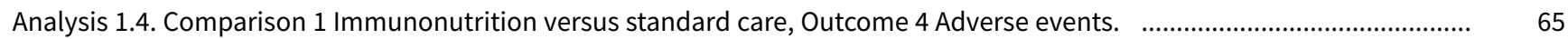

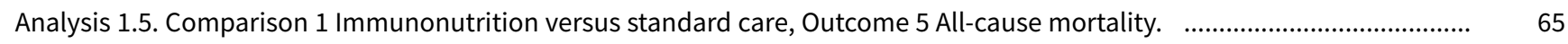

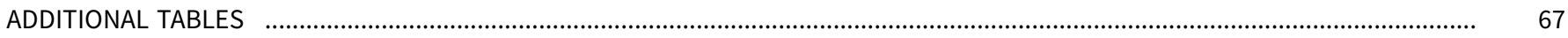

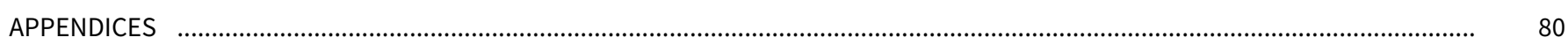

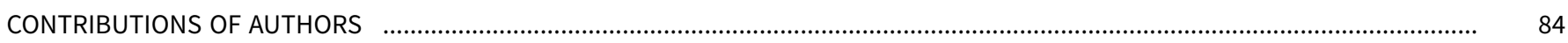

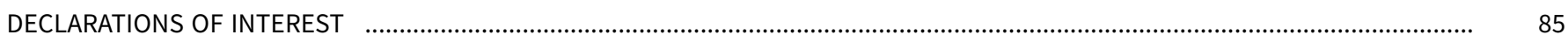

SOURCES OF SUPPORT

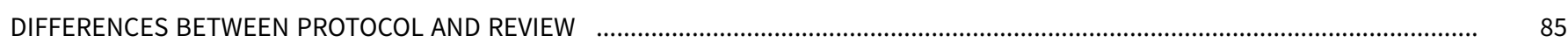

INDEX TERMS 
[Intervention Review]

\section{Immunonutrition for patients undergoing surgery for head and neck cancer}

Noah Howes ${ }^{1}$, Charlotte Atkinson ${ }^{2}$, Steven Thomas ${ }^{3}$, Stephen J Lewis ${ }^{4}$

1University of Bristol, Bristol, UK. 2NIHR Bristol Biomedical Research Centre, University Hospitals Bristol NHS Foundation Trust and the University of Bristol, Bristol, UK. ${ }^{3}$ Head \& Neck Surgery, University Hospitals Bristol NHS Trust, Bristol, UK. ${ }^{4}$ Department of Gastroenterology, Derriford Hospital, Plymouth, UK

Contact: Stephen J Lewis, Department of Gastroenterology, Derriford Hospital, Derriford Road, Plymouth, Devon, PL6 8DH, UK. sjl@doctors.org.uk.

Editorial group: Cochrane ENT Group.

Publication status and date: New, published in Issue 8, 2018.

Citation: Howes N, Atkinson C, Thomas S, Lewis SJ. Immunonutrition for patients undergoing surgery for head and neck cancer. Cochrane Database of Systematic Reviews 2018, Issue 8. Art. No.: CD010954. DOI: 10.1002/14651858.CD010954.pub2.

Copyright @ 2018 The Cochrane Collaboration. Published by John Wiley \& Sons, Ltd.

\section{A B S T R A C T}

\section{Background}

Patients with head and neck cancer are often malnourished. Surgery for such cancers is complex and may be undertaken after a course of radiotherapy. As a result, patients may have postoperative complications such as fistulae and wound infections, as well as more generalised infections such as pneumonia. One possible way to enhance recovery, and reduce the incidence of these complications, is by improving nutrition. Nutritional formulas that deliver basic nutrients as well as amino acids (arginine and glutamine), ribonucleic acid (RNA) and/or lipids (omega-3 fatty acids) are known as immunonutrition.

\section{Objectives}

To assess the effects of immunonutrition treatment, compared to standard feeding, on postoperative recovery in adult patients undergoing elective (non-emergency) surgery for head and neck cancer.

\section{Search methods}

The Cochrane ENT Information Specialist searched the ENT Trials Register; Central Register of Controlled Trials (CENTRAL); PubMed; Ovid Embase; CINAHL; Web of Science; ClinicalTrials.gov; ICTRP and additional sources for published and unpublished trials. The date of the search was 14 February 2018.

\section{Selection criteria}

We included randomised controlled trials (RCTs) comparing immunonutrition given either preoperatively, postoperatively or perioperatively to adult patients (18 years of age or older) undergoing an elective surgical procedure for head and neck cancer, compared with a control group receiving either standard polymeric nutritional supplements or no supplements.

\section{Data collection and analysis}

We used the standard methodological procedures expected by Cochrane. The primary outcomes were: length of hospital stay (days), wound infection, fistula formation and adverse events/tolerance of feeds, as defined by trial authors. Secondary outcomes were: all-cause mortality and postoperative complications (as defined by trial authors). We used GRADE to assess the quality of the evidence for each outcome; this is indicated in italics. 


\section{Main results}

We included 19 RCTs (1099 participants). The mean age of participants ranged from 47 to 66 years. Most studies (12/19) had fewer than 25 patients in each treatment group. Most studies (16/19) used immunonutrition formulas containing arginine, but there was variation in the actual products and amounts used, and in the length of intervention postoperatively. Follow-up time for outcome measurement varied considerably across studies, ranging from five days to greater than or equal to 16 months.

\section{Primary outcomes}

We found no evidence of a difference in the length of hospital stay (mean difference -2.5 days, $95 \%$ confidence interval (CI) -5.11 to 0.12 ; 10 studies, 757 participants; low-quality evidence). Similarly, we found no evidence of an effect of immunonutrition on wound infection (risk ratio (RR) $0.94,95 \% \mathrm{Cl} 0.70$ to $1.26 ; 12$ studies, 812 participants; very low-quality evidence). Fistula formation may be reduced with immunonutrition; the absolute risks were $11.3 \%$ and $5.4 \%$ in the standard care and immunonutrition groups, with a RR of $0.48(95 \% \mathrm{Cl} 0.27$ to $0.85 ; 10$ studies, 747 participants; low-quality evidence). We found no evidence of a difference in terms of tolerance of feeds ('adverse events') between treatments (RR 1.33, $95 \% \mathrm{Cl} 0.86$ to 2.06; 9 studies, 719 participants; very low-quality evidence).

\section{Secondary outcomes}

We found no evidence of a difference between treatments in all-cause mortality (RR 1.33, 95\% $\mathrm{Cl} 0.48$ to 3.66 ; 14 studies, 776 participants; low-quality evidence). Other postoperative complications such as pneumonia and urinary tract infections were not commonly reported.

\section{Authors' conclusions}

The risk of postoperative fistula formation may be reduced with immunonutrition, but we found no evidence of an effect of immunonutrition on any of the other outcomes that we assessed. The studies included in this review were generally small or at high risk of bias (or both). We judged the overall quality of the evidence to be low for the outcomes length of hospital stay and all-cause mortality, and very low for wound infection and adverse events. Further research should include larger, better quality studies.

\section{PLAIN LANGUAGE SUMMARY}

\section{Immunonutrition for patients undergoing surgery for head and neck cancer}

\section{Review question}

This review compared how people recover after surgery for head and neck cancer if they have been given either 'immunonutrition' or a standard feed before and after or only after the surgery. We looked at how long people stayed in hospital, whether they had any complications and how many people in each treatment group died.

\section{Background}

Head and neck cancer surgery usually means surgery to treat cancer of the mouth, throat or larynx (voice box). The surgery is complicated and people often experience problems such as wound infections and wound breakdown, as well as infections such as pneumonia. These can lead to a longer stay in hospital. Specific nutrients, for example amino acids (found in protein-based foods), omega-3 fatty acids (often found in fish oils) and nucleotides (found in many foods) have been investigated for their role in helping people recover from surgery. When any of these specific nutrients are added to the patient's feed it is called immunonutrition. We wanted to see whether feeding people immunonutrition improved recovery (for example, led to a shorter length of stay and fewer complications) when compared with a standard feed.

\section{Study characteristics}

We included 19 studies that recruited 1099 adults in total (studies ranged in size from 8 to 209 participants, but most (12 out of 19) had fewer than 25 participants per treatment group). The studies focused on people who were given immunonutrition or a standard feed before and after or only after their surgery. The studies varied in the length of time over which people were given the feeds, but this was usually at least five days. The evidence is current to February 2018.

\section{Key results}

We did not find evidence of a difference in the length of hospital stay but there was wide variation between the individual studies in what they showed. We found some evidence that people who had immunonutrition may be about half as likely to have breakdown of their surgical wound called a fistula (a channel between the inside of the throat and the surface skin). We found no evidence that immunonutrition had any effect on wound infection (but not all studies were clear in how they measured this) or death. Study feeds were generally well tolerated and there was no evidence of a difference in adverse events such as diarrhoea between treatment groups. Other clinical complications such as pneumonia and urinary tract infections were not commonly reported, but there was little evidence of a reduction with immunonutrition.

\section{Quality of the evidence}


Most studies included in this review were small and poorly reported, which means that their results may be less reliable. More studies are needed that are larger, of better quality and conducted within current healthcare systems. 


\begin{tabular}{|c|c|c|c|c|c|c|}
\hline \multicolumn{7}{|c|}{$\begin{array}{l}\text { S U M M A R Y O F F I N D I N G S } \\
\text { Summary of findings for the main comparison. Immunonutrition compared to standard care for patients undergoing surgery for head and neck } \\
\text { cancer }\end{array}$} \\
\hline \multicolumn{7}{|c|}{ Immunonutrition compared to standard care for patients undergoing surgery for head and neck cancer } \\
\hline \multicolumn{7}{|c|}{$\begin{array}{l}\text { Patient or population: patients undergoing surgery for head and neck cancer } \\
\text { Setting: hospitals (international) } \\
\text { Intervention: immunonutrition } \\
\text { Comparison: standard care }\end{array}$} \\
\hline \multirow[t]{2}{*}{ Outcomes } & \multicolumn{2}{|c|}{ Anticipated absolute effects* $(95 \% \mathrm{Cl})$} & \multirow{2}{*}{$\begin{array}{l}\text { Relative effect } \\
(95 \% \mathrm{CI})\end{array}$} & \multirow{2}{*}{$\begin{array}{l}\text { № of partici- } \\
\text { pants } \\
\text { (studies) }\end{array}$} & \multirow{2}{*}{$\begin{array}{l}\text { Certainty of } \\
\text { the evidence } \\
\text { (GRADE) }\end{array}$} & \multirow[t]{2}{*}{ Comments } \\
\hline & $\begin{array}{l}\text { Risk with stan- } \\
\text { dard care }\end{array}$ & $\begin{array}{l}\text { Risk with im- } \\
\text { munonutrition }\end{array}$ & & & & \\
\hline $\begin{array}{l}\text { Postoperative length of hos- } \\
\text { pital stay (days) } \\
\text { Follow-up: } 8 \text { to } 90 \text { days } \\
\text { post surgery or hospital dis- } \\
\text { charge }\end{array}$ & $\begin{array}{l}\text { The mean of re- } \\
\text { ported length } \\
\text { of hospital stay } \\
\text { (mean values) } \\
\text { across the stan- } \\
\text { dard care groups } \\
\text { was } 27.0 \text { (17.4 to } \\
\text { 36.1) days }\end{array}$ & $\begin{array}{l}\text { The mean of report- } \\
\text { ed length of hos- } \\
\text { pital stay (mean } \\
\text { values) across the } \\
\text { immunonutrition } \\
\text { groups was } 23.2 \text { ( } 15.3 \\
\text { to } 31.1 \text { ) days }\end{array}$ & $\begin{array}{l}\text { MD } 2.5 \text { lower } \\
\text { (5.11 lower to } \\
0.12 \text { higher) }\end{array}$ & $\begin{array}{l}757 \\
\text { (10 RCTs) }\end{array}$ & $\begin{array}{l}\oplus \oplus \odot \odot \\
\text { LOW1 }\end{array}$ & $\begin{array}{l}\text { There may be a reduction in the } \\
\text { length of hospital stay of } 2.5 \text { days } \\
\text { with immunonutrition, but the esti- } \\
\text { mate is imprecise (wide } \mathrm{Cl} \text { ) and in- } \\
\text { cludes the null value. }\end{array}$ \\
\hline \multirow{2}{*}{$\begin{array}{l}\text { Wound infection } \\
\text { Follow-up: } 8 \text { to } 90 \text { days } \\
\text { post surgery or hospital dis- } \\
\text { charge }\end{array}$} & \multicolumn{2}{|l|}{ Study population } & \multirow{2}{*}{$\begin{array}{l}\text { RR } 0.94 \\
\text { (0.70 to } 1.26)\end{array}$} & \multirow{2}{*}{$\begin{array}{l}812 \\
(12 \text { RCTs) }\end{array}$} & \multirow{2}{*}{$\begin{array}{l}\oplus \odot \odot \odot \\
\text { VERY LOW } 1,2\end{array}$} & \multirow{2}{*}{$\begin{array}{l}\text { Immunonutrition may have little or } \\
\text { no effect on wound infection, but the } \\
\text { evidence is very uncertain. }\end{array}$} \\
\hline & 145 per 1000 & $\begin{array}{l}136 \text { per } 1000 \\
(101 \text { to } 182)\end{array}$ & & & & \\
\hline \multirow{2}{*}{$\begin{array}{l}\text { Fistula formation } \\
\text { Follow-up: } 8 \text { to } 90 \text { days } \\
\text { post surgery or hospital dis- } \\
\text { charge }\end{array}$} & \multicolumn{2}{|l|}{ Study population } & \multirow{2}{*}{$\begin{array}{l}\text { RR } 0.48 \\
\text { (0.27 to } 0.85)\end{array}$} & \multirow{2}{*}{$\begin{array}{l}747 \\
(10 \mathrm{RCTs})\end{array}$} & \multirow{2}{*}{$\begin{array}{l}\oplus \oplus \odot \ominus \\
\text { LOW } 1\end{array}$} & \multirow{2}{*}{$\begin{array}{l}\text { There may be an approximate halv- } \\
\text { ing of the risk of fistulae formation } \\
\text { but the evidence is of low quality. }\end{array}$} \\
\hline & 113 per 1000 & $\begin{array}{l}54 \text { per } 1000 \\
\text { (31 to } 96)\end{array}$ & & & & \\
\hline \multirow{2}{*}{$\begin{array}{l}\text { Adverse events/tolerance of } \\
\text { feeds } \\
\text { Follow-up: } 10 \text { to } 90 \text { days } \\
\text { post surgery or hospital dis- } \\
\text { charge }\end{array}$} & \multicolumn{2}{|l|}{ Study population } & \multirow{2}{*}{$\begin{array}{l}\text { RR } 1.33 \\
\text { (0.86 to } 2.06)\end{array}$} & \multirow{2}{*}{$\begin{array}{l}719 \\
\text { (9 RCTs) }\end{array}$} & \multirow{2}{*}{$\begin{array}{l}\oplus \ominus \ominus \ominus \\
\text { VERY LOW } 1,3\end{array}$} & \multirow{2}{*}{$\begin{array}{l}\text { There may be little or no difference } \\
\text { in adverse events such as diarrhoea } \\
\text { between the treatment groups, but } \\
\text { the evidence is very uncertain. }\end{array}$} \\
\hline & 91 per 1000 & $\begin{array}{l}121 \text { per } 1000 \\
\text { (78 to } 188)\end{array}$ & & & & \\
\hline
\end{tabular}

Patient or population: patients undergoing surgery for head and neck cancer

Setting: hospitals (international) 


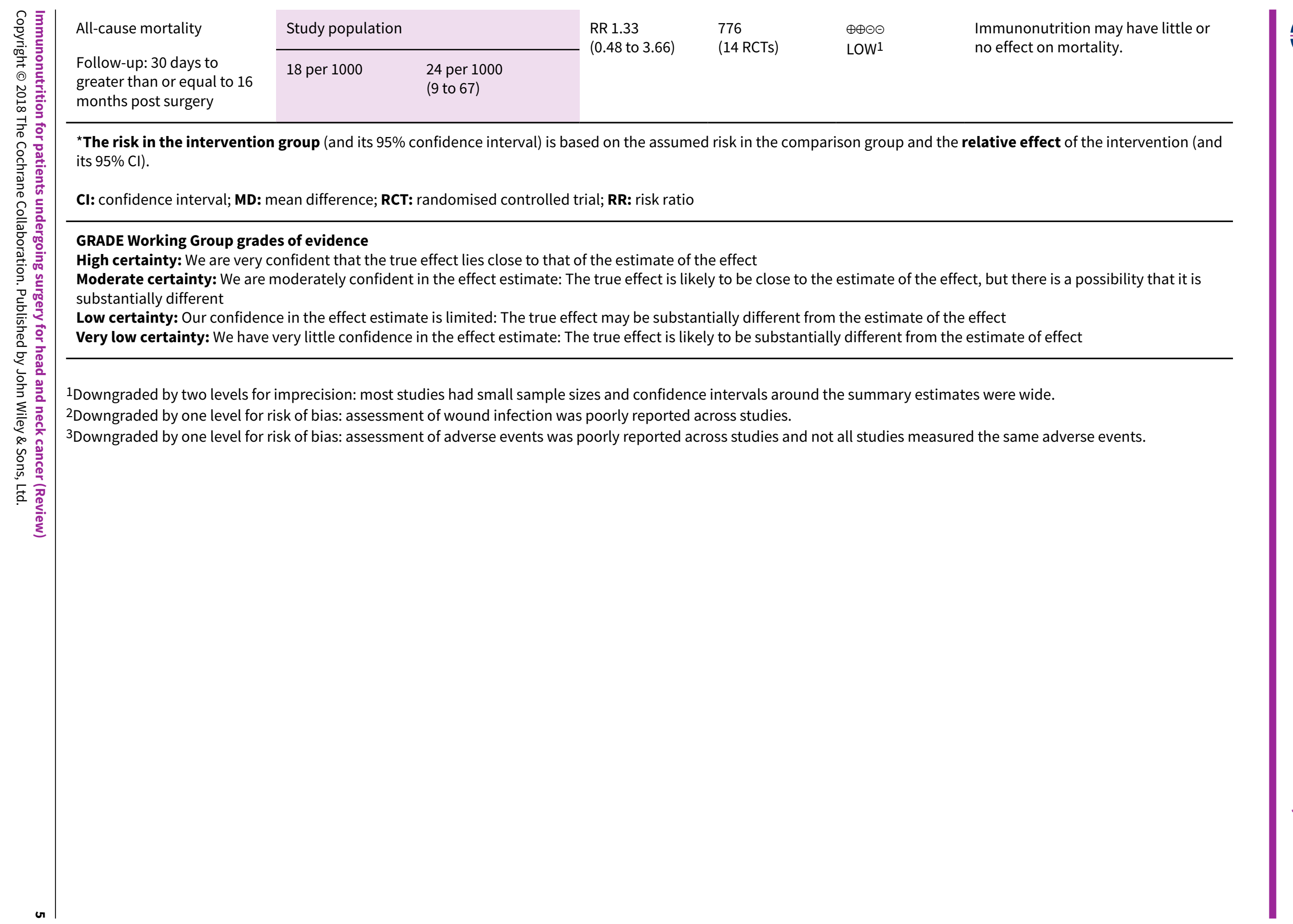




\section{B A C K G R O U N D}

\section{Description of the condition}

The term 'head and neck cancer' encompasses several sites including oral and laryngeal cancers. In 2014, over 11,000 people in the UK were diagnosed with cancers at these sites (Cancer Research UK). Surgical treatment of head and neck cancer can be aggressive and highly complex, and people undergoing these surgeries may have a $30 \%$ to $60 \%$ incidence of postoperative complications including wound infections and other infections such as pneumonia (Kucur 2015; McMahon 2013; Perisanidis 2012; Yang 2014). This substantial morbidity has inevitable implications for both patients and healthcare systems. Furthermore, a recent systematic review and meta-analysis showed that postoperative complications, especially infections, adversely affect long-term survival (Pucher 2014).

Many patients with head and neck cancer are malnourished for a number of reasons including mechanical obstruction, tumourinduced cachexia, poor dietary habits and excessive alcohol consumption. Poor nutrition is known to have an adverse impact on outcome in this patient group (van Bokhorst 2000). These patients have well-documented immune defects including Tlymphocytopenia and dysfunction, and reduced monocyte HLADR expression (Hadden 1997). These defects, combined with the immune suppressive effects of surgery, may contribute to increased postoperative complications such as poor wound healing and sepsis.

\section{Description of the intervention}

Nutrition supports immune function by preventing or reversing immunosuppression related to malnutrition. Standard commercial nutritional supplements are described as polymeric, which means they contain whole protein, partially digested starch and triglycerides, along with electrolytes, trace elements and vitamins. More recently, specific nutritional components have been combined with standard polymeric enteral feeds with the aim of specifically improving immune function. Immunonutrition describes enteral feeding formulas usually supplemented with combinations of the amino acids arginine or glutamine, omega- 3 fatty acids and nucleic acids. Animal models and human studies have suggested that the individual components have beneficial (or potentially beneficial) effects on immune function. There is evidence that nutritional supplements with immunonutritional additives can favourably modulate the immune and inflammatory response both in vitro and in patients with trauma, burns or those undergoing gastrointestinal surgery (Di Carlo 1999; Wu 2001; Zhang 2012). Meta-analysis suggests that immunonutrition reduces infectious complications in critically ill patients (Heyland 2001). They are usually given in liquid form and are designed to provide a patient's 'complete' nutritional requirements, provided they are given in an appropriate volume. Immunonutrition and standardised commercial nutrition supplements may be given either orally or via an enteral feeding tube.

\section{How the intervention might work}

The most studied nutrients in immunonutrition formulas are arginine, glutamine, omega- 3 fatty acids and nucleotides. Arginine is the most common immunonutrient given to patients with head and neck cancer. It is a non-essential amino acid with a role in the synthesis of nucleotides, polyamines, nitric oxide and proline.
Arginine may stimulate lymphocyte function and improve wound healing. Glutamine, also an amino acid, is a fuel for rapidly dividing cells in the body, in particular for enterocytes and colonocytes. The addition of omega- 3 fatty acids to enteral nutrition feeds reduces proinflammatory mediators in stressed patients and may reduce infections. The content of each immunonutrition formula varies between products. The biochemical and physiological properties of nutrients included in immunonutrition formulas have been discussed in detail (Worthington 2011).

\section{Why it is important to do this review}

Commercial enteral feed products containing specific nutritional components that may favourably affect immune function have been designed to improve the outcomes in surgical patients. Studies of head and neck cancer patients receiving immunonutrition in the perioperative period have not conclusively demonstrated benefit. We carried out a systematic review of randomised controlled trials, which was published in 2009 , to determine whether perioperative immunonutrition has a role in the treatment of head and neck cancer (Stableforth 2009). In that review we examined 10 trials investigating the effects of immunonutrition in patients treated surgically for head and neck cancer. A reduction in the length of postoperative hospital stay was seen, but the reason for this reduction was not clear. Most trials were too small to provide precise estimates of intervention effects. There were insufficient data to exclude substantial effects of immunonutrition on clinical outcomes or biochemical and immunological parameters. Since the publication of that review in 2009 there have been further studies that merit evaluation and inclusion in an updated review (Azman 2015; Casas-Rodera 2008; De Luis 2009; De Luis 2014; Falewee 2014; Felekis 2010; Ghosh 2012; Hanai 2018; Sorensen 2009; Turnock 2013).

\section{O B JECT IVES}

To assess the effects of immunonutrition treatment, compared to standard feeding, on postoperative recovery in adult patients undergoing elective (non-emergency) surgery for head and neck cancer.

\section{METHODS}

\section{Criteria for considering studies for this review}

\section{Types of studies}

Randomised controlled trials (RCTs), including quasi-randomised trials. We had planned to subject quasi-randomised trials to a sensitivity analysis (see Sensitivity analysis). We included studies irrespective of language or publication status.

We excluded non-randomised studies, such as cohort studies, because of the increased potential for bias. We also excluded crossover trials as this methodology is not suitable for evaluating an intervention that must be given at a specific time point.

\section{Types of participants}

We included all adult patients (18 years of age or older) undergoing an elective surgical procedure for head and neck cancer under a general anaesthetic. 


\section{Types of interventions}

\section{Intervention}

The intervention was polymeric nutritional supplements with immunonutritional additives given by an oral or enteral route. In order to be included, studies needed to administer the immunonutrition either preoperatively or postoperatively or both pre- and postoperatively. Co-intervention with other oral or parenteral substances was permitted as long as the dose of immunonutritional additives was quantified. The content of each immunonutrition formula can vary between products and we recorded the product used and its contents for each study.

\section{Control}

The control group received either standard care (intravenous fluids) and/or polymeric nutritional supplements.

The comparison was:

- immunonutrition versus standard care (intravenous fluids) and/ or polymeric nutritional supplements.

\section{Types of outcome measures}

We assessed the following outcomes in this review, but we did not use them as a sole basis for excluding studies.

\section{Primary outcomes}

- Length of hospital stay: measured in days from the day of surgery to discharge from hospital.

- Wound infections: as measured by the proportion of patients in whom any type or degree of wound infection was recorded, at any point postoperatively.

- Fistula formation: as measured by the proportion of patients in whom a fistula was recorded at any point postoperatively.

- Adverse events/tolerance of feeds, as defined by trial authors: as measured by the proportion of patients in whom adverse events relating to tolerance of feed was recorded, at any point postoperatively.

\section{Secondary outcomes}

We assessed the following secondary outcomes, measured postoperatively:

- All-cause mortality: as measured by the proportion of patients recorded as having died at any point postoperatively.

- Postoperative complications, as defined by trial authors: as measured by the proportion of patients in whom any type or degree of complication (other than wound infection, fistula formation or relating to tolerance of feed) was recorded, at any point postoperatively.

\section{Search methods for identification of studies}

The Cochrane ENT Information Specialist conducted systematic searches for randomised controlled trials and controlled clinical trials. There were no language, publication year or publication status restrictions. The date of the search was 14 February 2018.

\section{Electronic searches}

The Information Specialist searched:
- the Cochrane ENT Trials Register (searched 14 February 2018);

- the Cochrane Central Register of Controlled Trials (CENTRAL) (searched via CRS Web 14 February 2018);

- PubMed (1946 to 14 February 2018);

- Ovid EMBASE (1974 to 14 February 2018);

- Ovid CAB Abstracts (1910 to 14 February 2018);

- EBSCO CINAHL (1982 to 14 February 2018);

- LILACS, lilacs.bvsalud.org (searched 14 February 2018);

- KoreaMed (searched via Google Scholar 14 February 2018);

- IndMed, www.indmed.nic.in (searched 14 February 2018);

- PakMediNet, www.pakmedinet.com (searched 14 February 2018);

- Web of Knowledge, Web of Science (1945 to 14 February 2018);

- ClinicalTrials.gov (searched via the Cochrane Register of Studies 14 February 2018);

- World Health Organization (WHO) International Clinical Trials Registry Platform (ICTRP), www.who.int/ictrp (searched 14 February 2018);

- ISRCTN, www.isrctn.com (searched 14 February 2018).

The Information Specialist modelled subject strategies for databases on the search strategy designed for CENTRAL. Where appropriate, they were combined with subject strategy adaptations of the highly sensitive search strategy designed by Cochrane for identifying randomised controlled trials and controlled clinical trials (as described in the Cochrane Handbook for Systematic Reviews of Interventions Version 5.1.0, Box 6.4.b. (Handbook 2011). Search strategies for major databases including CENTRAL are provided in Appendix 1.

\section{Searching other resources}

We scanned the reference lists of identified publications for additional trials and contacted trial authors where necessary. In addition, the Information Specialist searched PubMed to retrieve existing systematic reviews relevant to this systematic review, so that we could scan their reference lists for additional trials. The Information Specialist also ran non-systematic searches of Google Scholar to retrieve grey literature and other sources of potential trials.

\section{Data collection and analysis}

\section{Selection of studies}

Two review authors independently examined the titles and abstracts of studies identified through the search strategy (either $\mathrm{NH}$ and ST or CA and SJL). Inconsistency between review authors regarding articles for full-text reading was resolved by consultation with another review author. We obtained full-text papers for all studies that could not be excluded on the basis of title and abstract. The same review authors then independently refined their selection by examining the selected articles and excluding those not relevant to this review. The review authors recorded agreement on study inclusion and resolved disagreement by consensus. We contacted original study authors where further clarity was needed in order to select a study for inclusion. We documented decisions on all studies and these are presented in the PRISMA flow chart (Figure 1). 
Figure 1. Process for sifting search results and selecting studies for inclusion.

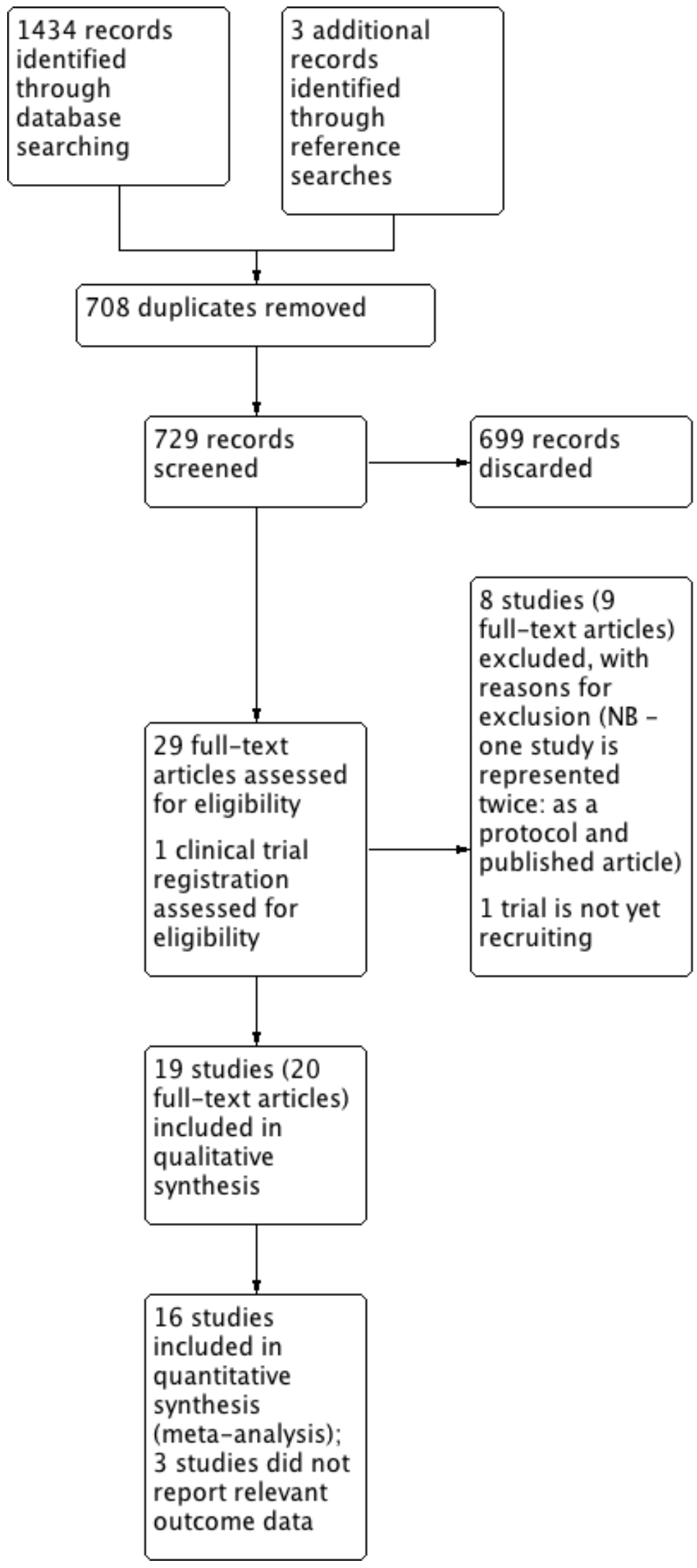




\section{Data extraction and management}

We minimally modified a data extraction form from the original provided by Cochrane. Three authors (NH, ST and SJL) tested this on several studies selected for inclusion, and revised it for ease of extraction and to include further useful data items. Two authors ( $\mathrm{NH}$ and ST) independently extracted data from each study. The review authors were blinded to each other's data.

We extracted data regarding participant demographics, participant disease status, surgical procedures, control group postoperative care and the intervention (frequency and duration of supplementary feeding). SJL and CA combined the tabulated data and checked it for inconsistency.

\section{Assessment of risk of bias in included studies}

Two review authors (ST and $\mathrm{NH}$ ) independently assessed risk of bias. Disagreements were resolved by discussion and consensus, in which the other authors (CA, SJL) arbitrated. We developed our own risk of bias tool based on the criteria described in the Cochrane Handbook for Systematic Reviews of Interventions (Handbook 2011), tailored to this review. We developed this tool as data extraction continued. We then discussed risk of bias for all studies to ensure uniformity and agreement. Where possible, we sought study protocols to aid assessment of selective outcome reporting bias.

We assessed each study according to the following domains:

- random sequence generation;

- allocation concealment;

- blinding of participants and personnel;

- blinding of outcome assessment;

- incomplete outcome data;

- selective reporting; and

- any other potential threats to validity.

To assess risk of bias for these domains we looked for: evidence of, for example, use of randomisation tables or lists or randomisation by computer; allocation concealment via, for example, opaque, sealed envelopes or pharmacy assignment; explicit statements on blinding (or otherwise) and clear descriptions of who was blinded (we did not judge blinding of outcome assessment in relation to mortality, as it would not have been affected by the outcome assessor); specific statements regarding an intention-to-treat (ITT) analysis being conducted, statements about dropouts, or data presented in a way that allowed the number of participants included in analyses to be ascertained; all outcomes in protocols being reported in the manuscript; and factors such as poor recruitment rates, differences in baseline demographics, inadequate or poorly defined methods for assessing outcomes such as wound infections and length of hospital stay.

We classified risk of bias as 'high', 'low' or 'unclear' for each of these domains.

\section{Measures of treatment effect}

Categorical data are presented as a risk ratio (RR) with $95 \%$ confidence interval $(\mathrm{Cl})$. We present continuous data as a mean difference (MD) or standardised mean difference (SMD) with $95 \% \mathrm{Cl}$, as appropriate.

\section{Unit of analysis issues}

The unit of analysis in all included studies was the individual participant. No studies used cluster-randomisation.

\section{Dealing with missing data}

We contacted the nominated trial investigator for the included studies to obtain any missing data necessary for meta-analysis ( $\mathrm{NH}$ and $\mathrm{SJL}$ ). We had planned to calculate missing standard deviations from the standard errors or confidence intervals, as described in the Cochrane Handbook for Systematic Reviews of Interventions (Handbook 2011), but this was not required. Where standard deviations could not be calculated, we planned to impute these using the mean of the reported standard deviations from the other studies, but this was not needed.

\section{Assessment of heterogeneity}

We assessed statistical heterogeneity using visual inspection of the forest plot, the $\mathrm{I}^{2}$ statistic (Handbook 2011), and the $\mathrm{Chi}^{2}$ test. We considered an $\mathrm{I}^{2}$ value of greater than $50 \%$ along with a $\mathrm{P}$ value of less than 0.10 in the $\mathrm{Chi}^{2}$ test to be indicative of the need to further examine heterogeneity (Handbook 2011).

\section{Assessment of reporting biases}

We assessed publication bias and other small study effects in a qualitative manner using a funnel plot.

\section{Data synthesis}

We performed analyses in RevMan 5.3 (RevMan 2014). Analyses comprised only within-study comparisons rather than individuallevel data. Comparisons were based on an intention-to-treat analysis. We used a random-effects model for the meta-analysis of results, as there was a high level of clinical heterogeneity among the included studies. Three authors (NH, ST and SJL) discussed the results for each outcome measure within each study, to determine the inclusion of data in the meta-analyses.

Where complications were reported as percentage incidence, we converted this into the number of participants who experienced complications. In the case of Snyderman 1999 we estimated the number of wound infections, pneumonias and urinary tract infections per treatment group by visual inspection of 'Figure 2' within their manuscript.

All authors participated in double-checking all of the continuous outcome data entered into RevMan for the included studies.

\section{Subgroup analysis and investigation of heterogeneity}

We planned to perform subgroup analyses as follows (and comparison of subgroups using an interaction term if appropriate).

Subgroup analysis of the participants, according to type of surgery:

- anatomical site of surgery;

- type of reconstruction ('primary closure' versus 'free flap').

Subgroup analysis of the intervention to assess clinical heterogeneity:

- preoperative immunonutrition versus placebo drink;

- postoperative immunonutrition versus postoperative polymeric feed. 


\section{Sensitivity analysis}

Sensitivity analyses were based on the risk of bias of the studies (i.e. the removal of studies judged at high risk of bias for at least two of the factors assessed), or if they were quasi-randomised trials. We also considered the appropriateness of comparing randomeffects and fixed-effect estimates of each outcome variable. If publication bias was suspected we planned to perform a 'trim and fill' sensitivity analysis of the primary outcomes. To assess trial influence we planned to perform sensitivity analyses by sequentially excluding each study. If it was not possible to conduct an analysis in RevMan 5.3, we would have used Stata (Stata 11, StataCorp).

\section{GRADE and 'Summary of findings' table}

We used the GRADE approach to rate the overall quality of evidence (Ryan 2016). Two authors (CA and SJL) made the GRADE ratings and any differences were resolved by consensus of all authors. The quality of evidence reflects the extent to which we are confident that an estimate of effect is correct and we applied this in the interpretation of results. There are four possible ratings: high, moderate, low and very low. A rating of high quality of evidence implies that we are confident in our estimate of effect and that further research is very unlikely to change our confidence in the estimate of effect. A rating of very low quality implies that any estimate of effect obtained is very uncertain.

The GRADE approach rates evidence from RCTs that do not have serious limitations as high quality. However, several factors can lead to the downgrading of the evidence to moderate, low or very low. The degree of downgrading is determined by the seriousness of these factors:

- study limitations (risk of bias);

- inconsistency;

- indirectness of evidence;

- imprecision; and

- publication bias.

We included a 'Summary of findings' table (Summary of findings for the main comparison), constructed according to the recommendations described in Chapter 10 of the Cochrane Handbook for Systematic Reviews of Interventions (Handbook 2011).

We included the following outcomes in the 'Summary of findings' table: length of hospital stay, wound infection, fistula formation, adverse events/tolerance of feeds and postoperative mortality.

\section{R E S U L T S}

\section{Description of studies}

See tables of Characteristics of included studies; Characteristics of excluded studies.

\section{Results of the search}

The electronic searches retrieved 1434 results. We identified three further records through scanning the reference lists of included studies. After screening titles and abstracts, we discarded 708 duplicates and 699 irrelevant records. We sought full texts for the remaining 29 records and retrieved trial information from ClinicalTrials.gov for one record (NCT03261180).
Upon screening we excluded a further nine records (see Characteristics of excluded studies). One of the records for which we sought a full text was the protocol associated with Palma-Milla 2016; as such, only eight studies are shown in the Characteristics of excluded studies table). One relevant trial is not yet recruiting (NCT03261180).

Nineteen studies (with 20 publications) met the full inclusion criteria. We therefore included 19 unique studies comprising 1099 participants, as shown in Figure 1. The searches were completed in February 2018.

\section{Included studies}

We included 19 studies see Characteristics of included studies.

One study was only published as an abstract (Felekis 2005). We obtained additional unpublished data from 12 studies (CasasRodera 2008; De Luis 2002; De Luis 2003; De Luis 2004; De Luis 2005; De Luis 2007; De Luis 2009; Falewee 2014; Ghosh 2012; Riso 2000; Sorensen 2009; Turnock 2013).

\section{Design}

All of the included studies were randomised trials of an active (immunonutrition) intervention versus control (see Table 1 for a description of the interventions used).

\section{Sample sizes}

Total sample sizes ranged from 8 to 209 participants (Table 2). Twelve of the 19 studies had fewer than 25 patients in each treatment group.

\section{Setting}

Studies were set in hospitals and conducted in eight countries. Seventeen studies were single-site studies and one study was multicentre (Falewee 2014). We identified eight studies from Spain (Casas-Rodera 2008; De Luis 2002; De Luis 2003; De Luis 2004; De Luis 2005; De Luis 2007; De Luis 2009; De Luis 2014). Two studies were from the USA (Snyderman 1999; Sorensen 2009), two studies from Greece (Felekis 2005; Felekis 2010), and one from each of the following countries: France (Falewee 2014), Italy (Riso 2000), Netherlands (Van Bokhorst 2000/2001), New Zealand (Turnock 2013), Malaysia (Azman 2015), Japan (Hanai 2018), and the UK (Ghosh 2012).

\section{Participants}

The 19 studies included in this review represent a total of 1099 participants undergoing head and neck cancer surgery of the upper aerodigestive tract (sites included mouth, pharynx and larynx) (see Characteristics of included studies).

Studies included adults only and the mean age of study participants across studies ranged from 47 to 66 years (Table 2). There were more males than females in most studies, and the mean body mass index (BMI) reported across studies ranged from 22.1 to 26.5 (Table 2). The stage of disease was reported in 18 studies with only one study not reporting this (Felekis 2005; published as an abstract).

Studies excluded people with a range of medical conditions including impaired renal or hepatic function (16 studies), ongoing infections (13 studies) and autoimmune disorders (13 studies), those on steroid treatment (10 studies) or nutritional oral 
supplementation in the previous six months and those who were malnourished/had severe cancer cachexia or sarcopenia (seven studies), those who were well nourished (two studies) or morbidly obese (one study), patients with contraindications to enteral nutrition/patients with inborn errors of metabolism relating to the composition of the formula (two studies), patients treated with chemotherapy and/or radiation therapy delivered to the head and neck area during the previous year (three studies) or chemoradiotherapy or other treatment protocols concurrent to the intervention (one study), patients testing positive for HIV (three studies), patients with diabetes (five studies), and pregnant or breast-feeding women (four studies).

\section{Interventions}

Detailed descriptions of the interventions used in each of the included studies are shown in Table 1. Most studies (16/19) used immunonutrition formulas that contained arginine, one study used glutamine powder, one study used an eicosapentaenoic acid (EPA)enriched oral nutritional supplement and one used an unspecified product. When study feeds were given pre-operatively, the length of intervention ranged from around 5 to 14 days ( $n=9$ studies). There was more variation when feeds were given postoperatively, with a range of around 5 days to an average duration of 22 days \pm 12 days ( $n=19$ studies). Most studies (12/19) based the intake of study feeds on body weight or 'requirements', some $(n=5 / 19)$ used a set amount (e.g. $1000 \mathrm{~mL}$ per day, or $30 \mathrm{~g}$ powder per day) and others $(n=2 / 19)$ did not state the amount. Follow-up time frames also varied considerably across studies, and ranged from five days post-operation (De Luis 2003) to greater than or equal to 16 months (Van Bokhorst 2000/2001 for survival data).

Immunonutrition was given postoperatively in all studies, and nine studies gave immunonutrition pre-operatively as well as postoperatively (Table 1). One study with three treatment groups gave pre-operative immunonutrition alone in one group (Falewee 2014), but data from that group were not included in analyses. A commercial polymeric feed was used in the control group postoperatively in most studies (17/19), some of which contained additional fibre (Table 1). In six studies the control group received a standard polymeric feed preoperatively as well as postoperatively
(Falewee 2014; Felekis 2005; Felekis 2010; Ghosh 2012; Sorensen 2009; Van Bokhorst 2000/2001). In one study, two groups (one of which had received the control feed both pre- and postoperatively and the other only postoperatively) were combined in their analyses (Snyderman 1999).

\section{Outcomes}

Of the outcomes considered, mortality was most commonly reported (14 studies; we obtained unpublished data on mortality for eight studies (Casas-Rodera 2008; De Luis 2003; De Luis 2004; De Luis 2005; De Luis 2007; De Luis 2009; Falewee 2014; Sorensen 2009), with the remaining data being available in the paper or abstract), followed by wound infection (12 studies), adverse events/ tolerance of feeds (11 studies), length of hospital stay (10 studies) and fistulae (10 studies).

\section{Excluded studies}

We excluded eight studies (see Characteristics of excluded studies).

We excluded one study (Buijs 2010), which was a follow-up of patients from a study already included in the review (Van Bokhorst 2000/2001). Buijs 2010 reported on long-term survival ( $\geq 10$ years) and we felt that including mortality data from a much longer followup time period than all other included studies (which measured mortality in a relatively short period of time post-intervention) would make the results more difficult to interpret.

Three studies were not randomised (De Luis 2013; Linn 1988; Reis 2016), and four had no suitable control group (De Luis 2005a; De Luis 2010; De Luis 2015; Palma-Milla 2016).

\section{Risk of bias in included studies}

The risk of bias for each study is described in detail in the Characteristics of included studies table. Details of risk of bias judgements for each study are presented in Figure 2, with an overall summary graph in Figure 3. Allocation concealment methods were most poorly reported, resulting in the greatest number of 'unclear' risk of bias assessments. Details of methodological quality are also presented in Table 3. 
Figure 2. 'Risk of bias' summary: review authors' judgements about each risk of bias item for each included study.

\begin{tabular}{|c|c|c|c|c|c|c|c|}
\hline & 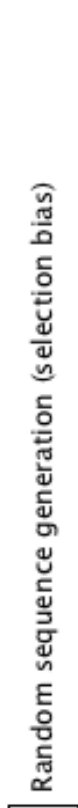 & 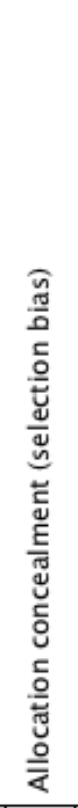 & 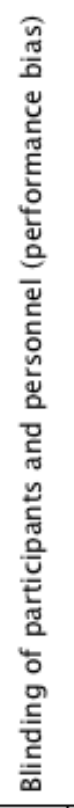 & 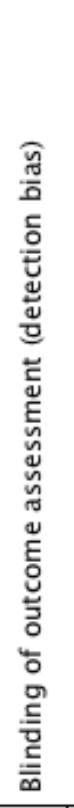 & 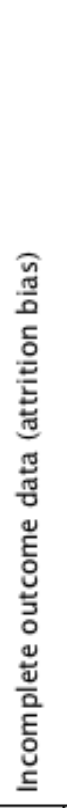 & 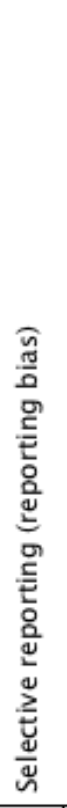 & 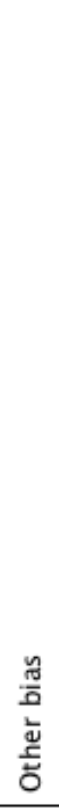 \\
\hline Azman 2015 & 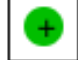 & ? & $O$ & $\Theta$ & $?$ & $?$ & 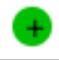 \\
\hline Casas-Rodera 2008 & $?$ & ? & $?$ & $?$ & 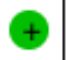 & $?$ & $\odot$ \\
\hline De Luis 2002 & 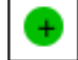 & ? & + & 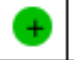 & 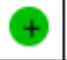 & $?$ & - \\
\hline De Luis 2003 & 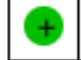 & $?$ & + & $\odot$ & 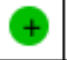 & $?$ & 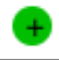 \\
\hline De Luis 2004 & + & $?$ & $?$ & $?$ & $\odot$ & $?$ & $\Theta$ \\
\hline De Luis 2005 & $\odot$ & $?$ & $?$ & $?$ & $\odot$ & $?$ & 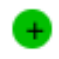 \\
\hline De Luis 2007 & + & $?$ & $?$ & $?$ & 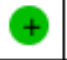 & $?$ & $\boldsymbol{\partial}$ \\
\hline De Luis 2009 & $?$ & $?$ & + & 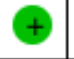 & 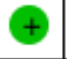 & $?$ & 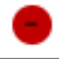 \\
\hline De Luis 2014 & $?$ & $?$ & + & $?$ & 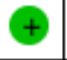 & $?$ & 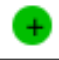 \\
\hline Falewee 2014 & $\odot$ & + & + & $\odot$ & $\odot$ & $\odot$ & $\odot$ \\
\hline Felekis 2005 & $?$ & $?$ & $?$ & $?$ & $?$ & $?$ & $?$ \\
\hline Felekis 2010 & + & $?$ & $?$ & $?$ & $\odot$ & $?$ & 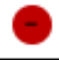 \\
\hline Ghosh 2012 & + & 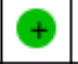 & + & 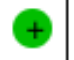 & $\odot$ & $?$ & - \\
\hline Hanai 2018 & ? & $?$ & 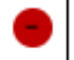 & $?$ & $\odot$ & $?$ & 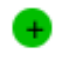 \\
\hline Riso 2000 & + & $?$ & $?$ & $?$ & $\odot$ & $?$ & 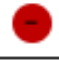 \\
\hline Snyderman 1999 & + & $?$ & $?$ & $?$ & 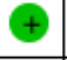 & $?$ & \\
\hline Sorensen 2009 & $?$ & $?$ & $?$ & $?$ & $?$ & $?$ & 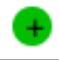 \\
\hline Turnock 2013 & + & + & - & $\odot$ & $\odot$ & - & 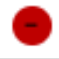 \\
\hline & I & 1,1 & 1 & 1 & A & $=1$ & \\
\hline
\end{tabular}


Figure 2. (Continued)

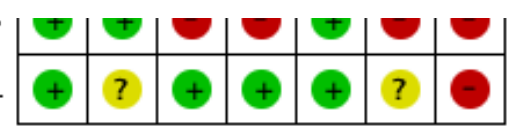

Figure 3. 'Risk of bias' graph: review authors' judgements about each risk of bias item presented as percentages across all included studies.

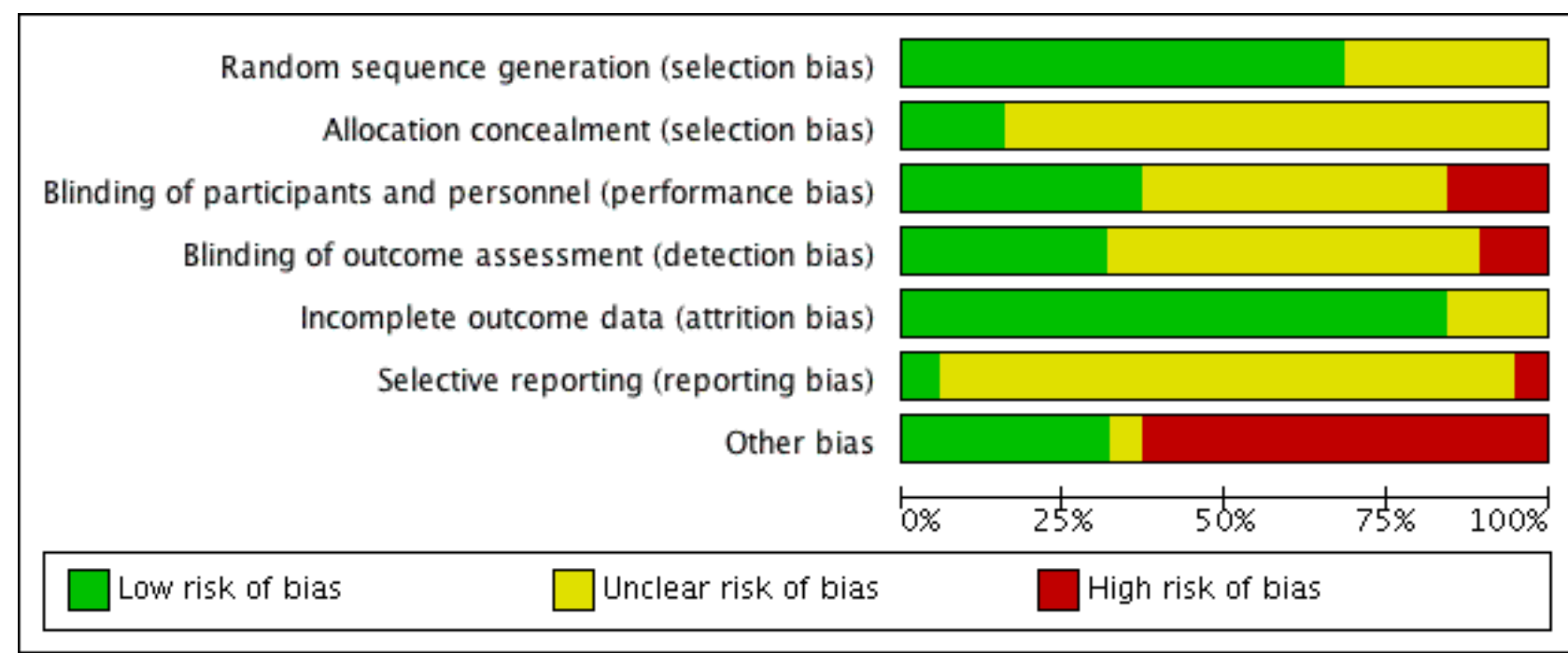

\section{Allocation}

\section{Random sequence generation}

We classed 13 studies at low risk of bias due to acceptable randomisation sequence generation through the use of computergenerated randomisation, randomisation lists, tables or a "randomization generator" (Azman 2015; De Luis 2002; De Luis 2003; De Luis 2004; De Luis 2005; De Luis 2007; Falewee 2014; Felekis 2010; Ghosh 2012; Riso 2000; Snyderman 1999; Turnock 2013; Van Bokhorst 2000/2001). In six studies the method of random sequence generation was not clear or not stated and therefore we classed this as an unclear risk of bias (Casas-Rodera 2008; De Luis 2009; De Luis 2014; Felekis 2005; Hanai 2018; Sorensen 2009).

\section{Allocation concealment}

We considered 16 studies to be at unclear risk of bias due to inadequately reported methods of allocation concealment. Of these, eight reported the use of envelopes but did not state whether or not they were opaque (Azman 2015; De Luis 2002; De Luis 2003; De Luis 2004; De Luis 2005; De Luis 2007; Riso 2000; Sorensen 2009). We classed the other eight at unclear risk of bias because allocation concealment was either not stated (Casas-Rodera 2008; De Luis 2009; De Luis 2014; Felekis 2005; Hanai 2018; Snyderman 1999; Van Bokhorst 2000/2001), or was not clear as documented (Felekis 2010). We classed three studies as low risk of bias due to the use of central telephone assignment (Falewee 2014; Ghosh 2012), or the use of opaque, sealed envelopes (Turnock 2013).

\section{Blinding \\ Participants and personnel}

Participants can be adequately blinded with this intervention, therefore we judged studies where patients were not blinded to be at high risk of bias. Two studies stated that they were not blinded and we classed them at a high risk of bias (Azman 2015; Turnock 2013), and one study used sachets in the intervention group and no treatment in the control group, so it was assumed to be unblinded and at high risk of bias (Hanai 2018). We classed nine studies at an unclear risk of bias because they either did not state whether or not participants and personnel were blinded (Casas-Rodera 2008; Felekis 2005), or they stated that the study was blinded but did not state who was blinded (De Luis 2004; De Luis 2005; Felekis 2010; Riso 2000), or they described partial blinding (Snyderman 1999; Sorensen 2009). We classed all other studies (seven) as at low risk of bias.

\section{Outcome assessment}

Judgements for risk of bias in regards to the blinding of outcome assessment were as described above for blinding of participants and personnel with two exceptions. De Luis 2014 stated that "Blinding of patients and dietitians involved in patient treatment was maintained", but they did not indicate who the outcome assessor was; as such, we judged it at unclear (rather than low) risk of bias. Hanai 2018 did not indicate who the outcome assessor was or whether or not anyone was blinded; as such, we judged it at unclear (rather than high) risk of bias. 


\section{Incomplete outcome data}

We considered most studies at low risk of bias for incomplete outcome data, with the exception of three studies that we classed at an unclear risk of bias because they did not mention whether or not an intention-to-treat (ITT) analysis had been conducted/whether any dropouts had occurred, or did not present data in such a way as to be able to determine the number of participants included in analyses (Azman 2015; Felekis 2005; Sorensen 2009). The remaining studies either had no attrition according to the numbers included in tables/figures, or stated that an ITT analysis had been conducted or that there were no dropouts/losses to follow-up. (NB: we obtained additional data for one study to enable an ITT analysis to be conducted; Falewee 2014).

\section{Selective reporting}

We classed most studies (17) at an unclear risk of selective reporting bias because protocols were not available to judge whether or not selective reporting had occurred. We classed one study at a low risk of bias because the primary outcome stated in the protocol was reported in the paper (Falewee 2014) (no secondary outcomes were specified in the protocol so it was not possible to judge whether selective reporting of secondary outcomes had occurred). We classed one study at a high risk of bias because not all primary outcomes stated in the protocol were presented in the manuscript (Turnock 2013).

\section{Other potential sources of bias}

Five studies reported problems with recruitment (Falewee 2014; Ghosh 2012; Snyderman 1999; Turnock 2013; Van Bokhorst 2000/2001), three reported baseline differences between treatment groups (Ghosh 2012; Snyderman 1999; Van Bokhorst 2000/2001), and six had poorly defined methods for assessment of wound infection (Casas-Rodera 2008; De Luis 2002; De Luis 2004; De Luis 2007; De Luis 2009; Felekis 2010). We classed these studies at high risk of bias for these other potential sources of bias. Of the 10 studies that reported length of hospital stay, six did not describe how this was determined (De Luis 2002; De Luis 2004; De Luis 2007; De Luis 2009; Riso 2000; Turnock 2013). The assessment of tolerance of feeds was not based on consistent descriptions across studies.

One study was available only as an abstract and we judged it at unclear risk of other bias (Felekis 2005). We classed the remaining studies at low risk of bias for other potential sources of bias as there was no evidence for this in the published data (Azman 2015; De Luis 2003; De Luis 2005; De Luis 2014; Sorensen 2009).

Most studies were small, with sample sizes that were unrealistically low for detecting clinical complications.

\section{Effects of interventions}

See: Summary of findings for the main comparison Immunonutrition compared to standard care for patients undergoing surgery for head and neck cancer

\section{Immunonutrition versus standard care}

\section{Primary outcomes}

\section{Length of hospital stay}

Length of hospital stay was reported in 10 studies. The mean length of stay ranged from 15.3 days to 31.1 days in immunonutrition groups and from 17.4 days to 36.1 days in control groups. We found no evidence of a difference between treatment groups in the length of hospital stay, but the confidence interval around the effect estimate was wide (mean difference -2.5 days, 95\% confidence interval $(\mathrm{Cl})-5.11$ to $0.12(\mathrm{P}=0.06) ; 10$ studies, 757 participants $)$ (GRADE: low-quality evidence). The results showed little evidence of heterogeneity between studies $\left(\mathrm{Chi}^{2}=12.89, \mathrm{P}=0.17, \mathrm{I}^{2}=30 \%\right)$ (Analysis 1.1).

\section{Wound infections}

Wound infections were reported in 12 studies, of which 10 studies reported events. One study reported 'wound complications' as the number with Clavien-Dindo grades above 3, above 2 or all grades and was not included in the meta-analysis (Hanai 2018). Absolute risks ranged from $0 \%(0 / 45)$ to $61 \%(17 / 28)$ in the immunonutrition groups and from $0 \%(0 / 45)$ to $59 \%(17 / 29)$ in the control groups. Events were more common (in both treatment groups) in studies that had used pre- and postoperative intervention (a total of 95 events among 458 participants) than in studies that used only postoperative intervention (a total of 14 events among 354 participants). We found no evidence of a difference between treatment groups for this outcome. The combined risk ratio (RR) was $0.94(95 \% \mathrm{Cl} 0.70$ to $1.26, \mathrm{P}=0.66 ; 12$ studies, 812 participants) (GRADE: very low-quality evidence), with little evidence of heterogeneity between trials $\left(\mathrm{Chi}^{2}=4.12, \mathrm{P}=0.90\right.$, $\mathrm{I}^{2}=0 \%$ ) (Analysis 1.2).

\section{Fistula formation}

Fistula formation was reported in 10 studies, all of which reported events. The absolute risk was $5.4 \%$ (range $0 \%(0 / 23)$ to $7 \%(7 / 105)$ ) in the immunonutrition groups and $11.3 \%$ (range $2 \%(1 / 47)$ to $29 \%(2 / 7))$ in the control groups. There was a reduction in fistula formation with immunonutrition compared to standard care; the combined RR was $0.48(95 \% \mathrm{Cl} 0.27$ to $0.85, \mathrm{P}=0.01 ; 10$ studies, 747 participants) (GRADE: low-quality evidence), with little evidence of heterogeneity between studies $\left(\mathrm{Chi}^{2}=6.99, \mathrm{P}=0.64, \mathrm{I}^{2}=10 \%\right)$ (Analysis 1.3; Figure 4). 
Figure 4. Forest plot of comparison: 1 Immunonutrition versus standard care, outcome: 1.3 Fistula formation.

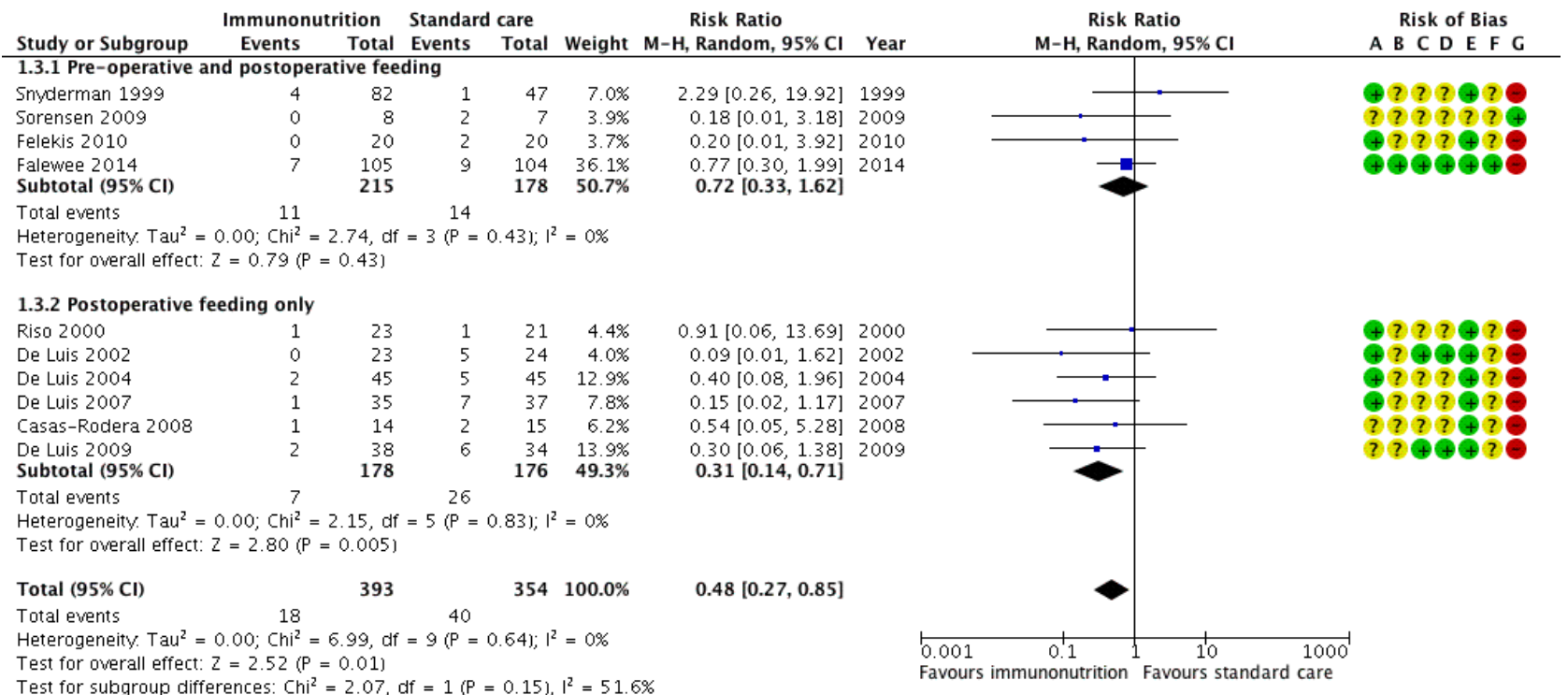

Test for subgroup differences: $\mathrm{Chi}^{2}=2.07, \mathrm{df}=1(\mathrm{P}=0.15), \mathrm{I}^{2}=51.6 \%$

(A) Random sequence generation (selection bias)

(B) Allocation concealment (selection bias)

(C) Blinding of participants and personnel (performance bias)

(D) Blinding of outcome assessment (detection bias)

(E) Incomplete outcome data (attrition bias)

(F) Selective reporting (reporting bias)

(G) Other bias

\section{Adverse events/tolerance of feeds}

Adverse events in relation to aspects of tolerance of feeds were reported in 11 studies, and included intolerance to feed (Snyderman 1999) and gastrointestinal intolerance (Falewee 2014), abdominal distension, abdominal cramps or emesis (Riso 2000), and diarrhoea (Azman 2015; Casas-Rodera 2008; De Luis 2002; De Luis 2004; De Luis 2007; De Luis 2009; Hanai 2018). One study stated that "gastrointestinal tract tolerance of both formula diets was excellent in both groups, and no dropouts occurred because of intolerance" (Felekis 2010); for analysis we assumed that there were zero adverse events in both treatment groups. In two studies, a control feed was not used and adverse events were documented only in relation to withdrawals from the immunonutrition treatment groups (one per study); data from these two studies were not included in the meta-analysis (Azman 2015; Hanai 2018). Among the nine studies that we included in the meta-analysis, absolute risks ranged from $0 \%(0 / 20)$ to $40 \%(18 / 45)$ in the immunonutrition groups and from $0 \%(0 / 20)$ to $29 \%(6 / 21)$ in the control groups. There was no evidence of a difference between treatment groups for this outcome. The combined RR was 1.33 (95\% $\mathrm{Cl} 0.86$ to $2.06, \mathrm{P}=0.20$; 9 studies, 719 participants) (GRADE: very low-quality evidence), with little evidence of heterogeneity between trials $\left(\mathrm{Chi}^{2}=7.11, \mathrm{P}=0.42, \mathrm{I}^{2}=2 \%\right.$ ) (Analysis 1.4).

\section{Secondary outcomes}

\section{All-cause mortality}

Mortality was reported in 14 studies (NB: additional unpublished information was obtained from eight authors) and ranged from $0 \%$ $(0 / 105)$ to $14 \%(4 / 28)$ in the immunonutrition groups, and from $0 \%$ $(0 / 45)$ to $8 \%(2 / 24)$ in the control groups. The follow-up timeframes varied considerably across studies, and ranged from 30 days to greater than or equal to 16 months in those studies that were meta- analysed (NB: one study did not state the follow-up timeframe). There was no evidence of a difference between treatment groups for this outcome. The combined RR was 1.33 (95\% Cl 0.48 to 3.66, P $=0.59 ; 14$ studies, 776 participants) (GRADE: low-quality evidence), with little evidence of heterogeneity between studies $\left(\mathrm{Chi}^{2}=3.66, \mathrm{P}\right.$ $=0.45, \mathrm{I}^{2}=0 \%$ ) (Analysis 1.5).

\section{Postoperative complications}

Other clinical complications such as pneumonia and urinary tract infections were uncommonly reported (Table 4), but there was no evidence of a reduction (or an increase) with immunonutrition.

\section{Subgroup analysis}

The direction of effect for length of stay, wound infection, fistula formation and mortality did not differ between studies that had given immunonutrition both pre- and postoperatively and studies that had given it only postoperatively (Analysis 1.1; Analysis 1.2; Analysis 1.3; Analysis 1.5). We observed some differences in effect sizes between the subgroups, but most subgroups included six or fewer studies (with the exception of eight studies in the postoperative feeding only subgroup for mortality) and $\mathrm{P}$ values for subgroup differences ranged from 0.08 for length of stay (Analysis 1.1) to 0.77 for mortality (Analysis 1.5) (corresponding $I^{2}$ values were $66.6 \%$ and $0 \%$, respectively). Studies that had given immunonutrition only postoperatively showed a more beneficial effect on fistula formation than those that had given immunonutrition pre- and postoperatively (RR $0.31,95 \% \mathrm{Cl} 0.14$ to $0.71, \mathrm{P}=0.005,6$ studies, 354 participants, and RR $0.72,95 \%$ $\mathrm{Cl} 0.33$ to $1.62, \mathrm{P}=0.43$; 4 studies, 393 participants, respectively). There was a difference in the direction of effect for adverse events/ tolerance of feeds between studies that had given immunonutrition both pre- and postoperatively and studies that had given it only 
postoperatively, but such a comparison is not warranted as only two studies were included in the pre- and postoperative feeding analysis.

For wound infections, more events were reported in the six studies that used pre- and postoperative immunonutrition ( $n=48$ events among 247 participants in the immunonutrition group and $n=47$ events among 211 participants in the standard care group) than in the six studies that used only postoperative immunonutrition $(n=5$ events among 178 participants in the immunonutrition group and $\mathrm{n}=9$ events among 176 participants in the standard care group).

Only one study gave pre-operative immunonutrition alone so it was not possible to conduct a subgroup analysis of preoperative immunonutrition versus placebo drink (Falewee 2014).

We did not conduct subgroup analyses according to the type of surgery as data were not presented in such a way in the original publications as to allow this to be done.

\section{Sensitivity analysis}

We did not conduct sensitivity analyses in which we removed studies judged at high risk of bias for at least two of the factors assessed or where we removed quasi-randomised trials because no studies met these criteria. We calculated randomeffects estimates for each outcome variable due to the extent of clinical heterogeneity. We did not judge fixed-effect estimates to be appropriate.

\section{Publication bias}

We examined publication bias for all outcomes by visual inspection of funnel plots and we have presented three of these: length of hospital stay (Figure 5), wound infection (Figure 6) and fistula formation (Figure 7). Study numbers were relatively small for these outcomes, which made it difficult to definitively assess publication bias; however, there was a suggestion of publication bias for length of hospital stay (Figure 5). Given the absence of clear publication bias, however, we did not conduct a trim and fill analysis for the primary outcomes.

Figure 5. Funnel plot of comparison: 1 Immunonutrition versus standard care, outcome: 1.1 Postoperative length of hospital stay [days].

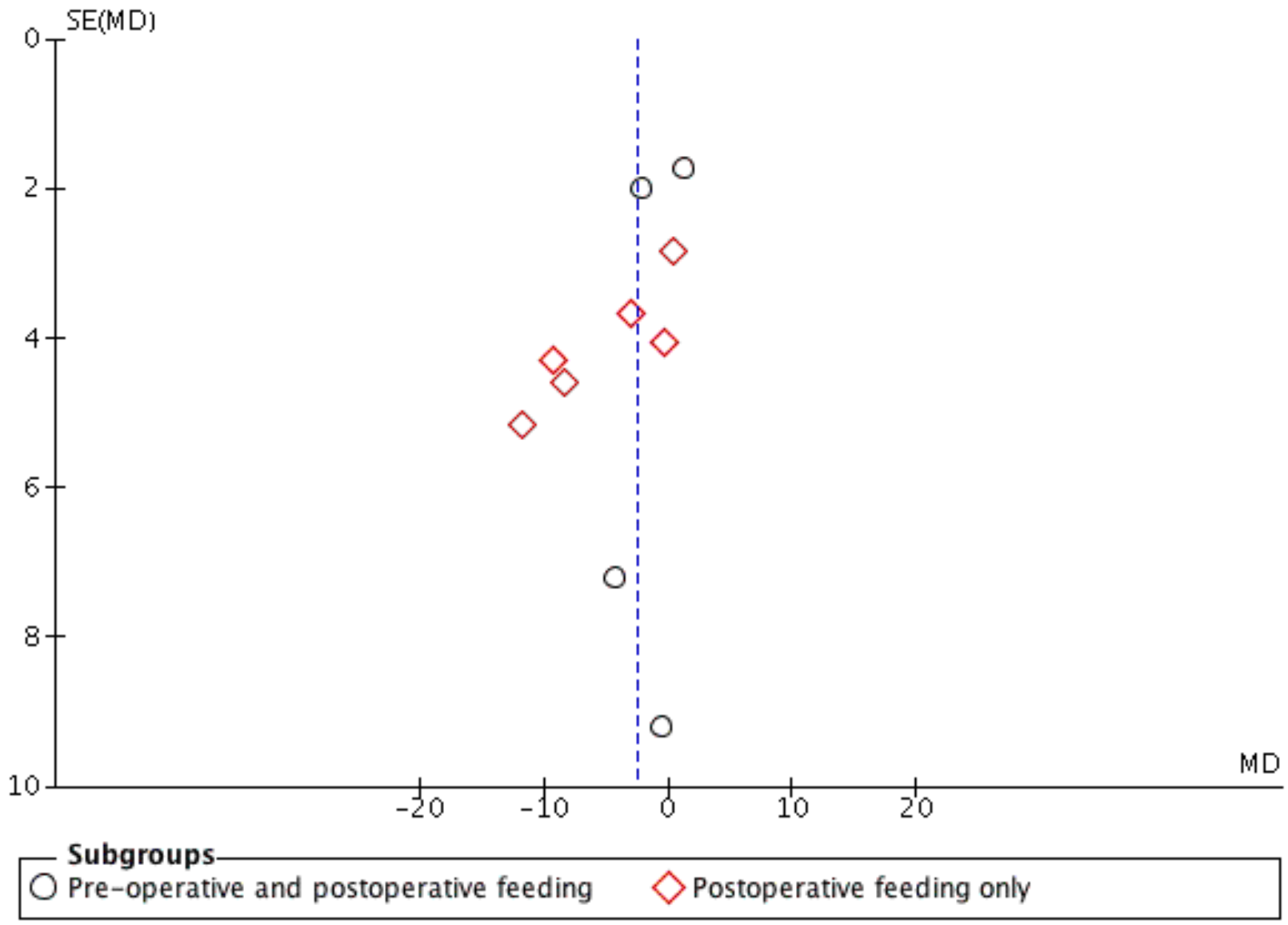


Figure 6. Funnel plot of comparison: 1 Immunonutrition versus standard care, outcome: 1.2 Wound infection.

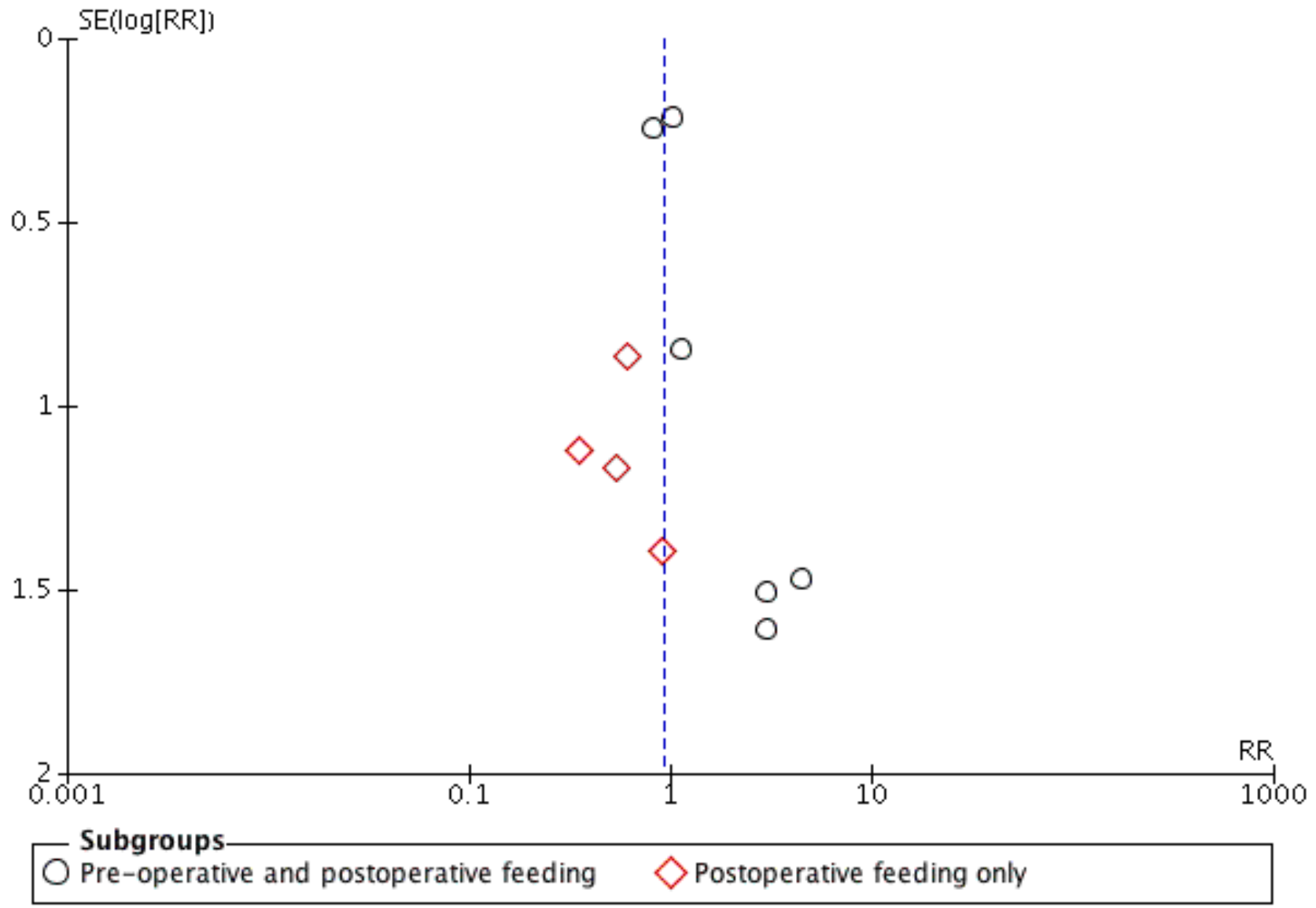


Figure 7. Funnel plot of comparison: 1 Immunonutrition versus standard care, outcome: 1.3 Fistula formation.

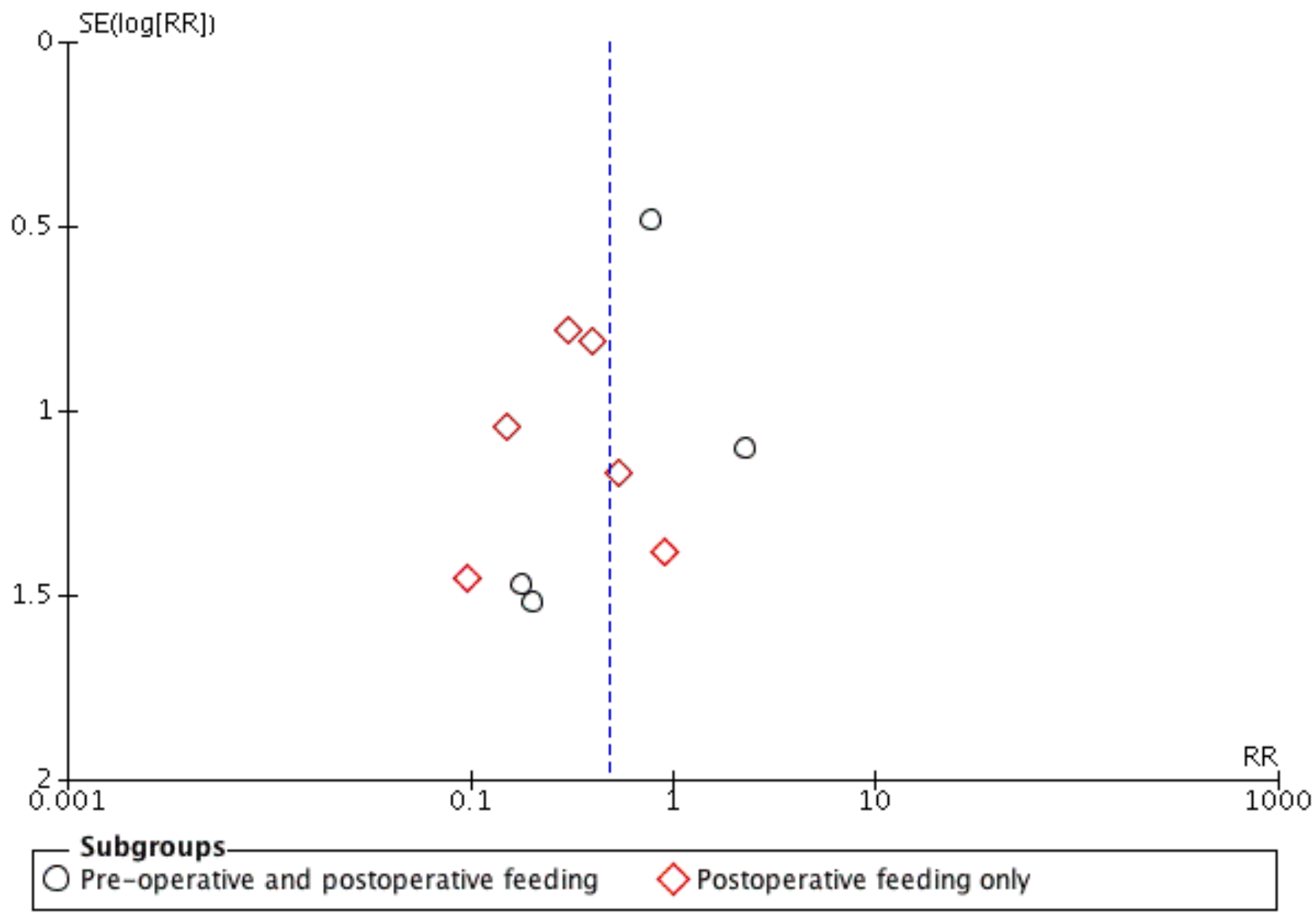

\section{DISCUSSION}

\section{Summary of main results}

Pooled estimates showed no evidence of a difference in the length of hospital stay between treatment groups. The mean difference was -2.5 days but the estimate was imprecise $(95 \%$ confidence interval ( $\mathrm{Cl})-5.11$ to 0.12 ) and included the null value. There may be an approximate halving of the risk of fistulae formation (risk ratio (RR) 0.48 ) with immunonutrition, but the evidence was of low quality. Immunonutrition may have little or no effect on wound infection and mortality, and there was little or no difference in adverse events such as diarrhoea between the treatment groups. We did not formally meta-analyse other complications because of their heterogeneity. The findings are summarised in Summary of findings for the main comparison. Length of hospital stay was reduced in 8 of the 10 studies where it was recorded. No reduction in hospital stay was seen in the largest recent study (Falewee 2014). Reduced fistula formation was seen in patients receiving immunonutrition, but no other reductions in clinical complications such as wound infections were seen. No substantial differences in the findings were seen when looking at the timing of intervention (i.e. pre- and postoperative or just postoperative).

Where stated, all but two of the studies looking at inhospital postoperative immunonutrition used arginine as an immunonutrient; Azman 2015 used glutamine and Hanai 2018 used an eicosapentaenoic acid (EPA)-enriched supplement. Ten studies evaluated postoperative nutrition alone and nine studies included pre- and postoperative nutrition. One study provided only preoperative immunonutrition in one of their treatment groups (Falewee 2014), but the numbers of patients and complications were too small to draw any conclusions. Studies that gave immunonutrition only postoperatively showed a larger beneficial effect on fistula formation than studies that gave it both preand postoperatively (RR 0.31 versus 0.72 , respectively). One study that gave immunonutrition both pre- and postoperatively reported more fistulas with immunonutrition than standard care (Snyderman 1999). The reasons for this are not clear and are in contrast with all other studies (irrespective of timing of intervention), which reported fewer fistulas with immunonutrition than standard care. The cause of mortality was often poorly reported and it may be inappropriate to ascribe any difference in mortality to immunonutrition. However, no evidence of any effect of immunonutrition on mortality (which was low) was seen. We did not formally analyse potential clinical complications such as pneumonia, diarrhoea, cardiovascular effects and the relationship of nutritional status to outcomes due to either limited data or outcomes not having been recorded.

Overall, most studies were too small to provide precise estimates of intervention effects. 


\section{Overall completeness and applicability of evidence}

\section{Completeness}

We attempted to identify and synthesise all existing research to provide a comprehensive estimate of the effect of immunonutrition on postoperative recovery following head and neck cancer surgery. We included 19 studies that recruited 1099 participants. We also conducted the largest systematic review prior to this one, which included 10 randomised controlled trials (RCTs) that had recruited 605 participants (Stableforth 2009). One of the trials (De Luis 2005a), which had been included in our previous review, was not included here as the immunonutrition intervention was administered at the point of discharge. Another systematic review from 2012 included 14 studies with 601 participants (Casas Rodera 2012); three of the studies in that review were not relevant to ours as two studies compared two doses/types of immunonutrients (De Luis 2005a; De Luis 2010), and one study, as noted above, was part of another publication (Buijs 2010). A third systematic review from 2014 included six studies and 397 participants, all of which were included in our review (Vidal-Casariego 2014). Despite being the largest systematic review to date, it is possible that our search strategies may not have identified all of the existing literature.

We looked at similar outcomes to other systematic reviews, but we did not analyse further outcomes reported in studies such as pneumonia, cardiovascular effects and the relationship of nutritional status to outcomes due to limited data.

This review was systematic, using extensive searches of several databases and inclusive search terms. We did not include unpublished literature, but we felt it unlikely that there are large unpublished trials that demonstrate a substantial effect of immunonutritional interventions in head and neck cancer. We made attempts to contact senior or corresponding authors as published in the original papers. We received further data from $\mathrm{Dr}$ De Luis, Professor Jones (re: Ghosh 2012), Dr Riso and Dr Falewee regarding research methods and outcomes.

\section{Applicability}

Most studies applied exclusion criteria to individuals for study participation. These frequently included renal or hepatic impairment, existing infection and altered immune function. Three studies excluded participants who were well nourished (De Luis 2003; De Luis 2005; Van Bokhorst 2000/2001), one excluded those who were morbidly obese (Snyderman 1999), and seven excluded people who were malnourished (Azman 2015; De Luis 2002; De Luis 2004; De Luis 2007; De Luis 2009; De Luis 2014; Turnock 2013).

Studies included in this review were conducted in various countries, incorporating a range of cultures and healthcare systems. Eight were undertaken in Spain (seven of which were conducted by the same group), two in the United States, one in New Zealand, one in Malaysia, one in Japan and the remainder in western Europe. This may have had an effect on outcomes. For example, standard healthcare practice (e.g. discharge policies, implementation of Enhanced Recovery After Surgery (ERAS) protocols, etc.) is likely to vary across countries, thus making comparisons across studies less meaningful. In addition, the studies were reported over an approximate 18-year period during which there are likely to have been changes in clinical practice. However, it was not possible from the information provided to assess the impact of this possibility. There were also differences between studies regarding patient populations and types of surgery. As such, it remains unknown who is most likely to benefit from immunonutrition (if indeed there is a true benefit) based on the included studies.

\section{Quality of the evidence}

Assessments of the quality of evidence for each outcome are presented in Summary of findings for the main comparison.

\section{Methodology}

In general studies were poorly reported with a large proportion of unclear risk of bias assignments for several of the items assessed (Figure 2; Figure 3). We assigned blinding of outcome assessment an unclear risk of bias in 11 studies and 'other' bias a high risk of bias in 11 studies (examples of 'other' bias included difficulties in recruitment/not meeting target sample size, and evidence of some baseline differences between treatment groups).

The generation of the random allocation sequence was reported in 13 studies (Table 3). In nine studies allocation was concealed using sealed envelopes but it was not stated whether or not these were opaque in eight of the studies (one explicitly stated that opaque envelopes were used). Concealment of allocation was achieved by using a central telephone assignment in two studies. Where stated, all studies were double-blind (as opposed to single-blind), although there was an overall lack of description of how this was achieved. One study (published as an abstract; Felekis 2005) did not state whether an intention-to-treat (ITT) analysis was conducted, and for another study we obtained additional data from the authors to enable an ITT analysis to be conducted (Falewee 2014).

More than half of the studies reported use of sample size or power calculations (Table 3), but of those that did, several did not meet the target sample size. Many other studies included small sample sizes, reducing the power of the study to observe clinically important differences in outcomes.

The GRADE rating of the evidence varied for all of the outcomes assessed, but we classed none as high-quality (Summary of findings for the main comparison). The main reasons for downgrading the evidence were small sample sizes and wide confidence intervals around effect estimates, and poor descriptions of the methods used for assessing outcomes reported within studies.

\section{Outcome assessment}

Infection is the clinical outcome of interest in this research area. However, this was poorly defined in most studies. Wound infections were not classified by site or severity in most studies. Systemic infection was also poorly defined. Similarly, persistent postoperative fistula was not defined in most studies. A more precise measure of infection and fistula could improve the quality of the evidence base. Wound infections were considerably more common (in both treatment groups) in studies that used preand postoperative supplementation than in studies that used only postoperative supplementation, but the reasons for this are not clear. Four of the six studies that used pre- and postoperative supplementation and that reported wound infections were from the same research group, and it is possible that their definition of wound infection or their length of follow-up meant that fewer wound infections were captured in their studies. 
Blinding of participants with this intervention is possible and should be undertaken, as an awareness of treatment allocation may result in participants misreporting outcomes. Length of hospital stay is likely to be influenced by variation in discharge criteria, which may result in differences between studies. This lack of uniformity across centres may introduce variability for some outcomes.

\section{Heterogeneity}

We observed little evidence of heterogeneity for each outcome ( $\mathrm{Chi}^{2}$ ranged from 3.66 to $12.89, \mathrm{P}=0.17$ to 0.91 , and $\mathrm{I}^{2}$ ranged from $0 \%$ to $30 \%$ ). For length of hospital stay and fistula formation, if heterogeneity existed it would be more likely to indicate variation in size of effect as opposed to direction of effect given that most studies suggested a beneficial effect of immunonutrition on postoperative recovery outcomes. Visual inspection of the forest plots and associated data did not indicate that size of study substantially altered the effect size (although it must be noted that the majority of studies had sample sizes of fewer than 25 participants per treatment group).

\section{Potential biases in the review process}

\section{Search strategy}

Although we believe that our electronic (February 2018) and handsearching strategies have identified all relevant studies, it is possible that we may have missed some available literature or unpublished material. We stopped handsearching at the end of January 2017. We have read reviews and references of recent publications and in the time period until publication other studies may have been published or made available. These will be incorporated into future updates of this review.

\section{Assumptions about the mechanism of effect}

The various components of immunonutrition supplements have been shown in studies done in vitro and in vivo to produce what are considered beneficial changes in immunological function. However, there is little evidence from clinical trials that these mechanisms result in reduced postoperative complications. In particular there is little evidence of the superiority of any given immunonutrient over another, for any given dose regimen, or for the time periods for which the immunonutrients need to be taken to produce benefit. The small size of most studies and the variety of dosing regimens meant that it was not possible to comment on the relative merits of each type or dose of immunonutrient. Future studies are required to examine these issues.

\section{Assumptions about the meta-analyses and results}

We think it unlikely that we have introduced bias through the methods used in the review process. The range of outcome metrics reported across studies was small and did not require conversion to common units for use in this review. We used a random-effects model (due to a high level of clinical heterogeneity among included studies), which may have resulted in smaller studies being granted a larger weighting than necessary, potentially biasing the overall meta-analysed results (Handbook 2011). We identified possible publication bias from visual inspection of the funnel plot for length of hospital stay (see Figure 5). Some of the studies published by De Luis et al have similar starting dates and trial designs (see Table 2), however the baseline data are different and in their 2004 paper they reference their 2002 paper as a different study. In their 2009 paper the patient characteristics (age, sex) and baseline data are different from their 2007 paper. However, we have been unable to obtain a response from the authors to clarify that there is no overlap in participants across studies.

We did not formally assess biochemical changes or immunological changes as secondary outcomes (as per the original protocol) because very few papers commented on such changes, and in each paper the markers chosen were different and assessed at differing time intervals. Meta-analysis of the few papers was thus not possible. Furthermore, given the expected profound influence of the operative inflammatory response on levels of such markers, their interpretation is not straightforward.

\section{Assumptions about study methodology}

Studies were not excluded on the basis of methodological quality, but exclusion of poor-quality studies would tend to move effect estimates towards the null. The major limitations of the review relate to the limitations of the literature, and we made a number of assumptions about the comparability of study methodology. In general, complications (especially wound infection) were poorly defined, and follow-up timeframes differed considerably across studies (Summary of findings for the main comparison). It may be difficult to detect any effects on postoperative outcomes in studies conducted at a late stage of disease. Different interventions may not have an equal effect, or even the same direction of effect, for different cancer sites and stages. We stratified our analysis according to whether or not immunonutrition was given both pre- and postoperatively or only postoperatively, but our analyses did not adjust for differences in the composition or volume of immunonutrition formulas provided, nor did they take into account the length of time for which participants were fed. Few studies reported on compliance with the intervention, but given that the feed was usually administered enterally (at least postoperatively) we assumed good compliance levels. Such diversity across studies may mean that results varied due to one or more of these factors, but we feel that this was unlikely to have greatly affected our findings. Of note, seven studies came from one centre, all of which had relatively small sample sizes (total sample sizes in these seven trials ranged from 29 to 90 participants). A number of factors that we were unable to control for also may have affected outcomes, such as the experience of the surgeon, the length of the operation and the success of the operation.

\section{Agreements and disagreements with other studies or reviews}

Other reviews have been published on this topic, with similarly positive results (Casas Rodera 2012; Stableforth 2009; VidalCasariego 2014). The most recent systematic review and metaanalysis included six head and neck cancer surgery studies (VidalCasariego 2014). Compared to that review, we observed a lower reduction in length of hospital stay (2.5 days in our analysis versus 6.8 days in theirs). As done here, the authors of that review also conducted analyses based on the timing of administration of immunonutrition. In contrast with that review, however, we did not meta-analyse infections other than wound infections due to the diverse range reported in studies. Our finding of little difference between treatments in wound infections is similar, as is the reduction in fistula formation with immunonutrition (VidalCasariego 2014). 
No prior review considered complications directly related to the immunonutrition intervention, and none were found in this review.

Some studies have reported on the tolerability of immunonutrition, but few in detail. In their systematic review, Vidal-Casariego et al reported no increase in diarrhoea, although this was based on very few studies (Vidal-Casariego 2014). Our review suggests that immunonutrition is generally as well tolerated as standard supplements in the head and neck cancer surgery patient group, but this finding is also based on very few studies.

Cost has not been reported in systematic reviews and nor were we able to assess costs due to a lack of published data. Snyderman 1999 considered costs in their study and suggested that a reduction in the infection rate between treatment groups (rates were reported as $23 \%$ and $45 \%$ in the immunonutrition and standard therapy groups, respectively) could reduce costs given the difference in length of hospital stay between those with and without infectious complications.

Overall, our findings are in agreement with other reviews in head and neck cancer surgery (Casas Rodera 2012; Stableforth 2009; Vidal-Casariego 2014), as well as reviews in gastrointestinal surgery (Marimuthu 2012; Zhang 2012), and suggest a potential benefit of immunonutrition. However, in agreement with Vidal-Casariego 2014, the findings for head and neck cancer are based on poorquality evidence.

There were insufficient data to exclude substantial effects of immunonutrition on other clinical outcomes or biochemical and immunological parameters.

\section{AUTHORS' CONCLUSIONS}

\section{Implications for practice}

Fistula formation was reduced by around $50 \%$ but there was no reduction in length of stay or wound infections and no effect on mortality. However, our GRADE rating of the evidence quality ranged from low to very low, primarily due to small sample sizes and wide confidence intervals around effect estimates, and poor reporting of methods used to assess outcomes. As such, we cannot be certain about the results, but if the effects on fistulas are real this would represent a clinically useful effect. There was no evidence of detriment from immunonutrition.

The actual volume of feeds taken in these studies was not always explicitly stated and it is possible that a minimum amount of immunonutrition may be needed to achieve clinical benefit. In trials conducted among patients undergoing surgery in other anatomical sites where feeding volumes were low, it was suggested that immunonutrition may be no better than an isonitrogenous control feed (McCowen 2003). It was also suggested that aggressive enteral feeding improves outcomes from immunonutrition and that pre-operative immunonutrition in surgical patients with cancer might be particularly beneficial (McCowen 2003). In our systematic review, seven studies excluded patients who were malnourished. Given that many patients with head and neck cancer are malnourished, the implications for practice in regard to the findings of this review in such populations remain unknown.

We were unable to relate disease severity to the effect of immunonutrition. For example, severe sepsis may not be responsive to any nutritional intervention, whereas mild illness may improve irrespective of feeding. If future trials can consider these vital points, Level 1 recommendations in favour of immunonutrition might be justified, although presently such evidence is lacking for most clinical indications.

The relatively recent implementation of Enhanced Recovery After Surgery (ERAS) programmes within some healthcare systems may complicate the assessment of specific interventions such as immunonutrition. Enhanced recovery programmes are made up of a composite of around 20 potentially effective interventions covering the preoperative, intraoperative and postoperative periods. Interventions include factors such as the use of minimally invasive surgical procedures, optimal pain relief, early postoperative feeding and early postoperative mobilisation. It could be expected that more interventions might have greater effect, but a recent meta-analysis of enhanced recovery programmes in surgery found that programmes with more elements were no more successful than those with fewer elements (Nicholson 2014). For example, studies with four to seven elements seemed to work as well as those with 11 or more. The difficulty in future studies will be to establish the contribution of individual interventions such as perioperative feeding and the specific effect of immunonutrition compared with standard feeding, when in reality there may be many effective interventions being combined. Of note, the length of hospital stay in our included studies was generally long compared with current practice (Coyle 2016), suggesting that future studies of immunonutrition may have less 'room for improvement' in outcomes such as length of hospital stay, possibly due to the use of ERAS programmes.

Some clinical guidelines recommend the use of immunonutrition in specific populations. For example, immunonutrition has been recommended in elective surgery patients prior to surgery, and postoperatively in 'high-risk' patients (McClave 2013). Others suggest that it may benefit patients undergoing major cancer surgery (including head and neck and gastrointestinal) and severe trauma patients, with recommendations to feed five to seven days prior to and five to seven days after 'uncomplicated' surgery (Weimann 2006). It has also been recommended in some intensive care patients (e.g. upper gastrointestinal surgery patients and patients with mild, but not severe, sepsis) (Kreymann 2006). However, the evidence base in head and neck cancer surgery remains relatively weak and the GRADE rating of evidence was low for all of the outcomes assessed. Nonetheless, given that a relatively recent meta-analysis showed that postoperative infectious complications adversely affect longterm survival (Pucher 2014), any reduction in such complications with immunonutrition might ultimately benefit long-term health.

\section{Implications for research}

Systematic reviews and meta-analyses in some surgical populations (e.g. gastrointestinal) are suggestive of a benefit of immunonutrition on length of hospital stay and complications (Cerantola 2011; Osland 2014; Zhang 2012), but the evidence is less convincing for head and neck cancer surgery, primarily due to a lack of large, high-quality trials. In addition, the potential for immunonutrition to improve outcomes of surgery in the ERAS era remain largely unknown. As such, recommendations for its use in head and neck cancer surgery may be premature. Furthermore, and as noted above, the applicability of the findings to malnourished populations (such as those undergoing surgery for head and neck cancer) is questionable, and this systematic review 
highlights the need for further research on the potential effect of immunonutrition in such populations. There is a clear case for a suitably powered, large contemporary trial to definitively establish the case for using immunonutrition in patients undergoing surgery for head and neck cancer. Some of the key factors to consider when designing such a trial include: an adequate (and achievable) sample size to address the primary outcome(s) (a feasibility or pilot trial may be advisable given the issues with recruitment reported in some trials); an assessment of the extent of malnutrition in the patient population (with appropriate stratification if warranted); collection of detailed information on the volume of immunonutrition study participants actually receive (with a view to assessing whether a minimum amount is required to be effective) and whether or not individual nutritional requirements are met; blinding of participants and personnel where possible; blinding of outcome assessment; and clear definitions of all outcome measures, particularly in regard to local or systemic infection.

\section{ACK N O WLEDGEMENTS}

We thank Jenny Bellorini (Managing Editor) and Samantha Cox (Information Specialist and Assistant Managing Editor) of Cochrane ENT. We also thank Dr Clare Shaw for her helpful comments on this manuscript.

We received further data from Dr De Luis, Professor Jones (re. Ghosh 2012), Dr Riso and Dr Falewee regarding research methods and outcomes.

This project was supported by the National Institute for Health Research via Cochrane Infrastructure, Cochrane Programme Grant or Cochrane Incentive funding to Cochrane ENT. The views and opinions expressed therein are those of the authors and do not necessarily reflect those of the Systematic Reviews Programme, NIHR, NHS or the Department of Health. 


\section{R E F E R E N C E S}

\section{References to studies included in this review}

Azman 2015 \{published data only\}

Azman M, Yunus MRM, Sulaiman S, Omar SNS. Enteral glutamine supplementation in surgical patients with head and neck malignancy: a randomised controlled trial. Head \& Neck 2015;37:1799-807.

\section{Casas-Rodera 2008 \{published data only\}}

Casas-Rodera P, Gómez-Candela C, Benítez S, Mateo R, Armero M, Castillo R, et al. Immunoenhanced enteral nutrition formulas in head and neck cancer surgery: a prospective, randomized clinical trial [Fórmulas de nutrición enteral inmuno-enriquecidas en la cirugía del cáncer de cabeza y cuello. Ensayo prospectivo y aleatorizado]. Nutricion Hospitalaria 2008;23(2):105-10.

De Luis 2002 \{published data only\}

De Luis DA, Aller R, Izaola O, Cuellar L, Terroba MC. Postsurgery enteral nutrition in head and neck cancer patients. European Journal of Clinical Nutrition 2002;56:1126-9.

De Luis 2003 \{published and unpublished data\} de Luis DA, Izaola O, Cuellar L, Terroba MC, Arranz M, Fernandez N, et al. Effect of c-reactive protein and interleukins blood levels in postsurgery arginine-enhanced enteral nutrition in head and neck cancer patients. European Journal of Clinical Nutrition 2003;57:96-9.

\section{De Luis 2004 \{published data only\}}

De Luis DA, Izaola O, Cuellar L, Terroba MC, Aller R. Randomized clinical trial with an arginine-enhanced formula in early postsurgical head and neck cancer patients. European Journal of Clinical Nutrition 2008;58:1505-8.

De Luis 2005 \{published and unpublished data\}

De Luis DA, Arranz M, Aller R, Izaola O, Cuellar L, Terroba MC. Immunoenhanced enteral nutrition, effect on inflammatory markers in head and neck cancer patients. European Journal of Clinical Nutrition 2005;59:145-7.

\section{De Luis 2007 \{published data only\}}

De Luis DA, Izaola O, Cuellar L, Terroba MC, Martin T, Aller R. Clinical and biochemical outcomes after a randomized trial with high dose of enteral arginine formula in postsurgical head and neck cancer patients. European Journal of Clinical Nutrition 2007;61:200-4.

\section{De Luis 2009 \{published data only\}}

De Luis DA, Izaola O, Cuellar L, Terroba MC, Martin T, Aller R. High dose of arginine enhanced enteral nutrition in postsurgical head and neck cancer patients. A randomized clinical trial. European Review for Medical and Pharmacological Sciences 2009;13:279-83.

De Luis 2014 \{published and unpublished data\} De Luis D, Izaola O, Fuente B, Aller R. Effect of L-arginine supplementation on insulin resistance and adipocitokines levels in head and neck cancer non diabetic patients after surgery. Nutrition Hospitalaria 2014;30:870-5.

Falewee 2014 \{published data only\}

Falewee MN, Schilf A, Boufflers E, Cartier C, Bachmann P, Pressoir $\mathrm{M}$, et al. Reduced infections with perioperative immunonutrition in head and neck cancer: exploratory results of a multicenter, prospective, randomized, double-blind study. Clinical Nutrition 2014;33:776-84.

Felekis 2005 \{published data only\}

Felekis DE, Alivizatos VA, Bosinakou E, Archontovassilis F, Kandiloros D, Katsaragakis $S$, et al. The effect of perioperative enteral immunonutrition on outcome of head and neck cancer patients: a prospective, randomised, controlled clinical trial. Clinical Nutrition (Edinburgh, Scotland). 2005; Vol. 24:296.

Felekis 2010 \{published data only\}

Felekis D, Eleftheriadou A, Papadakos G, Bosinakou I, Ferekidou E, Kandiloros D, et al. Effect of perioperative immuno-enhanced enteral nutrition on inflammatory response, nutritional status, and outcomes in head and neck cancer patients undergoing major surgery. Nutrition and Cancer 2010;62:1105-12.

\section{Ghosh 2012 \{published data only\}}

Ghosh S, Dempsey G, Skelly R, Shaw R, Rogers S, Lowe D, et al. A double blind randomised placebo controlled feasibility phase III clinical trial of peri-operative immune-enhancing enteral nutrition in patients undergoing surgery for advanced head and neck cancer. e-SPEN 2012;7(3):e107-14.

Hanai 2018 \{published data only\}

Hanai N, Terada H, Hirakawa H, Suzuki H, Nishikawa D, Beppu S, et al. Prospective randomized investigation implementing immunonutritional therapy using a nutritional supplement with a high blend ratio of $\omega-3$ fatty acids during the perioperative period for head and neck carcinomas. Japanese Journal of Clinical Oncology 2018;48(4):356-61.

Riso 2000 \{published data only\}

Riso S, Aluffi P, Brugnani M, Farinetti F, Pia F, D'Andrea F. Postoperative enteral immunonutrition in head and neck cancer patients. Clinical Nutrition (Edinburgh, Scotland) 2000;19:407-12.

\section{Snyderman 1999 \{published data only\}}

Snyderman CH, Kachman K, Molseed L, Wagner R, D'Amico F, Bumpous J, et al. Reduced postoperative infections with an immune-enhancing nutritional supplements. Laryngoscope 1999;109:915-21.

\section{Sorensen 2009 \{published data only\}}

Sorensen D, McCarthy M, Baumgartner B, Demars S. Perioperative immunonutrition in head and neck cancer. Laryngoscope 2009;119:1358-64.

Turnock 2013 \{published data only\}

Turnock A, Calder PC, West AL, Izzard M, Morton RP, Plank LD. Perioperative immunonutrition in well-nourished patients 
undergoing surgery for head and neck cancer: evaluation of inflammatory and immunologic outcomes. Nutrients 2013;5:1186-99. [DOI: 10.3390/nu5041186]

Van Bokhorst 2000/2001 \{published data only (unpublished sought but not used)\}

Van Bokhorst-de van der Schueren MAE, Langendoen SI, Vondeling H, Kuik DJ, Quak JJ, van Leeuwen PAM. Perioperative enteral nutrition and quality of life of severely malnourished head and neck cancer patients: a randomised clinical trial. Clinical Nutrition (Edinburgh, Scotland) 2000;19:437-44.

\section{References to studies excluded from this review}

Buijs 2010 \{published data only\}

Buijs N, Van Bokhorst-de van der Schueren MAE, Languis JAE, Leemans CR, Kuik DJ, Vermeulen MAR, et al. Perioperative arginine-supplemented nutrition in malnourished patients with head and neck cancer improves long-term survival. American Journal of Clinical Nutrition 2010;92:1151-6.

\section{De Luis 2005a \{published data only\}}

de Luis DA, Izaola O, Aller R, Cuellar L, Terroba MC. A randomized clinical trial with oral Immunonutrition (omega3enhanced formula vs. arginine-enhanced formula) in ambulatory head and neck cancer patients. Annals of Nutrition \& Metabolism 2005;49(2):95-9.

De Luis 2010 \{published data only\}

De Luis DA, Izaola O, Cuellar L, Terroba MC, Martin T, Ventosa $\mathrm{M}$. A randomized double-blind clinical trial with two different doses of arginine enhanced enteral nutrition in postsurgical cancer patients. European Review for Medical and Pharmacological Sciences 2010;14(11):941-5.

\section{De Luis 2013 \{published data only\}}

De Luis DA, Izaola O, Cuellar L, Terroba MC, Ventosa M, Martin T, et al. Clinical effects of an omega 3 enhanced powdered nutritional formula in post surgical ambulatory head and neck cancer patients. Nutricion Hospitalaria 2013;28(5):1463-7.

\section{De Luis 2015 \{published data only\}}

De Luis DA, Izaola O, Terroba MC, Cuellar L. Effect of three different doses of arginine enhanced enteral nutrition on nutritional status and outcomes in well nourished post surgical cancer patients a single blinded prospective trial. European Review for Medical and Pharmacological Sciences 2015;19(6):950-5.

\section{Linn 1988 \{published data only\}}

Linn BS, Robinson DS, Klimas NG. Effects of age and nutritional status on surgical outcomes in head and neck cancer. Annals of Surgery 1988;207(3):267-73.

\section{Palma-Milla 2016 \{published data only\}}

Palma-Milla S, López-Plaza B, Santamaría B, de ArribaSánchez Á, Bermejo LM, Gómez-Candela C. New, immunomodulatory, oral nutrition formula for use prior to surgery in patients with head and neck cancer: an exploratory study. JPEN. Journal of Parenteral and Enteral Nutrition 2016 Nov 10 [Epub ahead of print].
Reis 2016 \{published data only\}

Reis AM, Kabke GB, Fruchtenicht AV, Barreiro TD, Moreira LF. Cost-effectiveness of perioperative immunonutrition in gastrointestinal oncologic surgery: a systematic review. Arquivos Brasileiros de Cirurgia Digestiva 2016;29(2):121-5.

\section{References to ongoing studies}

NCT03261180 \{published data only\}

Clayburgh DR. Nestle impact advanced recovery in improving surgery recovery in patients with head and neck cancer. https:// clinicaltrials.gov/ct2/show/NCT03261180 (first received 24 August 2017). [NCT03261180]

\section{Additional references}

\section{Cancer Research UK}

Cancer Research UK. Oral Cancer Statistics. http:// www.cancerresearchuk.org/health-professional/cancerstatistics/statistics-by-cancer-type/oral-cancer\#heading-Zero (accessed March 2017).

\section{Casas Rodera 2012}

Casas Rodera P, de Luis DA, Gómez Candela C, Culebras JM. Immunoenhanced enteral nutrition formulas in head and neck cancer surgery: a systematic review. Nutricion Hospitalaria 2012;27:681-90.

\section{Cerantola 2011}

Cerantola Y, Hubner M, Grass F, Demartines N, Schafer M. Immunonutrition in gastrointestinal surgery. British Journal of Surgery 2011;98(1):37-48.

\section{Coyle 2016}

Coyle MJ, Main B, Hughes C, Craven R, Alexander R, Porter G, et al. Enhanced recovery after surgery (ERAS) for head and neck surgery: a prospective interventional study. Clinical Otolaryngology 2016;41(2):118-26. [DOI: 10.1111/coa.12482]

\section{Di Carlo 1999}

Di Carlo V, Gianotti I, Balzano G, Zerbi A, Braga M. Complications of pancreatic surgery and the role of perioperative nutrition. Digestive Diseases and Sciences 1999;16:320-6.

\section{Hadden 1997}

Hadden JW. The immunopharmacology of head and neck cancer: an update. International Journal of Immunopharmacology 1997;19:629-44.

\section{Handbook 2011}

Higgins JPT, Green S (editors). Cochrane Handbook for Systematic Reviews of Interventions Version 5.1.0 [updated March 2011]. The Cochrane Collaboration, 2011. Available from www.cochrane-handbook.org.

\section{Heyland 2001}

Heyland DK, Novak F, Drover F, Jain M, Su X, Suchner U. Should immunonutrition become routine in critically ill patients? A systematic review of the evidence. JAMA 2001;286:944-53. 


\section{Kreymann 2006}

Kreymann KG, Berger MM, Deutz NE, Hiesmayr M, Jolliet P, Kazandjiev G, et al. ESPEN (European Society for Parenteral and Enteral Nutrition). ESPEN guidelines on enteral nutrition: intensive care. Clinical Nutrition 2006;25(2):210-23.

\section{Kucur 2015}

Kucur C, Durmus K, Uysal IO, Old M, Agrawal A, Arshad H, et al. Management of complications and compromised free flaps following major head and neck surgery. European Archives of Oto-rhino-laryngology 2015;273(1):209-13.

\section{Lidder 2013}

Lidder P, Thomas S, Fleming S, Hosie K, Shaw S, Lewis S. A randomized placebo controlled trial of preoperative carbohydrate drinks and early postoperative nutritional supplement drinks in colorectal surgery. Colorectal Disease 2013;15(6):737-45.

\section{Marimuthu 2012}

Marimuthu K, Varadhan KK, Ljungqvist O, Lobo DN. A metaanalysis of the effect of combinations of immune modulating nutrients on outcome in patients undergoing major open gastrointestinal surgery. Annals of Surgery 2012;255:1060-8.

\section{McClave 2013}

McClave SA, Kozar R, Martindale RG, Heyland DK, Braga M, Carli F, et al. Summary points and consensus recommendations from the North American Surgical Nutrition Summit. Journal of Parenteral and Enteral Nutrition 2013;37(5 Suppl):99s-105s.

\section{McCowen 2003}

McCowen KC, Bistrian BR. Immunonutrition: problematic or problem solving?. American Journal of Clinical Nutrition 2003;77:764-70.

\section{McMahon 2013}

McMahon JD, Maclver C, Smith M, Stathopoulos P, Wales C, McNulty R, et al. Postoperative complications after major head and neck surgery with free flap repair--prevalence, patterns, and determinants: a prospective cohort study. British Journal of Oral \& Maxillofacial Surgery 2013;51(8):689-95.

\section{Nicholson 2014}

Nicholson A, Lowe MC, Parker J, Lewis SR, Alderson P, Smith AF. Systematic review and meta-analysis of enhanced recovery programmes in surgical patients. British Journal of Surgery 2014;101(3):172-88.

\section{Osland 2014}

Osland E, Hossain MB, Khan S, Memon MA. Effect of timing of pharmaconutrition (immunonutrition) administration on outcomes of elective surgery for gastrointestinal malignancies: a systematic review and meta-analysis. Journal of Parenteral and Enteral Nutrition 2014;38(1):53-69.

\section{Perisanidis 2012}

Perisanidis C, Herberger B, Papadogeorgakis N, Seemann R, Eder-Czembirek C, Tamandl D, et al. Complications after free flap surgery: do we need a standardized classification of surgical complications?. British Journal of Oral \& Maxillofacial Surgery 2012;50(2):113-8.

\section{Pucher 2014}

Pucher PH, Aggarwal R, Qurashi M, Darzi A. Meta-analysis of the effect of postoperative in-hospital morbidity on long-term patient survival. British Journal of Surgery 2014;101:1499-508.

\section{RevMan 2014 [Computer program]}

The Nordic Cochrane Centre, The Cochrane Collaboration. Review Manager (RevMan). Version 5.3. Copenhagen: The Nordic Cochrane Centre, The Cochrane Collaboration, 2014.

\section{Ryan 2016}

Ryan R, Hill S. How to GRADE the quality of the evidence (Version 3.0). Cochrane Consumers and Communication Group. http://cccrg.cochrane.org/author-resources 2016.

\section{Stableforth 2009}

Stableforth WD, Thomas S, Lewis SJ. A systematic review of the role of immunonutrition in patients undergoing surgery for head and neck cancer. International Journal of Oral and Maxillofacial Surgery 2009;38:103-10.

\section{van Bokhorst 2000}

Van Bokhorst-de van der Schueren MAE, Langendoen SI, Vondeling H, Kuik DJ, Quak JJ, van Leeuwen PAM. Perioperative enteral nutrition and quality of life of severely malnourished head and neck cancer patients: a randomised clinical trial. Clinical Nutrition 2000;19:437-44.

\section{Vidal-Casariego 2014}

Vidal-Casariego A, Calleja-Fernández A, Villar-Taibo R, Kyriakos G, Ballesteros-Pomar MD. Efficacy of arginine-enriched enteral formulas in the reduction of surgical complications in head and neck cancer: a systematic review and meta-analysis. Clinical Nutrition 2014;33:951-7.

\section{Weimann 2006}

Weimann A, Braga M, Harsanyi L, Laviano A, Ljungqvist O, Soeters P, DGEM (German Society for Nutritional Medicine), Jauch KW, Kemen M, Hiesmayr JM, Horbach T, Kuse ER, Vestweber KH, ESPEN (European Society for Parenteral and Enteral Nutrition). ESPEN guidelines on enteral nutrition: surgery including organ transplantation. Clinical Nutrition 2006;25(2):224-44.

\section{Worthington 2011}

Worthington ML, Cresci G. Immune-modulating formulas: who wins the meta-analysis race?. Nutrition in Clinical Practice 2011;26(6):650-5.

\section{Wu 2001}

Wu HH, Zhao YW, Wu ZH. Inflammatory response by immuneenhancing enteral diet in gastrointestinal cancer patients. World Journal of Surgery 2001;7:357-62.

\section{Yang 2014}

Yang R, Lubek JE, Dyalram D, Liu X, Ord RA. Head and neck cancer surgery in an elderly patient population: a retrospective 
review. International Journal of Oral and Maxillofacial Surgery 2014;43(12):1413-7.

\section{Zhang 2012}

Zhang Y, Gu Y, Guo T, Li Y, Cai H. Perioperative immunonutrition for gastrointestinal cancer: a systematic review of randomized controlled trials. Surgical Oncology 2012;2:87-95.

\section{References to other published versions of this review Howes 2014}

Howes N, Lewis SJ, Thomas S. Immunonutrition for patients undergoing surgery for head and neck cancer. Cochrane Database of Systematic Reviews 2014, Issue 3. [DOI: 10.1002/14651858.CD010954]

\section{CHARACTERISTICS OF STUDIES}

\section{Characteristics of included studies [ordered by year of study]}

Snyderman 1999

Methods

Design: double-blind, parallel-group randomised controlled trial with $\geq 5$ days pre- and $\geq 7$ days postoperative duration of treatment and 1 month duration of follow-up post-operation

\section{Participants}

Setting: University of Pittsburgh Medical Center and the University of Louisville, Kentucky; from 1994 to 1996

Sample size: 141

- Number randomised: 136

- Number completed: 129

\section{Participant (baseline) characteristics:}

- Age: Impact group mean age = 63 (SD 9.8) years; standard group mean age = 61 (SD 11.7) years

- Gender: male:female ratio Impact group = 3.3:1; standard group = 2.1:1

- Baseline differences/other characteristics: Quote: "The composition of treatment groups was similar. There were no significant differences in patient or tumor characteristics". No significant differences in preoperative weight, weight loss or biochemical measures of nutritional status. Quote: "More patients in the Impact group were randomly assigned to receive preoperative nutritional support ( $\mathrm{P}$ $=.002) . "$

Inclusion criteria: Quote: "patients with stage II-IV squamous cell carcinoma of the oral cavity, phar$y n x$, or larynx undergoing oncologic surgery with curative intent and requiring postoperative nutritional supplementation"

Exclusion criteria: Quote: "malabsorption, immune disorders or immunosuppressive medications, active infection, and morbid obesity (>130\% ideal body weight)."

$$
\begin{aligned}
& \mathbf{4} \text { arms: } \\
& \text { Group I = pre- and postoperative Impact } \\
& \text { Group II = postoperative Impact } \\
& \text { Group III = pre- and postoperative standard formula } \\
& \text { Group IV = postoperative standard formula }
\end{aligned}
$$

\section{Intervention group:}

Groups I and II combined as 'Impact' ( $\mathrm{n}=82$ )

\section{Comparator group:}

Groups III and IV combined as 'standard' ( $n=47)$

Quote: "Standard enteral formulas included Replete, Resource, Isosource, Jevity, Vivonex, and Osmolite. Replete was used in the majority (78\%) of control patients." 
Snyderman 1999 (Continued)

Quote: "Treatment goals consisted of preoperative consumption of a minimum of $500 \mathrm{~mL}$ of supplement per day for at least 5 days in treatment groups I and III, and postoperative consumption of an average of $1000 \mathrm{~mL}$ per day for at least 7 days in all treatment groups."

Use of additional interventions: Quote: "All the patients received standard antibiotic prophylaxis, consisting of 24 to 48 hours of intravenous antibiotics. In most cases, a regimen of clindamycin $(900 \mathrm{mg}$ IV every $8 \mathrm{~h}$ ) was employed. Continuation of antibiotics for more than 48 hours was only used for the treatment of documented infections."

\begin{abstract}
Outcomes Primary outcome and secondary outcomes:
Primary and secondary outcomes not separated out

Quote: "Outcome measures included changes in weight, laboratory evaluations of nutritional status, tolerance of tube feedings, infectious and wound healing complications, and duration of hospitalisation."

Results presented for: intolerance, postoperative weight, total protein, albumin, transferrin, haemoglobin, TLC, postoperative infection (total number and site specific percentages), wound healing problem, fistula, hospital days, ICU days. Also amino acid and fatty acids, and cost analysis.
\end{abstract}

\begin{tabular}{|c|c|}
\hline Funding sources & $\begin{array}{l}\text { Quote: "This study was supported by Novartis Nutrition (formerly Sandoz Nutrition), St Louis Park, Min } \\
\text { nesota" }\end{array}$ \\
\hline Declarations of interest & None stated \\
\hline \multirow[t]{2}{*}{ Notes } & $\begin{array}{l}\text { Participants lost to follow-up: Quote: "An intent-to-treat analysis was performed on the entire group } \\
\text { (129 patients)." }\end{array}$ \\
\hline & $\begin{array}{l}\text { Recruitment: Quote: "Because of problems with recruitment into the preoperative arms of the study } \\
\text { (groups I and III), patients in the latter part of the study were only randomly assigned to groups II and } \\
\text { IV, thus accounting for differences in sizes of treatment groups." }\end{array}$ \\
\hline
\end{tabular}

Stratification: Quote: "After meeting entry criteria, patients were stratified for site (larynx vs. other), stage (T1-3 versus T4, N0 versus N1 to 3), and preoperative weight loss (0-10 lbs, 11-20 lbs, > 20 lbs)"

\begin{tabular}{lll}
\hline Risk of bias & & \\
\hline Bias & Authors' judgement & Support for judgement \\
\hline $\begin{array}{l}\text { Random sequence genera- } \\
\text { tion (selection bias) }\end{array}$ & Low risk & Randomisation tables \\
\hline $\begin{array}{l}\text { Allocation concealment } \\
\text { (selection bias) }\end{array}$ & Unclear risk & No statement on allocation concealment \\
\hline $\begin{array}{l}\text { Blinding of participants } \\
\text { and personnel (perfor- } \\
\text { mance bias) } \\
\text { All outcomes }\end{array}$ & Unclear risk & $\begin{array}{l}\text { Partial blinding described } \\
\text { Quote: "Novartis Nutrition provided Impact and Replete (oral and enteral for- } \\
\text { mulas) in unlabeled containers for patients in groups I and III" and "Patients, } \\
\text { physicians, and nurses were blinded to the type of formula used." However, } \\
\text { whether blinding was achieved for groups II and IV is not stated. }\end{array}$
\end{tabular}

Blinding of outcome as-
sessment (detection bias)

\section{Partial blinding described}

Quote: "Novartis Nutrition provided Impact and Replete (oral and enteral formulas) in unlabeled containers for patients in groups I and III" and "Patients, physicians, and nurses were blinded to the type of formula used." However, whether blinding was achieved for groups II and IV is not stated.

Incomplete outcome data Low risk
(attrition bias)

(attrition bias)

All outcomes

\section{No evidence from the published data}

Quote: "An intent-to-treat analysis was performed on the entire group (129 patients)." 
Note: 136 patients were randomised and it was stated that " 7 patients did not receive any therapy and were withdrawn from the study preoperatively. Reasons for withdrawal included patient noncompliance and medical or laboratory evidence of ineligibility." This equates to $5 \%$ withdrawal. A 'per-protocol' analysis was also conducted and reported.

\begin{tabular}{|c|c|c|}
\hline $\begin{array}{l}\text { Selective reporting (re- } \\
\text { porting bias) }\end{array}$ & Unclear risk & Protocol not available \\
\hline Other bias & High risk & $\begin{array}{l}\text { Quote: "Because of problems with recruitment into the preoperative arms of } \\
\text { the study (groups I and III), patients in the latter part of the study were only } \\
\text { randomly assigned to groups II and IV, thus accounting for differences in sizes } \\
\text { of treatment groups." However, they do not indicate how many were in each of } \\
\text { the } 4 \text { groups (they only provide totals for the combined groups), but state that } \\
\text { "More patients in the Impact group were randomly assigned to receive preop- } \\
\text { erative nutritional support ( } \mathrm{P}=.002) \text {." }\end{array}$ \\
\hline
\end{tabular}

Methods Design: double-blind, parallel-group randomised controlled trial with 7 to 10 days pre- and $\geq 10$ days postoperative duration of treatment and 7 days duration of follow-up (greater than or equal to 16 months of follow-up for survival)

Participants

Setting: Department of Otolaryngology - Head and Neck Surgery of the University Hospital Vrije Universiteit, Amsterdam; from 1 January 1994 through 31 December 1997

\section{Sample size:}

- Number randomised: 56

- Number completed: 49

\section{Participant (baseline) characteristics:}

- Age: Group $1=55 \pm 10 ;$ Group $2=60 \pm 8$; Group $3=59 \pm 12$

- Gender: Group 1 = 11 males, 6 females; Group 2 = 7 males, 8 females; Group $3=12$ males, 5 females; overall total $=30$ males, 19 females

- Baseline differences/other characteristics: no difference between groups in age, tumour stage, tumour location, comorbidity, weight loss, the ratio between combined mandibular resections and total laryngectomies and the type of reconstructive surgery, mean duration of surgery, mean blood loss. Preoperatively, groups 2 and 3 reached $110 \%$ and $113 \%$ of their estimated energy requirements, but patients in group 1 reached $79 \%(P=0.007)$. Baseline weight was lower in group 2 than in the other groups; baseline serum albumin differed between groups; baseline numbers of lymphocytes and $T$ lymphocytes $\left(\mathrm{CD}^{+}\right)$and the percentage of T suppressor lymphocytes $\left(\mathrm{CD} 8^{+}\right)$.

Inclusion criteria: Quote: "Severely malnourished (preoperative weight loss > 10\% of body weight over the previous $6 \mathrm{mo}$ ) head and neck cancer patients eligible for surgery". Quote: "All patients had a histologically proven squamous cell carcinoma of the oral cavity, larynx, oropharynx, or hypopharynx'.

Exclusion criteria: Quote: "Patients were excluded from the study if they were well nourished (weight loss $<10 \%$ of body weight); received other investigational drugs or steroids; had renal insufficiency, hepatic failure, or any genetic immune disorder; or had a confirmed diagnosis of AIDS."

\section{3 arms:}

Quote: "After stratification for type of surgery (combined mandibular resection or total laryngectomy) and previous radiotherapy (yes or no) the patients were randomly assigned to 1 of 3 treatment groups."

Group 1 = no pre-operative and standard postoperative tube feeding 
Van Bokhorst 2000/2001 (Continued)

Group 2 = standard pre-operative and postoperative tube feeding (NB: this group used as the comparator in this review)

Group 3 = arginine supplemented pre-operative and postoperative tube feeding

Quote: "Group 1 received no preoperative nutritional support, group 2 received preoperative enteral nutrition with a specially formulated product that closely reflected the current standard of practice (standard formula), and group 3 received preoperative enteral nutrition in which $41 \%$ of the casein was replaced by arginine. Nutritional solutions were isoenergetic and isonitrogenous."

Standard formula: $62.5 \mathrm{~g}$ protein/L, $6.3 \mathrm{~g}$ glutamine/L, $9.8 \mathrm{~g}$ nitrogen/L, $48.61 \mathrm{~g}$ fat/L, $140.63 \mathrm{~g}$ carbohydrate/L, $5250 \mathrm{~kJ} / \mathrm{L}$

Arginine supplemented formula: $36.85 \mathrm{~g}$ protein/L, $12.5 \mathrm{~g}$ free arginine/L, $3.7 \mathrm{~g}$ glutamine/L, $9.8 \mathrm{~g}$ nitrogen/L, $48.61 \mathrm{~g}$ fat/L, 153.77 carbohydrate/L, $5250 \mathrm{~kJ} / \mathrm{L}$

Quote: "Patients in groups 2 and 3 were given enteral nutrition at home for 7-10 d preoperatively through a nasogastric feeding tube"

Quote: "Patients in group 1 were stimulated to continue their usual oral diet preoperatively"

Quote: "Postoperatively, all patients received tube feeding (1.5 x BEE) starting on the first postoperative day until and X-ray conducted to assess swallowing ability performed $10 \mathrm{~d}$ after surgery showed no leakage from anastomoses"

\section{Intervention group:}

Group 3: arginine supplemented pre-operative and postoperative tube feeding $(n=17)$

\section{Comparator group:}

Group 2: standard pre-operative and postoperative tube feeding $(n=15)$

(Data from group $1, \mathrm{n}=17$, not used in this review)

Use of additional interventions: none stated

\section{Primary and secondary outcomes:}

Primary and secondary outcomes not separated out

Van Bokhorst 2000: quality of life assessed via 2 questionnaires: the disease-specific EORTC QLQ-C30 and the generic COOP-WONCA. Time points assessed were recruitment (baseline), day before surgery, day of discharge, 6 months post surgery.

Van Bokhorst 2001: anthropometric measures included body weight, body composition (BIA), upper midarm circumference, skinfold thickness and muscle function (hand grip strength). Biochemical assessment included serum albumin and electrolytes and liver and kidney function tests.

Immune variables included: absolute numbers of leukocytes and lymphocytes, total lymphocyte count, percentages of monocytes (CD14+), pan T lymphocytes (CD3+), T helper lymphocytes (CD4+), T suppressor lymphocytes (CD8+), B lymphocytes (CD19+), natural killer (NK) cells (CD16/CD56+/CD3) and NK-like T cells (CD16/CD56+/CD3+). Also measured human leukocyte antigen-DR (HLA-DR) expression in CD14+ cells, interleukin 6 (IL-6) and tumour necrosis factor (TNF).

Clinical outcomes included perioperative use of blood, blood products and antibiotics; the occurrence of postoperative complications; the date of normal swallowing as confirmed by X-ray and the date of discharge from the hospital. Postoperative complications were categorised as absent, minor (including minor wound infections, redness and induration of the wound, pulmonary infections and urinary tract infections) or major (including wound infections requiring surgical drainage, orocutaneous or pharyngocutaneous fistula, flap failure, radiologic signs of anastomotic leakage, respiratory insufficiency, cardiac failure and septic shock).

Survival (and cause of death where applicable) were assessed after a follow-up period of $\geq 16$ months 
Van Bokhorst 2000/2001 (Continued)

Time points assessed: Quote: "at recruitment into the study, $1 \mathrm{~d}$ preoperatively, $1 \mathrm{~d}$ postoperatively, $4 \mathrm{~d}$ postoperatively, $7 \mathrm{~d}$ postoperatively, and on the day of discharge. Follow-up time for survival was $\geq 16$ mo."

\begin{tabular}{ll}
\hline Funding sources & None stated \\
\hline Declarations of interest & None stated \\
\hline
\end{tabular}

Notes

Participants lost to follow-up: Van Bokhorst 2001 stated "No patient was lost to follow up" in regards to the survival analysis (page 325)

Sample size: Quote: "To reduce the percentage of major postoperative complications from $60 \%$ to $30 \%$ in the nutrition intervention groups, the sample size was calculated to be 39 patients per study group with $80 \%$ power and $5 \%$ significance. Because patient recruitment was much slower than expected, however, recruitment ended on 31 December 1997 for financial reasons."

Further publication included data on longer-term follow-up: Buijs N, van Bokhorst-de van der Schueren MA, Langius JA, Leemans CR, Kuik DJ, Vermeulen MA, et al. Perioperative arginine-supplemented nutrition in malnourished patients with head and neck cancer improves long-term survival. American Journal of Clinical Nutrition 2010;92(5):1151-6

\section{Risk of bias}

\begin{tabular}{|c|c|c|}
\hline Bias & Authors' judgement & Support for judgement \\
\hline $\begin{array}{l}\text { Random sequence genera- } \\
\text { tion (selection bias) }\end{array}$ & Low risk & $\begin{array}{l}\text { Patients were randomly assigned "according to a computer-generated ran- } \\
\text { domization schedule with an equal probability of assignment to any of the nu- } \\
\text { tritional regimens." (Van Bokhorst 2001, page 324) }\end{array}$ \\
\hline $\begin{array}{l}\text { Allocation concealment } \\
\text { (selection bias) }\end{array}$ & Unclear risk & No statement as to how allocation was concealed \\
\hline $\begin{array}{l}\text { Blinding of participants } \\
\text { and personnel (perfor- } \\
\text { mance bias) } \\
\text { All outcomes }\end{array}$ & Low risk & $\begin{array}{l}\text { Quote: "Blinding of patients, health care professionals involved in patient } \\
\text { treatment and assessors was only possible in groups II and III" (Van Bokhorst } \\
\text { 2000, page 438) - these } 2 \text { groups were used in analyses }\end{array}$ \\
\hline $\begin{array}{l}\text { Blinding of outcome as- } \\
\text { sessment (detection bias) } \\
\text { All outcomes }\end{array}$ & Low risk & $\begin{array}{l}\text { Quote: "Blinding of patients, health care professionals involved in patient } \\
\text { treatment and assessors was only possible in groups II and III" (Van Bokhorst } \\
\text { 2000, page 438) - these } 2 \text { groups were used in analyses }\end{array}$ \\
\hline $\begin{array}{l}\text { Incomplete outcome data } \\
\text { (attrition bias) } \\
\text { All outcomes }\end{array}$ & Low risk & $\begin{array}{l}49 \text { patients recruited } \\
\text { Quote: (Van Bokhorst 2001) "No patient was lost to follow up" in regards to the } \\
\text { survival analysis (page 325) No evidence of attrition bias from published data } \\
\text { (figures and tables present data on relevant outcomes for } 49 \text { patients) }\end{array}$ \\
\hline $\begin{array}{l}\text { Selective reporting (re- } \\
\text { porting bias) }\end{array}$ & Unclear risk & Protocol not available \\
\hline Other bias & High risk & $\begin{array}{l}\text { Some evidence of baseline differences } \\
\text { Sample size not achieved } \\
\text { Quote: "Because patient recruitment was much slower than expected, howev- } \\
\text { er, recruitment ended on } 31 \text { December } 1997 \text { for financial reasons." }\end{array}$ \\
\hline
\end{tabular}




\section{Methods}

Participants
Design: double-blind, parallel-group randomised controlled trial with $\geq 10$ days (following total laryngectomy) or $\geq 21$ days (following partial laryngectomy) duration of treatment and follow-up to hospital discharge

Setting: not stated but authors affiliated to Maggiore della Carita Hospital, Novara, Italy. Stated that the trial was "carried out from January to December 1998"

\section{Sample size:}

- Number randomised: 44

- Number completed: 44

\section{Participant (baseline) characteristics:}

- Age: enriched group mean age $60.8( \pm 9.1)$; control group mean age $63.2( \pm 5.7)$

- Gender: male/female: enriched 21/2; control 18/3

- Baseline differences/other characteristics: Quote: "Characteristics of the patients on enrolment were similar for the two groups"

Inclusion criteria: Quote: "adult patients with oral, pharyngeal and laryngeal cancer were enrolled."

Exclusion criteria: Quote: "Exclusion criteria included severely impaired renal function (serum creatinine concentration $>2.5 \mathrm{mg} / \mathrm{dl}$ ) and hepatic function (total serum bilirubin concentration $>3 \mathrm{mg} / \mathrm{dl}$ ), autoimmune disorders, insulin-dependent diabetes mellitus, ongoing infections."

\section{Intervention group:}

Enteral diet supplemented with arginine (enriched group) $(n=23)$

\section{Comparator group:}

Isocaloric, isonitrogenous enteral formula (control group) $(n=21)$

Quote: "At surgery, patients were randomly allocated to two groups: a) patients receiving an enteral diet supplemented with arginine (Nutrison Intensive, Nutricia, Zoetermeer, The Netherlands) (enriched group); b) patients receiving an isocaloric, isonitrogenous enteral formula (Nutrison Protein Plus, Nutricia, Zoetermeer, The Netherlands) (control group)."

Quote: "Enteral feeding was started within $24 \mathrm{hrs}$ of surgery at a rate of $40 \mathrm{ml} / \mathrm{hour}$. The infusion rate was progressively increased by $20 \mathrm{ml} /$ hour every $24 \mathrm{hrs}$ until the daily nutritional goal (31.0 total kcal/ $\mathrm{kg} ; 25.0$ non-protein $\mathrm{kcal} / \mathrm{kg} ; 1.5 \mathrm{~g}$ protein $/ \mathrm{kg}$ ) was reached, on postoperative day (POD) 4 . In the first 3 PODs, all patients received calories and nitrogen by parenteral route to achieve the nutritional goal."

\section{Use of additional interventions:}

Quote: "In the first 3 PODs, all patients received calories and nitrogen by parenteral route to achieve the nutritional goal."

Quote: "Prophylactic antibiotic treatment (amoxicillin/clavulanate, $2.2 \mathrm{~g}$ bid i.v.) was given for 7 days postoperatively."

\section{Primary outcome and secondary outcomes:}

Primary and secondary outcomes not separated out

Quote: "Preoperatively and on postoperative days 1, 4 and 8 the following parameters were evaluated: serum level of albumin $(\mathrm{g} / \mathrm{dl})$, prealbumin $(\mathrm{mg} / \mathrm{dl})$, and transferrin $(\mathrm{mg} / \mathrm{dl})$, total number of lymphocytes $\left(10^{6} / \mathrm{ml}\right)$, lymphocyte subsets (CD3, CD4, CD8 and CD4/CD8 ratio; \%), and serum immunoglobulin concentrations (IgG, IgA, IgM; mg/dl)."

Quote: "All patients were followed-up until discharge. Postoperative complications were recorded as none, minor (urinary tract infection; respiratory tract infection: abnormal chest X-ray), and major (fistula; wound infection: spontaneous or surgical purulent drainage and necrosis; anastomotic leakage). 
Riso 2000 (Continued)

The clinical complications were not defined. Gastrointestinal problems related to enteral feeding were also recorded."

Abstract states that length of hospital stay was also recorded

\begin{tabular}{ll}
\hline Funding sources & None stated \\
\hline Declarations of interest & None stated \\
\hline Notes & Participants lost to follow-up: no attrition according to figures on outcomes
\end{tabular}

\section{Risk of bias}

\begin{tabular}{|c|c|c|}
\hline Bias & Authors' judgement & Support for judgement \\
\hline $\begin{array}{l}\text { Random sequence genera- } \\
\text { tion (selection bias) }\end{array}$ & Low risk & Computer-generated (information from authors) \\
\hline $\begin{array}{l}\text { Allocation concealment } \\
\text { (selection bias) }\end{array}$ & Unclear risk & $\begin{array}{l}\text { Quote: "Concealed (envelopes)" (information from authors) but not known if } \\
\text { these were opaque }\end{array}$ \\
\hline $\begin{array}{l}\text { Blinding of participants } \\
\text { and personnel (perfor- } \\
\text { mance bias) } \\
\text { All outcomes }\end{array}$ & Unclear risk & $\begin{array}{l}\text { Quote: "double-blindly performed" (information from authors) but no indica- } \\
\text { tion of who was blinded }\end{array}$ \\
\hline $\begin{array}{l}\text { Blinding of outcome as- } \\
\text { sessment (detection bias) } \\
\text { All outcomes }\end{array}$ & Unclear risk & $\begin{array}{l}\text { Quote: "double-blindly performed" (information from authors) but no indica- } \\
\text { tion of who was blinded }\end{array}$ \\
\hline $\begin{array}{l}\text { Incomplete outcome data } \\
\text { (attrition bias) } \\
\text { All outcomes }\end{array}$ & Low risk & $\begin{array}{l}\text { No attrition according to number of participants included in figures on out- } \\
\text { comes }\end{array}$ \\
\hline $\begin{array}{l}\text { Selective reporting (re- } \\
\text { porting bias) }\end{array}$ & Unclear risk & $\begin{array}{l}\text { Protocol not available. Subgroup analysis performed on 'malnourished' sub- } \\
\text { set of patients (Quote: "Patients with a weight loss of } 10 \% \text { or more in less than } \\
6 \text { months, with respect to pre-illness body weight"). Unclear if this was a pre- } \\
\text { planned analysis; } 6 \text { patients in the enriched diet group and } 7 \text { in the control } \\
\text { group were classed as malnourished. }\end{array}$ \\
\hline Other bias & High risk & $\begin{array}{l}\text { No description of how length of stay was determined. No sample size calcula- } \\
\text { tions }\end{array}$ \\
\hline
\end{tabular}

\section{De Luis 2002}

$\begin{array}{ll}\text { Methods } & \text { Design: double-blind, parallel-group randomised controlled trial with an average duration of treat- } \\ \text { ment of } 22 \text { days }( \pm 12 \text { days) and duration of follow-up of } 14 \text { days postoperatively, or } 3 \text { months post-dis- } \\ \text { charge for mortality }\end{array}$

Participants

Setting: author affiliations in Spain (Institute of Endocrinology and Nutrition, Medicine School and Hospital Rio Hortega, Spain; and Hospital Clinico, University of Valladolid, Valladolid, Spain)

\section{Sample size:}

- Number randomised: 47

- Number completed: 47 
De Luis 2002 (Continued)

\section{Participant (baseline) characteristics:}

- Age: mean age was $61.4 \pm 11.7$ years $(63.15 \pm 12.7$ in group 1 and $59.3 \pm 10.5$ in group 2$)$

- Gender: 5 females, 42 males

- Baseline differences/other characteristics: Quote: "Characteristics of the patients on enrollment were similar for the two groups."

Inclusion criteria: oral and laryngeal cancer

Exclusion criteria: Quote: "severely impaired hepatic function (total bilirubin concentration > $3.5 \mathrm{mg}$ / $\mathrm{dl}$ ) and renal function (serum creatinine concentration $>2.5 \mathrm{mg} / \mathrm{dl}$ ); ongoing infections; autoimmune disorders; steroid treatment; nutritional oral supplementation in the previous 6 months; and severe malnourishment (weight loss $>10 \%$ of body weight)."

Interventions

Intervention group:

Enteral diet supplemented with arginine and fibre $(n=23)$

Comparator group:

Isocaloric, isonitrogenous enteral formula $(n=24)$

Enteral feeding was started within 24 hours of surgery

Use of additional interventions: Quote: "Prophylactic antibiotic treatment was given for 7 days postoperatively (ceftazidime, $500 \mathrm{mg}$ three times daily i.v. and clyndamicine $300 \mathrm{mg}$ three times daily i.v.)"

Outcomes

\section{Primary outcome and secondary outcomes:}

Primary and secondary outcomes not separated out

Quote: "Perioperatively and on postoperative days 7 and 14 the following parameters were evaluated: serum values of prealbumin $(\mathrm{mg} / \mathrm{dl})$, transferrin $(\mathrm{mg} / \mathrm{dl})$, albumin $(\mathrm{g} / \mathrm{dl})$ and total number of lymphocytes $\left(10^{6} / \mathrm{ml}\right)$. Postoperative complications were recorded as none, general infections (respiratory tract infection was diagnosed when the chest radiographic examination showed new or progressive unfiltration, temperature above $38.5^{\circ} \mathrm{C}$ and isolation of pathogens from the sputum or blood culture and/ or urinary tract infection was diagnosed if the urine culture showed at least 105 colonies of a pathogen) and local complications such as fistula and/or wound infection, assessing all complications using standard methods and the same investigator. Gastrointestinal problems related to enteral feeding were also recorded (diarrhoea, $>5$ liquid stools in a $24 \mathrm{~h}$ period or an estimated volume $>2000 \mathrm{ml} /$ day). Mortality was assessed 3 months after hospital discharge."

\begin{tabular}{ll}
\hline Funding sources & None stated \\
\hline Declarations of interest & None stated \\
\hline Notes & Participants lost to follow-up: stated that an ITT analysis was conducted \\
& $\begin{array}{l}\text { Quote: "Sample size was calculated to decrease fistula complication by } 20 \% \text { with } 80 \% \text { power and } 5 \% \\
\text { significance." }\end{array}$
\end{tabular}

\section{Risk of bias}

\begin{tabular}{lll}
\hline Bias & Authors' judgement & Support for judgement \\
\hline $\begin{array}{l}\text { Random sequence genera- } \\
\text { tion (selection bias) }\end{array}$ & Low risk & $\begin{array}{l}\text { No statement in manuscript on the generation of random sequence. Author } \\
\text { contacted: tables of random numbers used. }\end{array}$ \\
\hline $\begin{array}{l}\text { Allocation concealment } \\
\text { (selection bias) }\end{array}$ & Unclear risk & $\begin{array}{l}\text { No statement in manuscript as to how allocation was concealed. Author con- } \\
\text { tacted: sealed envelopes used (but not known if these were opaque). }\end{array}$ \\
\hline
\end{tabular}


De Luis 2002 (Continued)

Blinding of participants Low risk Quote: "The main investigator and patients remained blind to the treatment and personnel (performance bias)

All outcomes

$$
\text { group." }
$$

\begin{tabular}{|c|c|c|}
\hline $\begin{array}{l}\text { Blinding of outcome as- } \\
\text { sessment (detection bias) }\end{array}$ & Low risk & $\begin{array}{l}\text { Quote: "The main investigator and patients remained blind to the treatment } \\
\text { group." }\end{array}$ \\
\hline
\end{tabular}

Incomplete outcome data Low risk (attrition bias)

All outcomes

\begin{tabular}{lll}
\hline $\begin{array}{l}\text { Selective reporting (re- } \\
\text { porting bias) }\end{array}$ & Unclear risk & Protocol not available \\
\hline Other bias & High risk & $\begin{array}{l}\text { Assessment of wound infection poorly described (Quote: "using standard } \\
\text { methods by the same investigator") and no description of how length of stay } \\
\text { was determined }\end{array}$ \\
\hline
\end{tabular}

No evidence from the published data. Quote: "Any drop-outs were present in the study"

\section{De Luis 2003}

Methods

Design: double-blind, parallel-group randomised controlled trial with an average duration of treatment of 20 days (in the supplemented group) and a 5-day duration of follow-up

\section{Participants}

Setting: author affiliations: Valladolid, Spain

\section{Sample size:}

- Number randomised: 36

- Number completed: 36

\section{Participant (baseline) characteristics:}

- Age: mean age was $59.6 \pm 10.9$ years $(63.1 \pm 12.7$ years in group 1 and $59.3 \pm 10.5$ years in group 2$)$

- Gender: 2 females, 34 males

- Baseline differences/other characteristics: Quote: "Characteristics of the patients on enrollment were similar for the two groups"

Inclusion criteria: a previous weight loss of $5 \%$ to $10 \%$ (6 months) and oral or laryngeal cancer

Exclusion criteria: Quote: "Exclusion criteria included severely impaired hepatic function (total bilirubin concentration $>3.5 \mathrm{mg} / \mathrm{dl}$ ) and renal function (serum creatinine concentration $>2.5 \mathrm{mg} / \mathrm{dl}$ ), ongoing infections, autoimmune disorders, steroids treatment and well-nourished (weight loss $<10 \%$ of body weight)."

\section{Intervention group:}

Enteral diet supplemented with arginine $(n=18)$

\section{Comparator group:}

Isoenergetic, isonitrogenous enteral formula $(n=18)$

Quote: "Enteral feeding was started within $24 \mathrm{~h}$ of surgery"

Quote: "Group I received a daily dose of arginine of $12.5 \mathrm{~g}$ during an average of 20 days" 
De Luis 2003 (Continued)

Use of additional interventions: Quote: "Prophylactic antibiotic treatment was given for 3 days postoperatively (ceftazidime, $500 \mathrm{mg}$ three times daily i.v. and clyndamicine $300 \mathrm{mg}$ three times daily i.v.)"

\begin{tabular}{|c|c|c|}
\hline \multirow[t]{3}{*}{ Outcomes } & \multicolumn{2}{|c|}{ Primary outcome and secondary outcomes: } \\
\hline & \multicolumn{2}{|c|}{ Primary and secondary outcomes not separated out } \\
\hline & \multicolumn{2}{|c|}{$\begin{array}{l}\text { Perioperatively and on postoperative day } 5 \text { the following parameters were evaluated: serum values of } \\
\text { prealbumin, transferrin, albumin, total number of lymphocytes, interleukin } 6 \text {, tumour necrosis factor- } \alpha \\
\text { and C-reactive protein }\end{array}$} \\
\hline Funding sources & \multicolumn{2}{|l|}{ None stated } \\
\hline Declarations of interest & \multicolumn{2}{|l|}{ None stated } \\
\hline Notes & \multicolumn{2}{|c|}{$\begin{array}{l}\text { Participants lost to follow-up: stated that an ITT analysis was conducted. No postoperative deaths } \\
\text { (information from authors). }\end{array}$} \\
\hline \multicolumn{3}{|l|}{ Risk of bias } \\
\hline Bias & Authors' judgement & Support for judgement \\
\hline $\begin{array}{l}\text { Random sequence genera- } \\
\text { tion (selection bias) }\end{array}$ & Low risk & Author contacted: tables of random numbers used \\
\hline $\begin{array}{l}\text { Allocation concealment } \\
\text { (selection bias) }\end{array}$ & Unclear risk & $\begin{array}{l}\text { Quote: "At surgery patients were randomly allocated (sealed envelopes) to two } \\
\text { groups". Also states that the study was a "prospective concealed randomized } \\
\text { trial" but no information available on how allocation was concealed. }\end{array}$ \\
\hline $\begin{array}{l}\text { Blinding of participants } \\
\text { and personnel (perfor- } \\
\text { mance bias) } \\
\text { All outcomes }\end{array}$ & Low risk & Quote: "The study was blinded (patients and investigator)" \\
\hline $\begin{array}{l}\text { Blinding of outcome as- } \\
\text { sessment (detection bias) } \\
\text { All outcomes }\end{array}$ & Low risk & Quote: "The study was blinded (patients and investigator)" \\
\hline $\begin{array}{l}\text { Incomplete outcome data } \\
\text { (attrition bias) } \\
\text { All outcomes }\end{array}$ & Low risk & $\begin{array}{l}\text { No evidence from the published data } \\
\text { Quote: "all randomized patients were included in the comparisons, irrespec- } \\
\text { tive of whether or not and for how long they complied with their allocated reg- } \\
\text { imen (intention-to-treat analysis)." }\end{array}$ \\
\hline $\begin{array}{l}\text { Selective reporting (re- } \\
\text { porting bias) }\end{array}$ & Unclear risk & Protocol not available \\
\hline Other bias & Low risk & None \\
\hline
\end{tabular}

De Luis 2004

Methods

Design: blinded (information from author but not stated who was blinded), parallel-group randomised controlled trial with $\geq 10$ days duration of treatment and 14 days duration of follow-up

Participants

Setting: author affiliations: Valladolid, Spain

Sample size: 
De Luis 2004 (Continued)

- Number randomised: 90

- Number completed: 90

Participant (baseline) characteristics:

- Age: mean age was $60.57 \pm 12.3$ years (60.2 \pm 12.5 years in group 1 and $60.6 \pm 11.5$ years in group 2$)$

- Gender: 6 females, 84 males

- Baseline differences/other characteristics: Quote: "The characteristics of the patients on enrollment were similar for the two groups"

Inclusion criteria: oral and laryngeal cancer

Exclusion criteria: Quote: "Exclusion criteria included: severely impaired hepatic function (total bilirubin concentration $>3.5 \mathrm{mg} / \mathrm{dl}$ ) and renal function (serum creatinine concentration $>2.5 \mathrm{mg} / \mathrm{dl}$ ), ongoing infections, autoimmune disorders, steroids treatment, nutritional oral supplementation in previous 6 months, and severely malnourished (weight loss $>10 \%$ of body weight)."

Interventions
Enterval diet supplemented with arginine ( $\mathrm{n}=45)$
Comparator group:
Isoenergetic, isonitrogenous enteral formula ( $\mathrm{n}=45)$
Enteral feeding was started within 12 hours of surgery
Use of additional interventions: Quote: "In all patients, prophylactic antibiotic treatment was given
for 7 days postoperatively (ceftazidime, 500 mg tid i.v. and clyndamicine 300 mg tid i.v.)"
Primary outcome and secondary outcomes:
Primary and secondary outcomes not separated out
Quote: "Perioperatively and on postoperative day 14 the following parameters were evaluated: serum
values of prealbumin (mg/dl), transferrin (mg/dl), albumin (g/dl), and total number of lymphocytes
(106 /ml). Postoperative complications were recorded as none, general infections (respiratory tract in-
fection was diagnosed when the chest radiographic examination showed new or progressive unfiltra-
tion, temperature above $38.5^{\circ} \mathrm{C}$ and isolation of pathogens from the sputum or blood culture and/or
urinary tract infection was diagnosed if the urine culture showed at least $10^{5}$ colonies of a pathogen),
and wound complications such as fistula and/or wound infection. All complications were assessed with
standard methods by the same investigator. Gastrointestinal problems related to enteral feeding were
also recorded (diarrhoea, $>5$ liquid stools in a 24 -h period or an estimated volume $>2000$ ml/day)."

\begin{tabular}{ll}
\hline Funding sources & None stated \\
\hline Declarations of interest & None stated
\end{tabular}

Notes Participants lost to follow-up: Quote: "No dropouts were present in the study" and an ITT analysis was conducted.

Quote: "The sample size was calculated to decrease $20 \%$ of fistula complication with $90 \%$ power and $5 \%$ significance."

\section{Risk of bias}

\begin{tabular}{lll}
\hline Bias & Authors' judgement & Support for judgement \\
\hline $\begin{array}{l}\text { Random sequence genera- } \\
\text { tion (selection bias) }\end{array}$ & Low risk & Author contacted: tables of random numbers used \\
\hline
\end{tabular}


De Luis 2004 (Continued)

Allocation concealment Unclear risk Sealed envelopes used for allocation concealment (information from authors) (selection bias) but not known if envelopes were opaque

Blinding of participants and personnel (perfor-

Unclear risk mance bias)

All outcomes

\section{Blinding of outcome as- Unclear risk} sessment (detection bias)

All outcomes
States blinded (information from authors) but no indication as to who was blinded
States blinded (information from authors) but no indication as to who was blinded

Incomplete outcome data Low risk
(attrition bias)

All outcomes

No evidence from the published data

Quote: "all randomized patients were included in the comparisons, irrespective of whether or not and for how long they complied with their allocated regimen (intention-to-treat analysis)." Also stated "There were no dropouts due to intolerance"

Selective reporting (re- Unclear risk $\quad$ Protocol not available
porting bias)

Other bias High risk

Assessment of wound infection poorly described (Quote: "with standard methods by the same investigator") and no description of how length of stay was determined controlled trial with an average duration of treatment of 20 days (in the supplemented group) and 6day duration of follow-up

\section{Participants}

Setting: author affiliations: Valladolid, Spain

\section{Sample size:}

- Number randomised: 29

- Number completed: 29

\section{Participant (baseline) characteristics:}

- Age: mean age was $61.1 \pm 10.8$ years (60.7 \pm 11.6 years in group 1 and $62.96 \pm 11.6$ years in group 2$)$

- Gender: 5 females, 24 males

- Baseline differences/other characteristics: Quote: "Characteristics of the patients and tumour stage... on enrollment were similar for the two groups"

Inclusion criteria: Quote: "patients with a previous weight loss of 5-10\% (6 months), (IL-6 levels 45 pg/ $\mathrm{ml}$ ) and oral or laryngeal cancer were enrolled."

Exclusion criteria: Quote: "Exclusion criteria included; severely impaired hepatic function (total bilirubin concentration $>3.5 \mathrm{mg} / \mathrm{dl}$ ) and renal function (serum creatinine concentration $>2.5 \mathrm{mg} / \mathrm{dl}$ ), ongoing infections, steroid treatment and well nourished (weight loss $<10 \%$ of body weight)."

$\begin{array}{ll}\text { Interventions } & \text { Intervention group: } \\ & \text { Enteral diet supplements with arginine }(n=14) \\ \text { Comparator group: }\end{array}$


De Luis 2005 (Continued)

Isocaloric, isonitrogenous enteral formula without arginine $(n=15)$

Quote: "Group I received a daily dose of arginine of $12.5 \mathrm{~g}$ during an average of 20 days"

Use of additional interventions: none described

Primary outcome and secondary outcomes:
Primary and secondary outcomes not separated out
Perioperatively and on postoperative day 6, the following blood parameters were evaluated: prealbu-
$\min (\mathrm{mg} / \mathrm{dl})$, transferrin $(\mathrm{mg} / \mathrm{dl})$, albumin $(\mathrm{g} / \mathrm{dl})$, total number of lymphocytes $\left(10^{6} / \mathrm{ml}\right), \mathrm{IL}-6(\mathrm{pg} / \mathrm{ml})$,
$\mathrm{TNFa}(\mathrm{pg} / \mathrm{ml})$ and c-reactive protein $(\mathrm{mg} / \mathrm{dl})$

\begin{tabular}{ll}
\hline Funding sources & None stated \\
\hline Declarations of interest & None stated \\
\hline Notes & $\begin{array}{l}\text { Participants lost to follow-up: an ITT analysis was conducted. No postoperative deaths (information } \\
\text { from authors). }\end{array}$ \\
\hline
\end{tabular}

\section{Risk of bias}

\begin{tabular}{|c|c|c|}
\hline Bias & Authors' judgement & Support for judgement \\
\hline $\begin{array}{l}\text { Random sequence genera- } \\
\text { tion (selection bias) }\end{array}$ & Low risk & Author contacted: tables of random numbers used \\
\hline \multirow[t]{2}{*}{$\begin{array}{l}\text { Allocation concealment } \\
\text { (selection bias) }\end{array}$} & Unclear risk & $\begin{array}{l}\text { Quote: "At surgery, patients were randomly allocated (sealed envelops) to two } \\
\text { groups" }\end{array}$ \\
\hline & & $\begin{array}{l}\text { Also states that the study was a "prospective concealed randomized trial" but } \\
\text { no statement on how concealed }\end{array}$ \\
\hline $\begin{array}{l}\text { Blinding of participants } \\
\text { and personnel (perfor- } \\
\text { mance bias) } \\
\text { All outcomes }\end{array}$ & Unclear risk & Quote: "Study was blinded" but no indication as to who was blinded \\
\hline $\begin{array}{l}\text { Blinding of outcome as- } \\
\text { sessment (detection bias) } \\
\text { All outcomes }\end{array}$ & Unclear risk & Quote: "Study was blinded" but no indication as to who was blinded \\
\hline $\begin{array}{l}\text { Incomplete outcome data } \\
\text { (attrition bias) } \\
\text { All outcomes }\end{array}$ & Low risk & $\begin{array}{l}\text { No evidence from the published data } \\
\text { Quote: "all randomized patients were included in the comparisons, irrespec- } \\
\text { tive of whether or not and for how long they complied with their allocated reg- } \\
\text { imen (intention-to-treat analysis)." }\end{array}$ \\
\hline $\begin{array}{l}\text { Selective reporting (re- } \\
\text { porting bias) }\end{array}$ & Unclear risk & Protocol not available \\
\hline Other bias & Low risk & None \\
\hline
\end{tabular}

Felekis 2005

$\begin{array}{ll}\text { Methods } & \begin{array}{l}\text { Design: parallel-group randomised controlled trial (no statement on blinding) with } 6 \text { days pre- and } 8 \\ \text { days postoperative duration of treatment and unclear duration of follow-up }\end{array}\end{array}$


Felekis 2005 (Continued)

$\begin{array}{ll}\text { Participants } & \text { Setting: Greece } \\ & \text { Sample size: }\end{array}$

- Number randomised: 37

- Number completed: 37

Participant (baseline) characteristics:

- Age: not stated

- Gender: not stated

- Baseline differences/other characteristics: 35 were well nourished and 2 ( 1 in each group) were severely malnourished

Inclusion criteria: patients undergoing major head and neck surgery (for cancer)

Exclusion criteria: none stated

\section{Intervention group:}

Enteral immunonutrition for 6 days preoperatively and for 8 days postoperatively $(n=20)$

\section{Comparator group:}

Regular oral diet and standard polymeric enteral feeding $(n=17)$

Quote: "Both groups received isocaloric and isonitrogenous regimens"

Use of additional interventions: none stated

\begin{tabular}{ll} 
Outcomes & Primary outcome and secondary outcomes: \\
& Primary and secondary outcomes not separated out \\
& Quote: "The parameters analyzed were the incidence of postop. complications and mortality" \\
\hline Funding sources & Not stated \\
\hline Declarations of interest & Not stated \\
\hline Notes & Participants lost to follow-up: not stated \\
& $\begin{array}{l}\text { Note: abstract only. There is a linked reference: Felekis D, Eleftheriadou A, Papadakos G, Bosinakou I, } \\
\text { Ferekidou E, Kandiloros D, et al. Effect of perioperative immuno-enhanced enteral nutrition on inflam- } \\
\text { matory response, nutritional status, and outcomes in head and neck cancer patients undergoing ma- } \\
\text { jor surgery. Nutrition and Cancer } 2010 ; 62(8): 1105-12 . \text { We tried to contact the corresponding author by } \\
\text { email and telephone but were unable to get a response using the information given in the above paper. }\end{array}$
\end{tabular}

\section{Risk of bias}

\begin{tabular}{lll}
\hline Bias & Authors' judgement & Support for judgement \\
\hline $\begin{array}{l}\text { Random sequence genera- } \\
\text { tion (selection bias) }\end{array}$ & Unclear risk & No statement on the generation of random sequence \\
\hline $\begin{array}{l}\text { Allocation concealment } \\
\text { (selection bias) }\end{array}$ & Unclear risk & No statement on allocation concealment \\
\hline $\begin{array}{l}\text { Blinding of participants } \\
\begin{array}{l}\text { and personnel (perfor- } \\
\text { mance bias) }\end{array}\end{array}$ & Unclear risk & No statement on blinding \\
\hline
\end{tabular}


Felekis 2005 (Continued)

All outcomes

Blinding of outcome as-
sessment (detection bias) $\quad$ Unclear risk No statement on blinding

All outcomes

\begin{tabular}{lll}
\hline $\begin{array}{l}\text { Incomplete outcome data } \\
\text { (attrition bias) } \\
\text { All outcomes }\end{array}$ & Unclear risk & Unable to judge from the published data (abstract only) \\
\hline $\begin{array}{l}\text { Selective reporting (re- } \\
\text { porting bias) }\end{array}$ & Unclear risk & Unable to judge from the published data (abstract only) \\
\hline Other bias & Unclear risk & unable to judge from the published data (abstract only) \\
\hline
\end{tabular}

\section{De Luis 2007}

Mesign: blinded (information from author but not stated who was blinded), parallel-group randomised
controlled trial with $\geq 10$ days duration of treatment and 12 days duration of follow-up

controlled trial with $\geq 10$ days duration of treatment and 12 days duration of follow-up

Participants

Setting: author affiliations: Valladolid, Spain

Sample size:

- Number randomised: 72

- Number completed: 72

Participant (baseline) characteristics:

- Age: mean age was $61.8 \pm 13.3$ years (62.1 \pm 12 years in group 1 and $61.5 \pm 11$ years in group 2 )

- Gender: 7 females, 65 males

- Baseline differences/other characteristics: epidemiological data for the patients on enrollment were similar for the 2 groups

Inclusion criteria: patients with oral and laryngeal cancer

Exclusion criteria: Quote: "Exclusion criteria included: severely impaired hepatic function (total bilirubin concentration $>3.5 \mathrm{mg} / \mathrm{dl}$ and serum glutamic pyruvate $>150 \mathrm{UI} / \mathrm{l}$ ) and renal function (serum creatinine concentration $>2.5 \mathrm{mg} / \mathrm{dl}$ ), ongoing infections, autoimmune disorders, steroids treatment, nutritional oral supplementation in previous 6 months and severely malnourished (weight loss $>10 \%$ of body weight)."

\section{Intervention group:}

Enteral diet supplements with arginine $(n=35)$

\section{Comparator group:}

Isocaloric, isonitrogenous enteral formula $(n=37)$

Enteral feeding was started within 8 to 12 hours of surgery

Use of additional interventions: Quote: "In all patients, prophylactic antibiotic treatment was given for 7 days postoperatively (ceftazidime, $500 \mathrm{mg}$ t.i.d. intravenously (i.v.) and clyndamicine $300 \mathrm{mg}$ t.i.d. i.v.)"

\section{Outcomes \\ Primary outcome and secondary outcomes: \\ Primary and secondary outcomes not separated out}


De Luis 2007 (Continued)

Quote: "Perioperatively and on postoperative day 12 , the following parameters were evaluated: serum values of prealbumin $(\mathrm{mg} / \mathrm{dl})$, transferrin $(\mathrm{mg} / \mathrm{dl})$, albumin $(\mathrm{g} / \mathrm{dl})$ and total number of lymphocytes $\left(10^{6} / \mathrm{ml}\right)$. Postoperative complications were recorded as none; general infections (respiratory tract infection was diagnosed when the chest radiographic examination showed new or progressive unfiltration, temperature above $38.5^{\circ} \mathrm{C}$ and isolation of pathogens from the sputum or blood culture and/or urinary tract infection was diagnosed if the urine culture showed at least $10^{5}$ colonies of a pathogen) and wound complications, such as fistula and/or wound infection, assessed all complications with standard methods by the same investigator surgeon. Gastrointestinal problems related to enteral feeding were also recorded (diarrhoea, $>5$ liquid stools in a 24-h period or an estimated volume $>2000 \mathrm{ml}$ ) day)."

\begin{tabular}{|c|c|}
\hline Funding sources & Not stated \\
\hline Declarations of interest & Not stated \\
\hline \multirow[t]{2}{*}{ Notes } & $\begin{array}{l}\text { Participants lost to follow-up: stated that an ITT analysis was conducted and "No drop-outs were } \\
\text { present in the study" }\end{array}$ \\
\hline & $\begin{array}{l}\text { Quote: "Sample size was calculated to decrease } 25 \% \text { of wound complication with } 90 \% \text { power and } 5 \% \\
\text { significance." }\end{array}$ \\
\hline
\end{tabular}

\section{Risk of bias}

\begin{tabular}{|c|c|c|}
\hline Bias & Authors' judgement & Support for judgement \\
\hline $\begin{array}{l}\text { Random sequence genera- } \\
\text { tion (selection bias) }\end{array}$ & Low risk & Author contacted: tables of random numbers used \\
\hline $\begin{array}{l}\text { Allocation concealment } \\
\text { (selection bias) }\end{array}$ & Unclear risk & Envelopes (information from authors) but not known if these were opaque \\
\hline $\begin{array}{l}\text { Blinding of participants } \\
\text { and personnel (perfor- } \\
\text { mance bias) } \\
\text { All outcomes }\end{array}$ & Unclear risk & $\begin{array}{l}\text { Blinding stated (information from authors) but no indication as to who was } \\
\text { blinded }\end{array}$ \\
\hline $\begin{array}{l}\text { Blinding of outcome as- } \\
\text { sessment (detection bias) } \\
\text { All outcomes }\end{array}$ & Unclear risk & $\begin{array}{l}\text { Blinding stated (information from authors) but no indication as to who was } \\
\text { blinded }\end{array}$ \\
\hline $\begin{array}{l}\text { Incomplete outcome data } \\
\text { (attrition bias) } \\
\text { All outcomes }\end{array}$ & Low risk & $\begin{array}{l}\text { No evidence from the published data: Quote: "all randomized patients were } \\
\text { included in the comparisons, irrespective of whether or not and for how long } \\
\text { they complied with their allocated regimen (intention-to-treat analysis)." Also } \\
\text { stated "There were no dropouts due to intolerance" }\end{array}$ \\
\hline $\begin{array}{l}\text { Selective reporting (re- } \\
\text { porting bias) }\end{array}$ & Unclear risk & Protocol not available \\
\hline Other bias & High risk & $\begin{array}{l}\text { Assessment of wound infection poorly described (Quote: "with standard meth- } \\
\text { ods by the same investigator surgeon") and no description of how length of } \\
\text { stay was determined }\end{array}$ \\
\hline
\end{tabular}


Casas-Rodera 2008 (Continued)

Participants Setting: La Paz University Hospital, Spain. Trial carried out for 12 months.

\section{Sample size:}

- Number randomised: 44

- Number completed: 44

Participant (baseline) characteristics:

- Age: group 1: $59.67 \pm 9.07$, group 2: $54.27 \pm 13.04$, group 3: $50.07 \pm 13.79$

- Gender: group 1: 13 men, 2 women, group 2: 15 men, 0 women, group 3: 14 men, 0 women

- Baseline differences/other characteristics: Quote: "The characteristics of the patients on enrolment were similar for the three groups, reflecting the homogeneity of patients. There were no significant differences with respect to gender, mean age, body weight, location, and stage of tumor"

Inclusion criteria: oral and laryngeal cancer

Exclusion criteria: Quote: "Severely impaired hepatic function (total bilirubin concentration over 43.5 $\mathrm{mg} / \mathrm{dl}$ ) and renal function (serum creatinine concentration over $42.5 \mathrm{mg} / \mathrm{dl}$ ), ongoing infections, autoimmune disorders, steroids treatment, nutritional oral supplementation in previous 6 months."

\section{Intervention group:}

Group 1 (enteral diet supplemented with arginine) $(n=15)$

Group 3 (enteral diet supplemented with arginine, RNA and omega-3 fatty acids) $(n=14)$

\section{Comparator group:}

Group 2 (standard polymeric enteral formula) $(n=15)$

Quote: "Enteral feeding was started within $12 \mathrm{~h}$ of surgery, via an intraoperatively placed nasogastric tube."

Use of additional interventions: none stated

\section{Outcomes Primary outcome and secondary outcomes:}

Primary and secondary outcomes not separated out

Quote: "Perioperatively and on postoperative day 7 and day 14 the following parameters were evaluated: serum values of transferrin $(\mathrm{mg} / \mathrm{dl})$, albumin $(\mathrm{g} / \mathrm{dl})$, and total number of lymphocytes $\left(10^{6} / \mathrm{ml}\right)$, IL-6 $(\mathrm{mg} / \mathrm{dl})$, TNFa $(\mathrm{pg} / \mathrm{dl})$ and CPR $(\mathrm{mg} / \mathrm{dl})$. Postoperative complications were recorded as none, general infections (respiratory tract infection was diagnosed when the chest radiographic examination showed new or progressive infiltration, temperature above $38.5^{\circ} \mathrm{C}$ and isolation of pathogens from the sputum or blood culture and/or urinary tract infection was diagnosed if the urine culture showed at least $10^{6}$ colonies of a pathogen), and wound complications such as fistula and/or wound infection. All complications were assessed with standard methods by the same investigator. Gastrointestinal problems related to enteral feeding were also recorded (diarrhoea, $>5$ liquid stools in a 24-h period or an estimated volume $>2,000 \mathrm{ml} /$ day). The duration of hospitalisation was based on the date that the patient was medically eligible for discharge."

Funding sources None stated

Declarations of interest None stated

Notes $\quad$ Participants lost to follow-up: Quote: "No dropouts were present in the study"

The comparison used is group 2 (standard polymeric feed) and group 3 (arginine, RNA and omega-3 fatty acids). Data from group 1 (arginine only) were not used. 
Casas-Rodera 2008 (Continued)

Risk of bias

\begin{tabular}{|c|c|c|}
\hline Bias & Authors' judgement & Support for judgement \\
\hline $\begin{array}{l}\text { Random sequence genera- } \\
\text { tion (selection bias) }\end{array}$ & Unclear risk & $\begin{array}{l}\text { Quote: "At surgery, patients were randomly allocated to three groups" but } \\
\text { does not say how sequence was generated }\end{array}$ \\
\hline $\begin{array}{l}\text { Allocation concealment } \\
\text { (selection bias) }\end{array}$ & Unclear risk & No statement on allocation concealment \\
\hline $\begin{array}{l}\text { Blinding of participants } \\
\text { and personnel (perfor- } \\
\text { mance bias) } \\
\text { All outcomes }\end{array}$ & Unclear risk & No statement on blinding \\
\hline $\begin{array}{l}\text { Blinding of outcome as- } \\
\text { sessment (detection bias) } \\
\text { All outcomes }\end{array}$ & Unclear risk & No statement on blinding \\
\hline $\begin{array}{l}\text { Incomplete outcome data } \\
\text { (attrition bias) } \\
\text { All outcomes }\end{array}$ & Low risk & $\begin{array}{l}\text { No evidence from the published data } \\
\text { Quote: "No dropouts were present in the study" }\end{array}$ \\
\hline $\begin{array}{l}\text { Selective reporting (re- } \\
\text { porting bias) }\end{array}$ & Unclear risk & Protocol not available \\
\hline Other bias & High risk & $\begin{array}{l}\text { Assessment of wound infection poorly described (Quote: "with standard meth- } \\
\text { ods by the same investigator") }\end{array}$ \\
\hline
\end{tabular}

Sorensen 2009

Methods Design: double-blind (NB: some outcome assessors not blinded - see Table 3 for more information), parallel-group randomised controlled trial with 7 days pre- and 7 days postoperative duration of treatment and 29 days duration of follow-up

Participants

Setting: Department of Surgery, Otolaryngology - Head and Neck Surgery Service, Madigan Army Medical Center, Tacoma, Washington, USA

\section{Sample size:}

- Number randomised: 15

- Number completed: 15

Participant (baseline) characteristics:

- Age: mean age 60.6 years (SD 8.2, range 46 to 73 years), group 1 mean age 61.9 years (SD 8.5, range 46 to 73 years), group 2 mean age 58.9 years (SD 7.4 , range 48 to 67 years)

- Gender: all male

- Baseline differences/other characteristics: Quote: "Nutritional status was similar for patients in both groups upon enrollment. Baseline values of height, weight, body mass index, weight loss in previous 6 months, subjective global assessment, nutritional risk, albumin, and prealbumin showed no statistically significant differences." and "Immunologic measures...of white blood cell, TLC, and lymphocyte subsets were not different between groups at baseline. CRP did not pass Levene's test for equality of variances at baseline $(P=.023)$, but was not statistically significantly different between groups" 
Inclusion criteria: age > 18 years, histologically documented squamous cell carcinoma of the head and neck, candidates for curative surgery

Exclusion criteria: history of renal, hepatic or cardiopulmonary dysfunction, ongoing infection and immune deficiency

\author{
Interventions \\ Intervention group: \\ Impact Recover oral drink or Impact Glutamine tube feeding (Novartis Nutrition) $(n=8)$

\section{Comparator group:} \\ Standard supplement (Isosource 1.5 from Novartis Nutrition) $(n=7)$ \\ Participants received/were asked to drink about $1 \mathrm{~L}$ per day for 7 days preoperatively and 7 days post- \\ operatively. Postoperative feeding began within 24 hours post surgery.
}

Use of additional interventions: none stated

Primary outcome and secondary outcomes:
Primary and secondary outcomes not separated out
The following were measured at baseline, day of surgery and postoperative days 1, 4 and $8:$ complete
blood count, total lymphocyte count, T-lymphocyte subsets (CD3, CD4, CD8, CD4:8 ratio, CD19, CD56),
albumin, prealbumin and CRP. Cell mediated immunity was evaluated by delayed-type hypersensi-
tivity. Serious wound complications included wound infection, wound dehiscence and wound fistula.
Wound assessments used the ASEPSIS scoring method.

Funding sources

Quote: "Sponsored by the TriService Nursing Research Program and supported by a grant of $\$ 35,884 . "$

Declarations of interest None stated

Notes Participants lost to follow-up: no statement about dropouts. Few participants completed the delayed-type hypersensitivity (DTH) skin test.

Power/sample size calculation not done as it was a feasibility study.

\title{
Risk of bias
}

\begin{tabular}{lll}
\hline Bias & Authors' judgement & Support for judgement \\
\hline $\begin{array}{l}\text { Random sequence genera- } \\
\text { tion (selection bias) }\end{array}$ & Unclear risk & $\begin{array}{l}\text { Stated to have a "Randomized design" but no statement on the generation of } \\
\text { the random sequence }\end{array}$ \\
\hline $\begin{array}{l}\text { Allocation concealment } \\
\text { (selection bias) }\end{array}$ & Unclear risk & Envelopes used but not known if these were opaque \\
\hline $\begin{array}{l}\text { Blinding of participants } \\
\text { and personnel (perfor- } \\
\text { mance bias) } \\
\text { All outcomes }\end{array}$ & Unclear risk & $\begin{array}{l}\text { Quote: "The principal investigator and otolaryngology head and neck service } \\
\text { residents were blinded to study group, an associate investigators (Al) and re- } \\
\text { search assistant (RA) were not." }\end{array}$ \\
\hline $\begin{array}{l}\text { Blinding of outcome as- } \\
\text { sessment (detection bias) } \\
\text { All outcomes }\end{array}$ & Unclear risk & $\begin{array}{l}\text { Quote: "The principal investigator and otolaryngology head and neck service } \\
\text { residents were blinded to study group, an associate investigators (Al) and re- } \\
\text { search assistant (RA) were not." }\end{array}$ \\
\hline $\begin{array}{l}\text { Incomplete outcome data } \\
\text { (attrition bias) } \\
\text { All outcomes }\end{array}$ & Unclear risk & \begin{tabular}{l} 
No statement on dropouts \\
\hline
\end{tabular} \\
\hline
\end{tabular}


Sorensen 2009 (Continued)

Selective reporting (re- Unclear risk Protocol not available porting bias)

$\begin{array}{lll}\text { Other bias } \quad \text { Low risk None } & \end{array}$

De Luis 2009

Methods Design: double-blind, parallel-group randomised controlled trial with $\geq 10$ days duration of treatment and 10 days duration of follow-up

Participants

Setting: author affiliations: Valladolid, Spain

Sample size:

- Number randomised: 72

- Number completed: 72

Participant (baseline) characteristics:

- Age: mean age was $62.3 \pm 11.3$ years (63.1 \pm 13 years in group 1 and $61.2 \pm 9.9$ years in group 2$)$

- Gender: 15 females, 57 males (8 females, 30 males in group 1 and 7 females, 27 males in group 2)

- Baseline differences/other characteristics: "Epidemiological data of the patients on enrollment were similar for the two groups, reflecting the homogeneity of patients. There were no significant differences with regard to gender, mean age, body weight, location, and stage of tumor"

Inclusion criteria: oral and laryngeal cancer

Exclusion criteria: Quote: "Exclusion criteria included: severely impaired renal function (serum creatinine concentration $>2.5 \mathrm{mg} / \mathrm{dl}$ ) and hepatic function (total bilirubin concentration $>3.5 \mathrm{mg} / \mathrm{dl}$ and serum glutamic pyruvate $>150 \mathrm{UI} / \mathrm{l}$ ), ongoing infections, autoimmune disorders, steroids treatment, nutritional oral supplementation in previous 6 months and severely malnourished (weight loss $>10 \%$ of body weight)"

\section{Interventions $\quad$ Intervention group:}

Enteral diet supplements with arginine and fibre $(n=38)$

\section{Comparator group:}

Isocaloric, isonitrogenous enteral formula $(n=34)$

Quote: "Enteral feeding was started within 24 hours of surgery"

Use of additional interventions: Quote: "In all patients, prophylactic antibiotic treatment was given for 7 days postoperatively (ceftazidime, $500 \mathrm{mg}$ t.i.d. intravenously (i.v.) and clyndamicine $300 \mathrm{mg}$ t.i.d. i.v.)."

Outcomes

\section{Primary outcome and secondary outcomes:}

Primary and secondary outcomes not separated out

Quote: "Perioperatively and on postoperative day 10 , the following parameters were recorded: serum values of prealbumin $(\mathrm{mg} / \mathrm{dl})$, transferrin $(\mathrm{mg} / \mathrm{dl})$, albumin $(\mathrm{g} / \mathrm{dl})$, total number of lymphocytes $\left(10^{6} /\right.$ $\mathrm{ml}$ ). Postoperative complications were registered as none; general infections (urinary tract infection was diagnosed if the urine culture showed at least $10^{5}$ colonies of a pathogen and/or respiratory tract infection was diagnosed when the chest radiographic examination showed new or progressive unfiltration, temperature above $38,5^{\circ} \mathrm{C}$ and isolation of pathogens from the sputum or blood culture) and local complications such as fistula and/or wound infection, assessed all complications with standard meth- 
De Luis 2009 (Continued)

ods by the same investigator. Gastrointestinal problems related to enteral feeding were also recorded

(diarrhoea, $>5$ liquid tools in a 24-hour period or an estimated volume $>2000 \mathrm{~mL} / \mathrm{d}$ )."

Data on length of stay were also presented

\begin{tabular}{ll}
\hline Funding sources & None stated \\
\hline Declarations of interest & None stated \\
\hline Notes & Participants lost to follow-up: stated that an ITT analysis was conducted \\
& $\begin{array}{l}\text { Quote: "Sample size was calculated to decrease } 20 \% \text { of wound complication with } 80 \% \text { power and } 5 \% \\
\text { significance." }\end{array}$
\end{tabular}

\section{Risk of bias}

\begin{tabular}{|c|c|c|}
\hline Bias & Authors' judgement & Support for judgement \\
\hline $\begin{array}{l}\text { Random sequence genera- } \\
\text { tion (selection bias) }\end{array}$ & Unclear risk & $\begin{array}{l}\text { Quote: "At surgery, patients were randomly allocated to two groups", but no } \\
\text { statement on the generation of random sequence }\end{array}$ \\
\hline $\begin{array}{l}\text { Allocation concealment } \\
\text { (selection bias) }\end{array}$ & Unclear risk & No statement on allocation concealment \\
\hline $\begin{array}{l}\text { Blinding of participants } \\
\text { and personnel (perfor- } \\
\text { mance bias) } \\
\text { All outcomes }\end{array}$ & Low risk & $\begin{array}{l}\text { Quote: "Main investigator and patients remained blind to the treatment } \\
\text { group." }\end{array}$ \\
\hline $\begin{array}{l}\text { Blinding of outcome as- } \\
\text { sessment (detection bias) } \\
\text { All outcomes }\end{array}$ & Low risk & $\begin{array}{l}\text { Quote: "Main investigator and patients remained blind to the treatment } \\
\text { group." }\end{array}$ \\
\hline $\begin{array}{l}\text { Incomplete outcome data } \\
\text { (attrition bias) } \\
\text { All outcomes }\end{array}$ & Low risk & $\begin{array}{l}\text { No evidence from the published data } \\
\text { Quote: "all randomized patients were included in the comparisons, irrespec- } \\
\text { tive of whether or not and for how long they complied with their allocated reg- } \\
\text { imen (intention-to-treat analysis)." Also stated "There were no drop outs due } \\
\text { to intolerance" }\end{array}$ \\
\hline $\begin{array}{l}\text { Selective reporting (re- } \\
\text { porting bias) }\end{array}$ & Unclear risk & Protocol not available \\
\hline Other bias & High risk & $\begin{array}{l}\text { Assessment of wound infection poorly described (Quote: "with standard meth- } \\
\text { ods by the same investigator") and no description of how length of stay was } \\
\text { determined }\end{array}$ \\
\hline
\end{tabular}

\section{Felekis 2010}

\begin{tabular}{ll}
\hline Methods & $\begin{array}{l}\text { Design: double-blind, parallel-group randomised controlled trial with } 5 \text { days pre- and } 8 \text { days postoper- } \\
\text { ative duration of treatment and } 8 \text { days duration of follow-up }\end{array}$ \\
\hline Participants & Setting: First Department of Otolaryngology, University of Athens, Greece \\
Sample size: & Number randomised: 40 \\
- Number completed: 40
\end{tabular}


Felekis 2010 (Continued)

\section{Participant (baseline) characteristics:}

- Age: mean age $62.1 \pm 2.6$ years, group 1 mean age $63.2 \pm 3.9$ years, group 2 mean age $61.0 \pm 3.8$ years

- Gender: 4 females, 36 males ( 2 females and 18 males in each of the 2 treatment groups)

- Baseline differences/other characteristics: Quote: "Characteristics of the patients on enrollment were similar for the two groups" and "There were no significant differences with regard to gender, mean age, nutritional status, location, and stage of the disease." Also stated that there were no baseline differences in the outcome variables.

Inclusion criteria: Quote: "In all cases, there was a histologically proven diagnosis of squamous cell carcinoma of head and neck eligible for surgical treatment. No previous radiotherapy or chemotherapy was applied. Patients did not receive immunoglobulin before the study."

Exclusion criteria: Quote: "Exclusion criteria included severely impaired renal and hepatic function and autoimmune disorders."

Interventions

\section{Intervention group:}

Oral Impact (Novartis) for 5 days pre-operatively and enteral Impact for 8 days postoperatively $(n=20)$

\section{Comparator group:}

No pre-operative nutritional support and enteral Nutrison (Nutricia) for 8 days postoperatively $(n=20)$

Quote: "The immuno-enhanced formula was incorporated in a way that caloric equivalence between Groups 1 and 2 was preserved."

Enteral feeding was started within 24 hours of surgery

Use of additional interventions: none stated

\section{Outcomes}

\section{Primary and secondary outcomes:}

Primary and secondary outcomes not separated out

Quote: "Five days before and 8 days after surgery the following parameters were evaluated: Albumin $(\mathrm{g} / \mathrm{dl})$, prealbumin $(\mathrm{mg} / \mathrm{dl})$, fibrinogen $(\mathrm{mg} / \mathrm{dl})$, and C-reactive protein (CRP; $\mathrm{mg} / \mathrm{dl}), \mathrm{ll}-6 \mathrm{(pg} / \mathrm{ml})$, and TNF- $\alpha(\mathrm{pg} / \mathrm{ml})$ by ELISA."

Postoperative complications were also assessed but not mentioned in the methods. Results that were presented suggest that the following were assessed: minor complications (increase of temperature), major complications (pneumonia, urinary tract infection, fistula, wound infection).

Funding sources Q Quote: "The authors declare that there is no conflict of interest and no funding also."

Declarations of interest

Quote: "The authors declare that there is no conflict of interest and no funding also."

Notes

Participants lost to follow-up: Quote: "No dropouts occurred because of intolerance"

Of the 40 participants, 30 were considered well nourished ( $<10 \%$ weight loss in last 6 months) and 10 malnourished (> $10 \%$ weight loss in last 6 months). Subgroup analyses conducted with the 30 well nourished participants and the 10 malnourished participants.

No description of how the postoperative complications were assessed. We tried to contact the corresponding author by email and telephone but were unable to get a response using the information given in the paper.

\section{Risk of bias}

\section{Bias} Authors' judgement Support for judgement 
Felekis 2010 (Continued)

Random sequence genera- Low risk Quote: "The randomization was based on known techniques (using a randomtion (selection bias) ization generator)."

Allocation concealment Unclear risk

(selection bias)

Quote: "We generated a series of random numbers that ranged from 1 to 32 for operated patients for the larynx- or hypopharynx-sited tumours and 1 to 8 for operated patients for the oral cavity or tongue-sited tumours. We then tabulated the two series according to their randomization rating. We assigned the solution for each number, following the randomized sequence, using an alternating mode. Patients were numbered from 1 to 32 if they were in the first category according to the site of the tumour, and from 1 to 8 for the second category, following the sequence of their arrival, and they were introduced to the solution according to the randomization table."

The authors also stated that they monitored the distribution of gender and age within groups, but observed no difference (and did not need to interrupt the randomisation procedure to balance the groups with respect to these $2 \mathrm{pa}-$ rameters).

\begin{tabular}{|c|c|c|}
\hline $\begin{array}{l}\text { Blinding of participants } \\
\text { and personnel (perfor- }\end{array}$ & Unclear risk & $\begin{array}{l}\text { Stated "double-blinded" in the methods section but no indication as to who } \\
\text { was blinded }\end{array}$ \\
\hline
\end{tabular}

mance bias)

All outcomes

\begin{tabular}{lll}
\hline Blinding of outcome as- & Unclear risk & $\begin{array}{l}\text { Stated "double-blinded" in the methods section but no indication as to who } \\
\text { sessment (detection bias) }\end{array}$
\end{tabular}

All outcomes

\begin{tabular}{|c|c|c|}
\hline $\begin{array}{l}\text { Incomplete outcome data } \\
\text { (attrition bias) }\end{array}$ & Low risk & $\begin{array}{l}\text { No evidence from the published data: no loss to follow-up described } \\
\text { Quote: "No dropouts occurred because of intolerance" }\end{array}$ \\
\hline
\end{tabular}

All outcomes

Selective reporting (re- Unclear risk $\quad$ Protocol not available
porting bias)

Other bias High risk Assessment of complications (wound infection) poorly described

Ghosh 2012

Methods Design: double-blind, parallel-group randomised controlled trial with 5 days pre- and 7 days postoper-
ative duration of treatment and 30 days duration of follow-up

Participants

Setting: Aintree University Hospitals NHS Foundation Trust, Liverpool, UK. Patients randomised between November 2005 and July 2008

\section{Sample size:}

- Number randomised: 60

- Number completed: 57

Participant (baseline) characteristics:

- Age: median age was 62 (IQR 57 to 65 ) in the Impact group and 60 (IQR 53 to 66) in the control group

- Gender: 50 males (24 in Impact group, 26 in control group), 7 females (4 in Impact group, 3 in control group)

- Baseline differences/other characteristics: some imbalances were anticipated and confirmed: the Impact group had more patients with oral cavity tumours, more with later stage tumours and less comorbidity 
Inclusion criteria: Quote: "Eligible patients were those with advanced squamous cell carcinoma of the oral cavity, oropharynx, larynx or hypopharynx, for whom surgery +/- adjuvant radiotherapy or chemoradiotherapy had been decided upon as the treatment of choice and for whom enteral feeding was considered appropriate. Previous radiotherapy was not an exclusion criterion."

Exclusion criteria: Quote: "Specific exclusion criteria included patients with malabsorption syndromes; primary immune disorders; active infection on presentation; patients undergoing secondary surgical reconstruction; patients aged under 18 years, and patients who were pregnant or breast feeding."

\section{Intervention group:}

Impact (Nestlé Healthcare Nutrition, Minnetonka, MN, USA) - contains supplemental L-arginine (1.25 g/ $\mathrm{L})$, dietary nucleotides $(1.2 \mathrm{~g} / \mathrm{L})$ and omega-3 fatty acids in the form of eicosapentaenoic acid (EPA) and docosahexaenoic acid (DHA) (EPA/DHA $1.7 \mathrm{~g} / \mathrm{L})$

$(n=28)$

\section{Comparator group:}

Isocaloric isonitrogenous control feed manufactured for the trial $(n=29)$

The feed was given enterally by NG or PEG tube (to enhance blinding) for 5 days pre- and 7 days postsurgery

Quote: "The target duration and rate of feeding was $500 \mathrm{ml} /$ day for 5 days pre-surgery and $1 \mathrm{~L} /$ day for 7 days post-surgery. Patients, who were able, were allowed to eat or drink in addition to their supplemental enteral feeds."

Use of additional interventions: none stated

Outcomes

Primary outcome: Quote: "The primary outcome event was defined as any patient with an infection of the lower respiratory tract, gastro-intestinal tract, urinary tract or blood which required antibiotic treatment and occurred at any time, up to the 30th post-operative day."

Quote: "surgical site/wound infections were defined according to CDC Definitions of Nosocomial Surgical Site infections, 1992, and the ASEPSIS wound score. The diagnosis of the non-wound infection was as stipulated in the Trial Antibiotic Policy"

Secondary outcomes: Quote: "Secondary outcome measures included infections of primary surgical site, neck wound, PEG site, tracheostomy, free-flap or split skin graft donor site and the length of hospital stay e defined as the time from surgery to the date when the patient was deemed medically fit for discharge."

Funding sources Quote: "Nestlé Healthcare Nutrition provided the control and experimental feeds, together with the
giving sets free of charge. Novartis UK granted $£ 4000$ towards the running costs of the trial."

Declarations of interest Quote: "Neither do any of the authors have any other potential conflict of interest to declare."

Notes

Participants lost to follow-up: 3 early withdrawals (post-randomisation). Quote: "One who stopped feeding following the decision to proceed with radical radiotherapy rather than surgery; one was deemed inoperable following clinical review after randomisation, and one patient opted to withdraw."

\section{Risk of bias}

\begin{tabular}{lll}
\hline Bias & Authors' judgement & Support for judgement \\
\hline $\begin{array}{l}\text { Random sequence genera- } \\
\text { tion (selection bias) }\end{array}$ & Low risk & The Trust Pharmacy Clinical Trials Unit generated randomisation lists \\
\hline $\begin{array}{l}\text { Allocation concealment } \\
\text { (selection bias) }\end{array}$ & Low risk & $\begin{array}{l}\text { Quote: "The allocation of patients to trial groups was administered indepen- } \\
\text { dently by the Trust Pharmacy Clinical Trials Unit using randomisation lists }\end{array}$ \\
\hline
\end{tabular}


which were stratified on the basis of clinical specialty to whom the patient presented (Otorhinolaryngology/Head and Neck Surgery or Maxillofacial Surgery) and whether patients had previously received radiotherapy or not."

$\begin{array}{ll}\begin{array}{l}\text { Blinding of participants } \\ \text { and personnel (perfor- }\end{array} & \text { Low risk } \\ \begin{array}{ll}\text { mance bias) } & \text { pliance, both groups were fed enterally, either by nasogastric (NG) or percu- } \\ \text { All outcomes } & \text { taneous endoscopic gastrostomy (PEG) feeding tube depending on clinical } \\ & \text { appropriateness. Feed bottles containing either Impact or control feed were } \\ & \text { packaged identically." }\end{array}\end{array}$

Blinding of outcome as- Low risk Stated that study personnel were blinded (feed bottles were packaged identisessment (detection bias) cally and both groups fed enterally)

All outcomes

\begin{tabular}{|c|c|c|}
\hline $\begin{array}{l}\text { Incomplete outcome data } \\
\text { (attrition bias) } \\
\text { All outcomes }\end{array}$ & Low risk & $\begin{array}{l}\text { Stated that an ITT analysis was conducted. Also states that "Of the } 60 \text { patients } \\
\text { randomised there were three early withdrawals: One who stopped feeding fol- } \\
\text { lowing the decision to proceed with radical radiotherapy rather than surgery; } \\
\text { one was deemed inoperable following clinical review after randomisation, and } \\
\text { one patient opted to withdraw". NB: length of stay analysis "excludes } 4 \text { pa- } \\
\text { tients who died as inpatients, } 3 \text { from the Impact group (LOS 18, } 22 \text { \& } 32 \text { days) } \\
\text { and } 1 \text { from the control group (LOS } 30 \text { days)" }\end{array}$ \\
\hline
\end{tabular}

\begin{tabular}{|c|c|c|}
\hline $\begin{array}{l}\text { Selective reporting (re- } \\
\text { porting bias) }\end{array}$ & Unclear risk & Protocol not available \\
\hline Other bias & High risk & $\begin{array}{l}\text { Sample size calculation done, but "The trial was discontinued before achiev- } \\
\text { ing the calculated sample size as our rate of recruitment was insufficient to en- } \\
\text { able study completion in a practical time-frame and in the absence of funding } \\
\text { to allow the inclusion of additional centres." Also quoted that "some imbal- } \\
\text { ances were anticipated and confirmed: the Impact group had more patients } \\
\text { with oral cavity tumours, more with later stage tumours, and less co-morbidi- } \\
\text { ty." }\end{array}$ \\
\hline
\end{tabular}

Turnock 2013

$\begin{array}{ll}\text { Methods } & \text { Design: non-blinded, parallel-group randomised controlled trial with } 5 \text { days pre- and } \geq 5 \text { days postop- } \\ \text { erative duration of treatment and duration of follow-up to hospital discharge }\end{array}$

Participants

Setting: head and neck outpatient clinics at Auckland City Hospital, New Zealand. Carried out between May 2007 and January 2008.

\section{Sample size:}

- Number randomised: 8

- Number completed: 8

\section{Participant (baseline) characteristics:}

- Age: ranged from 28 to 68 years in the immunonutrition group and from 17 to 79 years in the control group

- Gender: 6 males ( 3 per treatment group) and 2 females (1 per treatment group)

- Baseline differences/other characteristics: not specifically reported, but no major differences reported/presented in the paper

Inclusion criteria: Quote: "patients who were scheduled for radical resection of the oral cavity, pharynx or larynx and who were expected to require artificial feeding by the enteral route postoperatively." 
Exclusion criteria: Quote: "Patients were excluded if they were: aged < 16 year, malnourished (weight loss $\geq 10 \%$ of body weight within the last 6 months), had undergone previous wide-field radical radiotherapy, or were pregnant, diabetic or immuno-suppressed."

Interventions

\section{Intervention group:}

Preoperative oral Impact and postoperative enteral Impact $(n=4)$

Quote: "IMN patients were provided with three $74 \mathrm{~g}$ sachets per day of powdered Oral Impact ${ }^{\circledR}$ (Novartis Consumer Health, Nyon, Switzerland) to be taken for 5 days immediately preceding day of surgery" and IMN patients received enteral Impact ${ }^{\circledR}$ (Novartis) post-operatively. If tube feeding was discontinued, nutritional support was continued with Oral Impact until at least POD5."

\section{Comparator group:}

Patients did not receive preoperative nutritional supplement and received standard hospital enteral nutrition (Isosource Standard ${ }^{\circledR}$, Novartis) postoperatively $(n=4)$

Postoperative feeding began as soon as tolerated via an intraoperatively placed nasogastric tube

Use of additional interventions: Quote: "Prophylactic antibiotic treatment was given to all patients for 7 days postoperatively."

\section{Outcomes}

\section{Primary and secondary outcomes:}

Primary and secondary outcomes not separated out

Blood samples taken at baseline, day of surgery, immediately preceding induction of anaesthesia and on postoperative days (POD) 2, 4 and 10: measured for plasma fatty acids, immunoglobulins ( $A, G$ and M), inflammatory markers (tumour necrosis factor (TNF)- $\alpha$, interleukin (IL)- 6 and IL-10, and C-reactive protein) and full blood count determinations.

Quote: "Assessment of clinical outcome was undertaken until discharge and included postoperative complications and length of hospital stay. General infections (urinary tract infection, respiratory tract infection), flap anastomosis complications (venous or arterial), and wound complications (dehiscence, tissue necrosis, haematoma, chyle leak, salivary fistula or wound infection) were recorded. Infectious complications were judged using CDC criteria and were considered significant if antibiotic therapy was instituted."

\begin{tabular}{|c|c|}
\hline Funding sources & Quote: "This study was supported by a grant from the Greenlane Research and Educational Fund" \\
\hline Declarations of interest & $\begin{array}{l}\text { Quote: "LDP has received funding support from Novartis/Nestle, Nutricia and Abbott Laboratories, and } \\
\text { honoraria from Baxter Healthcare. PCC is a consultant to Danone Research Center for Specialised Nu- } \\
\text { trition and Pronova Biopharma; has received speaking honoraria from Fresenius Kabi, B. Braun, Baxter } \\
\text { Healthcare, Abbott Nutrition, and Nestle; and has research funding from Abbott Nutrition. The authors } \\
\text { report no other conflicts of interest." }\end{array}$ \\
\hline
\end{tabular}

Notes Participants lost to follow-up: none stated

\section{Risk of bias}

\begin{tabular}{lll}
\hline Bias & Authors' judgement & Support for judgement \\
\hline $\begin{array}{l}\text { Random sequence genera- } \\
\text { tion (selection bias) }\end{array}$ & Low risk & $\begin{array}{l}\text { Quote: "The allocation sequence was derived from a computer-generated ran- } \\
\text { dom enumeration." }\end{array}$ \\
\hline $\begin{array}{l}\text { Allocation concealment } \\
\text { (selection bias) }\end{array}$ & Low risk & Opaque, sealed envelopes \\
\hline
\end{tabular}


Turnock 2013 (Continued)

Blinding of participants High risk The study was non-blinded and personnel (performance bias)

All outcomes

\begin{tabular}{lll}
\hline $\begin{array}{l}\text { Blinding of outcome as- } \\
\text { sessment (detection bias) } \\
\text { All outcomes }\end{array}$ & High risk & The study was non-blinded \\
\hline $\begin{array}{l}\text { Incomplete outcome data } \\
\text { (attrition bias) } \\
\text { All outcomes }\end{array}$ & Low risk & No attrition according to number of participants included in results \\
\hline $\begin{array}{l}\text { Selective reporting (re- } \\
\text { porting bias) }\end{array}$ & High risk & $\begin{array}{l}\text { Not all primary outcomes stated in the protocol were presented (data for CD3, } \\
\text { CD4 and CD8 were not included in the manuscript). Additional outcomes to } \\
\text { those stated in the protocol were presented in the manuscript (IL-10, length of } \\
\text { stay, EPA, DHA, AA) }\end{array}$
\end{tabular}

Other bias High risk Target sample size was 30 (15 per treatment group); only recruited 8

\section{De Luis 2014}

Methods

Design: double-blind, parallel-group randomised controlled trial with minimum of 15 days duration of treatment and 10 days duration of follow-up

\section{Participants}

Setting: author affiliations: Valladolid, Spain

\section{Sample size:}

- Number randomised: 82

- Number completed: 82

Participant (baseline) characteristics:

- Age: mean age 64.6 years (SD 11.4)

- Gender: male $n=72$, female $n=10$

- Baseline differences/other characteristics: no differences at baseline in age, gender, weight, tumour location or stage

Inclusion criteria: Quote: "The study protocol was designed to study patients with head and neck cancer after a surgery in abcense of type 2 diabetes mellitus or alteration of fasting glucose, diagnosed by fasting plasma glucose less than $110 \mathrm{mg} / \mathrm{dl}$." and "All patients have a histologically proven squamous cell carcinoma of the oral cavity, larynx, oropharyns or hypopharynx and required major ablative surgery."

Exclusion criteria: Quote: "Patients were excluded from the study if they were impaired renal function (serum creatinine concentration $>2.5 \mathrm{mg} / \mathrm{dl}$ ), ongoing infections, autoimmune disorders, steroids treatment, nutritional oral supplementation in previous 6 months and severely malnourished (weight loss $>10 \%$ of body weight)."

\footnotetext{
Interventions
}

\section{Intervention group:}

Group 1 received an enteral diet supplements with a high dose of L-arginine ( 20 g per day) $(n=42)$

\section{Comparator group:}

Group 2 received an isocaloric, isonitrogenous enteral formula without L-arginine $(n=40)$ 
Both groups were tube fed for 15 days post surgery. The rate of feed was increased so the target rate of $35 \mathrm{kcal} / \mathrm{kg}$ (1.7 g protein $/ \mathrm{kg}$ ) was reached within 4 days.

Use of additional interventions: none stated

\begin{tabular}{ll}
\hline Outcomes & Primary and secondary outcomes: \\
& Primary and secondary outcomes not separated out \\
& $\begin{array}{l}\text { Quote: "At basal time and on postoperative day 10, the following parameters were recorded: glucose, } \\
\text { c-reactive protein (CRP), insulin, HOMA (homeostasis model assessment), leptin and adiponectin." Al- } \\
\text { so measured weight, waist and hip circumferences, and body composition via bioelectrical impedance, } \\
\text { and reported on BMI. }\end{array}$ \\
\hline Funding sources & None declared \\
\hline Declarations of interest & None declared
\end{tabular}

Notes Participants lost to follow-up: Quote: "No drop-outs were present in the study"

Outcomes: no relevant outcomes for this review

Other: stated that an ITT analysis was conducted

\section{Risk of bias}

\begin{tabular}{|c|c|c|}
\hline Bias & Authors' judgement & Support for judgement \\
\hline $\begin{array}{l}\text { Random sequence genera- } \\
\text { tion (selection bias) }\end{array}$ & Unclear risk & Quote: "Patients were randomly assigned" but no other information provided \\
\hline $\begin{array}{l}\text { Allocation concealment } \\
\text { (selection bias) }\end{array}$ & Unclear risk & No information provided \\
\hline $\begin{array}{l}\text { Blinding of participants } \\
\text { and personnel (perfor- } \\
\text { mance bias) } \\
\text { All outcomes }\end{array}$ & Low risk & $\begin{array}{l}\text { Quote: "Blinding of patients and dietitians involved in patient treatment was } \\
\text { maintained" }\end{array}$ \\
\hline $\begin{array}{l}\text { Blinding of outcome as- } \\
\text { sessment (detection bias) } \\
\text { All outcomes }\end{array}$ & Unclear risk & $\begin{array}{l}\text { Quote: "Blinding of patients and dietitians involved in patient treatment was } \\
\text { maintained", but no indication of who outcome assessor was }\end{array}$ \\
\hline $\begin{array}{l}\text { Incomplete outcome data } \\
\text { (attrition bias) } \\
\text { All outcomes }\end{array}$ & Low risk & $\begin{array}{l}\text { No evidence from the published data } \\
\text { Quote: "No drop-outs were present in the study" }\end{array}$ \\
\hline $\begin{array}{l}\text { Selective reporting (re- } \\
\text { porting bias) }\end{array}$ & Unclear risk & Protocol not available \\
\hline Other bias & Low risk & None \\
\hline
\end{tabular}

Falewee 2014

$\begin{array}{ll}\text { Methods } & \text { Design: double-blind, parallel-group randomised controlled trial with } 7 \text { days pre- and } 7 \text { to } 15 \text { days } \\ \text { postoperative duration of treatment and } 90 \text { days duration of follow-up }\end{array}$


Falewee 2014 (Continued)

Participants

Setting: 8 centres in France; conducted between July 2007 and April 2011

Sample size:

- Number randomised: 298

- Number completed: 205

Participant (baseline) characteristics:

- Age: Group A: 59.5 (SD 9.6) years, group B: 59 (SD 9.7) years, group C: 58.2 (SD 8.7) years

- Gender: Group A: 12 female, 52 male, group B: 11 female, 57 male, group C: 10 female, 63 male

- Baseline differences/other characteristics: no evidence of baseline differences between groups

Inclusion criteria: Quote: "To enter the study, patients must have confirmed squamous cell carcinoma of the oral cavity, oropharynx, larynx or hypopharynx, with anticipated surgery and postoperative enteral feeding for a minimum of seven days. They had to be aged $\geq 18$ and $\leq 75$, with adequate hematopoietic function [absolute neutrophil count $>1.810^{9} / \mathrm{l}$, haemoglobin level $\geq 9 \mathrm{~g} / \mathrm{dl}$ ], adequate hepatic function [total serum bilirubin, serum aminotransferases $\leq 3 \mathrm{x}$ institutional upper limit of normal (ULN)], and adequate renal function [serum creatinine $\leq 2 \mathrm{ULN}$ ], urea $\leq 1.5 \mathrm{ULN}$ ], glucose $<1.5 \mathrm{~g} / \mathrm{L}$, sodium < $145 \mathrm{mmol} / \mathrm{L} . "$

Exclusion criteria: Quote: "Ineligible patients included: patients treated with neo-adjuvant chemotherapy, radiation therapy delivered on head and neck area during the previous year, patients having received oral supplements containing immune nutrients before study entry, patients testing positive for HIV, pregnant or breast-feeding women."

Interventions

\section{Intervention group:}

Group B: pre-operative Impact and postoperative standard diet $(n=68)$

Group C: pre- and postoperative Impact $(n=73)$

\section{Comparator group:}

Group A: control, i.e. 'standard diet' - Impact without immune nutrients that had been manufactured for the study $(n=64)$

Pre-operatively: Quote: "For seven days before surgery, well-nourished patients with no dysphagia received three sachets per day of nutrition according to the randomization (Oral Impact or standard diet). Each sachet dissolves in $250 \mathrm{ml}$ of water and represents $303 \mathrm{kcal}$ and $2.88 \mathrm{~g}$ of nitrogen. Patients with severe malnutrition or presenting a significant dysphagia received standard enteral nutrition according to their needs (French recommendations). Seven days before surgery, they switched $1000 \mathrm{kcal}$ from their intake to the investigational nutrition according to the randomization."

Postoperatively: Quote: "For a minimum of 7 days and a maximum of 15 days after surgery, all patients received enteral nutrition according to randomization"

Use of additional interventions: "Antibiotic prophylaxis was allowed for $24 \mathrm{~h}$ following the surgery, according to the guidelines published in 1998."

Randomly allocated to 3 groups: a) perioperative formula of Impact without immune nutrients, named "reference diet" (group A, control); b) preoperative Impact and "reference diet" postoperatively (group B); c) Impact perioperatively (group C)

Outcomes

\section{Primary outcome:}

Infectious complications

Quote: "The primary outcome event was defined as any patient with a systemic infection requiring antibiotic treatment (septicaemia, bacteraemia), surgical site infection (according to CDC Definitions of Nosocomial Surgical Site infections), documented nosocomial pneumopathy, up to the 30th post-operative day. It was named 'infectious complications' (IC)." 
Falewee 2014 (Continued)

\section{Secondary outcomes:}

Surgical site infections and length of hospital stay

Quote: "Secondary outcome measures included: surgical site infections (SSI) (primary surgical site, neck wound, free-flap or split skin graft donor site, and tracheotomy) and length of hospital stay (LOS) defined as the time from surgery to the date when the patient was deemed medically fit for discharge."

Funding sources Q Quote: "Nestlé Health Science, Switzerland kindly supplied Impact and the formula of Impact without immune nutrients. The study was supported by grants from the French National Cancer Institute (Hospital Clinical Research Program 2006)."

Declarations of interest Quote: "PB has perceived honoraria from Nestlé as member of the scientific board of the journal Nutrizoom until December 2012."

Notes Participants lost to follow-up: extra data obtained to enable intention-to-treat analysis

\section{Risk of bias}

Bias Authors' judgement Support for judgement

Random sequence genera- Low risk

Quote: "Randomization was centralized and carried out by the CS RAN-

tion (selection bias) DOMIZATION module from Clinsight software. The stratification consisted of searching with an algorithm, for the less-often allocated treatment code among patients whose randomisation criteria matched the ongoing patient."

\begin{tabular}{ll}
\hline $\begin{array}{l}\text { Allocation concealment } \\
\text { (selection bias) }\end{array}$ & Quw risk \\
& $\begin{array}{l}\text { Quote: "To ensure the blinding of study personnel, the allocation of patients } \\
\text { Units using randomisation lists." }\end{array}$
\end{tabular}

Blinding of participants Low risk
and personnel (perfor-
mance bias)
All outcomes

Quote: "Double-blinding with adequate labels was used to minimize bias with bedside physicians and nurses."

\begin{tabular}{lll}
\hline $\begin{array}{l}\text { Blinding of outcome as- } \\
\begin{array}{l}\text { sessment (detection bias) } \\
\text { All outcomes }\end{array}\end{array}$ & Low risk & $\begin{array}{l}\text { Quote: "Double-blinding with adequate labels was used to minimize bias with } \\
\text { bedside physicians and nurses." }\end{array}$ \\
\hline $\begin{array}{l}\text { Incomplete outcome data } \\
\text { (attrition bias) } \\
\text { All outcomes }\end{array}$ & Low risk & $\begin{array}{l}\text { Manuscript did not present an ITT analysis, but additional data obtained from } \\
\text { authors to enable ITT analysis to be conducted }\end{array}$ \\
\hline $\begin{array}{l}\text { Selective reporting (re- } \\
\text { porting bias) }\end{array}$ & Low risk & $\begin{array}{l}\text { Rate of infectious complications stated as a primary outcome in the protocol } \\
\text { (see: https://clinicaltrials.gov/show/NCT0076540) and presented in the man- } \\
\text { uscript. No secondary outcomes specified in protocol. }\end{array}$ \\
\hline Other bias & High risk & $\begin{array}{l}\text { Quote: "The recruitment was discontinued in April 2011 before reaching the } \\
\text { calculated sample size. The rate was too low to enable study completion in the } \\
\text { scheduled time frame and with the funding received." }\end{array}$ \\
\hline
\end{tabular}

Azman 2015

Design: non-blinded, parallel-group randomised controlled trial with 4 weeks duration of treatment
and 4 weeks duration of follow-up


Azman 2015 (Continued)

Participants
Setting: Department of Otorhinolaryngology and Oral and Maxillofacial Surgery, Universiti Kebangsaan Malaysia Medical Centre, between January 2011 and June 2012

\section{Sample size:}

- Number randomised: 46

- Number completed: 44

Quote: "One patient (control group) had to be excluded from the study as the patient died during the study period, and the other requested to be withdrawn from the study." Additional information was provided on the latter patient within the discussion section of the manuscript. Quote: "Only 1 patient had persistent diarrhea and abdominal discomfort after supplementation, hence, requested to be discontinued from supplements. The abdominal side effects resolved completely after a day of discontinuation from treatment and this patient was excluded from the study."

\section{Participant (baseline) characteristics:}

- Age: median age 49 years (range 22 to 74 )

- Gender: 24 male, 20 female

- Race: 26 were Malays (59.1\%), 14 were Chinese (31.8\%) and 4 were Indians (9.1\%)

- Baseline differences/other characteristics: no differences in baseline demographics

Inclusion criteria: Quote: "Patients diagnosed as having any head and neck malignancy being scheduled for surgery to address primary tumor site or nodal disease (clinical staging of tumor based on American Joint Committee on Cancer staging T1-4, N0-3, and M0). Patients age 20 to 75 years old."

Exclusion criteria: Quote: "Those contraindicated to enteral nutrition (maldigestion or malabsorption, such as in gut, atonia, ileus). Severe liver (serum bilirubin $>30 \mathrm{mmol} / \mathrm{L}$ or serum alanine transaminase $>100 \mathrm{IU} / \mathrm{L}$ or serum alkaline phosphatase $>200 \mathrm{IU} / \mathrm{L}$ ) or renal insufficiency (serum urea $>20 \mathrm{mmol} /$ $\mathrm{L}$, serum creatinine $>300 \mathrm{mmol} / \mathrm{L}$, or urine output $<500 \mathrm{~mL} /$ day). Severe malnutrition not amendable to enteral nutritional optimization (patients who cannot swallow at all and refuse any form of enteral feeding via Ryle's tube, gastrostomy, and jejunostomy tubes with fat-free mass $<14.6 \mathrm{~kg} / \mathrm{m}^{2}$ in men or $<11.4 \mathrm{~kg} / \mathrm{m}^{2}$ in women or serum albumin of $<15 \mathrm{~g} / \mathrm{dL}$ ). Severe cancer cachexia or sarcopenia (fat-free mass $<14.6 \mathrm{~kg} / \mathrm{m}^{2}$ in men or $<11.4 \mathrm{~kg} / \mathrm{m}^{2}$ in women or serum albumin of $<15 \mathrm{~g} / \mathrm{dL}$ ). Patients with inborn errors of metabolism of nutrients contained in Glutamine Plus. Patients with head and neck malignancy going for chemoradiotherapy, including patients who are irradiated while on glutamine supplementation. Patients with head and neck malignancy who had any form of concurrent treatment protocols (hormonal, alternative, antiviral, or photodynamic therapy) during the study duration."

Interventions

\section{Intervention group:}

Glutamine Plus (Fresenius Kabi, Bad Homburg, Germany), $10 \mathrm{~g} 3$ times a day for 4 weeks post surgery ( $\mathrm{n}$ $=22$ )

\section{Comparator group:}

No supplement $(\mathrm{n}=22)$

Patients in both groups received protein/calorie optimisation from dietary modifications as well as nutritional supplements

\section{Primary and secondary outcomes:}

Primary and secondary outcomes not separated out

Quote: "At the first visit, which was before surgery, demographic data, fat-free mass measurement using body impedance analysis, quality of life score, serum albumin measurement, and daily caloric intake (via 24-hour dietary recall) were assessed. At the end of 4-week duration, which corresponded to 4 weeks postsurgery, the investigator assessed the patients recruited to both groups with regard to 24hour dietary recall, quality of life scores, serum albumin, and body composition analysis." 
Azman 2015 (Continued)

NB: data included: age, sex, race, cancer type, staging, surgical procedures performed, height, weight and liver function (assessed at baseline and 4 weeks)

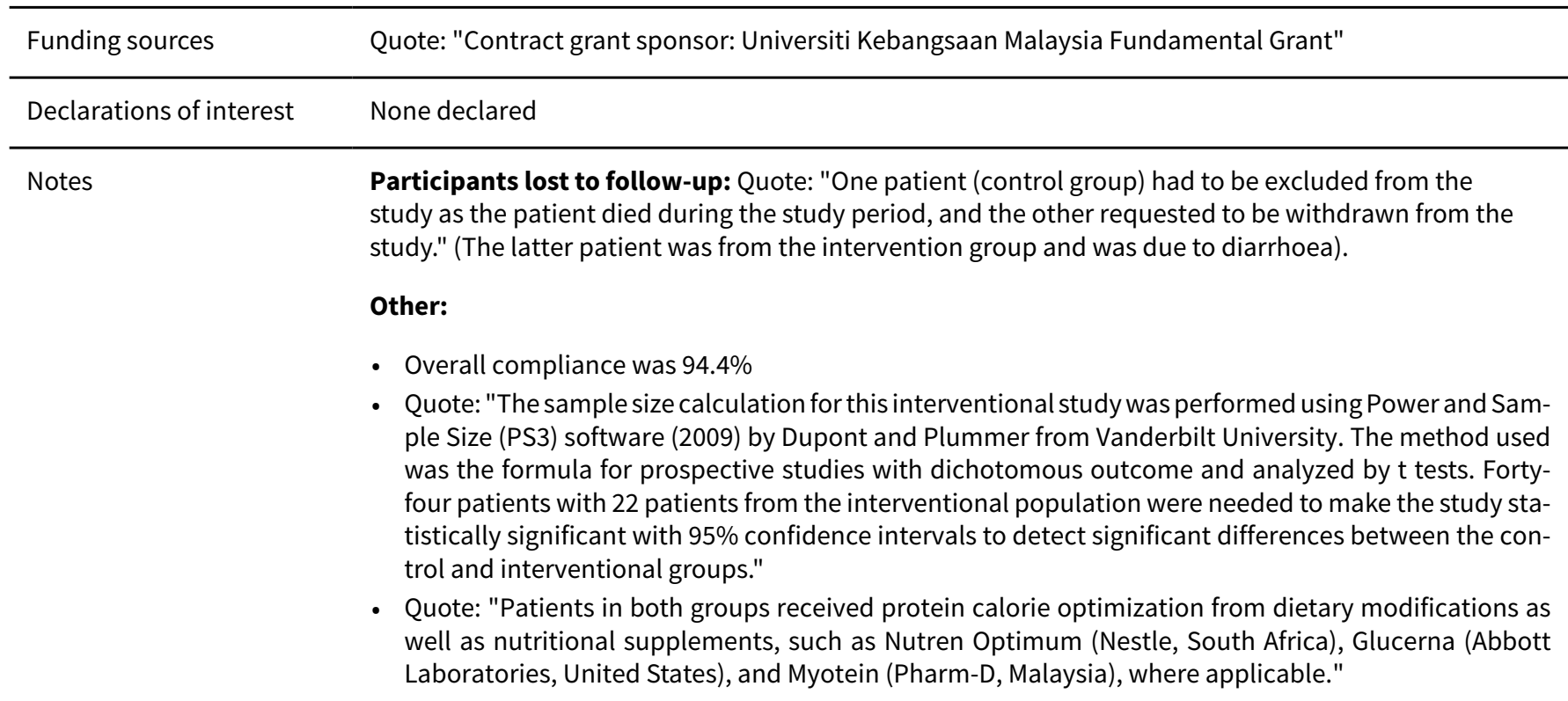

\section{Risk of bias}

\begin{tabular}{lll}
\hline Bias & Authors' judgement & Support for judgement \\
\hline $\begin{array}{ll}\text { Random sequence genera- } \\
\text { tion (selection bias) }\end{array}$ & Low risk & $\begin{array}{l}\text { Quote: "The method of randomization was random ballot picking of sealed en- } \\
\text { velopes that were assigned numbers from } 1 \text { to } 44 . \text { Odd numbers meant recruit- } \\
\text { ment into the control group and even numbers meant recruitment into the in- } \\
\text { terventional group." }\end{array}$ \\
& & \\
\hline
\end{tabular}

Allocation concealment Unclear risk Sealed envelopes used (but not known if these were opaque)

(selection bias)

Blinding of participants High risk Quote: "No blinding was used"
and personnel (perfor-
mance bias)
All outcomes

\begin{tabular}{|c|c|c|}
\hline $\begin{array}{l}\text { Blinding of outcome as- } \\
\text { sessment (detection bias) } \\
\text { All outcomes }\end{array}$ & High risk & Quote: "No blinding was used" \\
\hline $\begin{array}{l}\text { Incomplete outcome data } \\
\text { (attrition bias) } \\
\text { All outcomes }\end{array}$ & Unclear risk & $\begin{array}{l}\text { Not stated whether any dropouts occurred and unclear how many data points } \\
\text { are included in each figure }\end{array}$ \\
\hline $\begin{array}{l}\text { Selective reporting (re- } \\
\text { porting bias) }\end{array}$ & Unclear risk & Protocol not available \\
\hline Other bias & Low risk & None \\
\hline
\end{tabular}


Hanai 2018

\section{Methods}

Design: parallel-group randomised controlled trial (not stated if blinded) with 14 days pre- and 14 days postoperative duration of treatment and 14 days duration of follow-up

Participants

Setting: author affiliations: Department of Head and Neck Surgery, Aichi Cancer Center Hospital, Nagoya, Aichi, and Department of Otorhinolaryngology, Head and Neck Surgery, Graduate School of Medicine, University of the Ryukyus, Nishihara, Okinawa, Japan

\section{Sample size:}

- Number randomised: 28

- Number completed: 27

Participant (baseline) characteristics:

- Age: average age was 61.5 (range 45 to 77 ) years in the intervention group and 66.1 (range 47 to 76 ) years in the comparator group

- Gender: 16 male (8 per treatment group), 11 female ( 5 in the intervention group and 6 in the comparator group)

- Baseline differences/other characteristics: Quote: "There were no significant differences in the background factors of the patients in the two arms". Authors also quoted "Seven of the 13 patients in the experimental arm and 8 of the 14 patients in the control arm received preoperative chemotherapy."

Inclusion criteria: Quote: "patients undergoing head and neck cancer surgery who required resection and free flap reconstruction and who exhibited $\geq 5 \%$ weight loss". Quote: "Eligibility criteria: (1) histopathologically diagnosed head and neck squamous cell carcinoma, (2) indication for free flap reconstruction, (3) the subject intended to participate in this test and provided their written consent, (4) the age at the time of registration was $20-80$ years, (5) an ECOG performance status of $0-2,(6) \geq 5 \%$ weight loss within the past 6 months, (7) life expectancy $\geq 6$ months and (8) the patient's major organ function was maintained."

Exclusion criteria: Quote: "Patients who met any of the following exclusion criteria were excluded from the study: (1) intestinal occlusion and serious enterostenosis (enteral feeding intolerance), (2) combined resection of other organs, (3) obvious focal infection before surgery, (4) serious heart, liver or kidney disease, (5) uncontrolled diabetes, (6) refractory hyperlipemia, (7) a past history of chronic inflammatory disease, (8) continuous or general administration (oral or intravenous) of steroids, (9) subjects taking EPA, (10) a past history of anaphylaxis against components of Prosure ${ }^{\circledR}$ (e.g. milk and soybean), (11) patients who are pregnant, lactating or possibly pregnant and (12) patients who were deemed ineligible for other reasons by the principal investigator of the test."

Interventions

Intervention group: Prosure $^{\circledast}$ (an eicosapentaenoic acid (EPA)-enriched oral nutritional supplement) was administered at a dose of 2 packs/day $(480 \mathrm{~mL}$ ) during the 28-day intervention period (14 days before surgery and 14 days after surgery) in addition to a normal diet (or in lieu of part of a normal diet) (n $=14$, but 13 analysed)

Comparator group: no intervention $(n=14)$

Use of additional interventions: none stated

Outcomes $\quad$ Primary outcome:

Postoperative nutritional status (weight, lean body mass, albumin, prealbumin)

\section{Secondary outcomes:}

Inflammatory marker levels (CRP, IL6, white blood cell count, body temperature), compliance with the Prosure ${ }^{\circledast}$ dosage and the occurrence of postoperative complications

\begin{tabular}{ll}
\hline Funding sources & None declared \\
\hline Declarations of interest & None declared \\
\hline
\end{tabular}


Hanai 2018 (Continued)

Notes
Participants lost to follow-up: Quote: "For the intent-to-treat analysis, the object of the analysis included the registered subjects in each arm." NB: according to the CONSORT diagram in the manuscript, one person in the intervention group was, quote: "Excluded due to incomplete data", to give a sample size for analysis of 13 .

Other: Quote: "nine subjects in each arm would be required to detect a statistically significant difference by Student's t-test $[\alpha=0.1$ (bilateral), $1-\beta=0.8] . "$

\section{Risk of bias}

\begin{tabular}{|c|c|c|}
\hline Bias & Authors' judgement & Support for judgement \\
\hline $\begin{array}{l}\text { Random sequence genera- } \\
\text { tion (selection bias) }\end{array}$ & Unclear risk & No statement on the generation of the random sequence \\
\hline $\begin{array}{l}\text { Allocation concealment } \\
\text { (selection bias) }\end{array}$ & Unclear risk & No statement on allocation concealment \\
\hline $\begin{array}{l}\text { Blinding of participants } \\
\text { and personnel (perfor- } \\
\text { mance bias) } \\
\text { All outcomes }\end{array}$ & High risk & $\begin{array}{l}\text { No statement on blinding, but we presumed non-blinded as the intervention } \\
\text { group received sachets and the control group received no intervention }\end{array}$ \\
\hline $\begin{array}{l}\text { Blinding of outcome as- } \\
\text { sessment (detection bias) } \\
\text { All outcomes }\end{array}$ & Unclear risk & No statement on blinding or who outcome assessors were \\
\hline $\begin{array}{l}\text { Incomplete outcome data } \\
\text { (attrition bias) } \\
\text { All outcomes }\end{array}$ & Low risk & $\begin{array}{l}\text { No evidence from the published data } \\
\text { Quote: "For the intent-to-treat analysis, the object of the analysis included the } \\
\text { registered subjects in each arm" } \\
\text { NB: } 1 \text { patient randomised to the intervention group was, quote: "Excluded due } \\
\text { to incomplete data" }\end{array}$ \\
\hline $\begin{array}{l}\text { Selective reporting (re- } \\
\text { porting bias) }\end{array}$ & Unclear risk & Protocol not available \\
\hline Other bias & Low risk & No evidence from the published data \\
\hline
\end{tabular}

AA: $(E P A+D H A) /$ arachidonic acid ratio

ASEPSIS: Additional treatment, Serous discharge, Erythema, Purulent exudate, Separation of deep tissues, Isolation of bacteria, Stay duration as inpatient

COOP-WONCA: Dartmouth-Northern New England Primary Care Cooperative Information Project-World Organization of National Colleges, Academies and Academic Associations of general Practitioners

CRP: C-reactive protein

DHA: docosahexaenoic acid

ENT: ear, nose and throat

EORTC: European Organisation for Research and Treatment of Cancer

EPA: eicosapentaenoic acid

ICU: intensive care unit

IQR: interquartile range

IL-10: interleukin 10

ITT: intention-to-treat

i.v.: intravenous

NG: nasogastric

PEG: percutaneous endoscopic gastrostomy

POD: postoperative day

QOL: quality of life

RNA: ribonucleic acid 
SD: standard deviation

STD: standard group

TLC: total lymphocyte count

\section{Characteristics of excluded studies [ordered by year of study]}

\begin{tabular}{ll}
\hline Study & Reason for exclusion \\
\hline Linn 1988 & Allocation: not randomised \\
\hline De Luis 2005a & Allocation: randomised \\
& Participants: post hospital discharge after head and neck surgery \\
& Interventions: immunonutrition only (no standard diet comparison) \\
\hline
\end{tabular}

\begin{tabular}{|c|c|}
\hline \multirow[t]{4}{*}{ Buijs 2010} & Allocation: randomised \\
\hline & Participants: head and neck cancer patients who were malnourished \\
\hline & Interventions: standard feed or standard feed plus immunonutrition perioperatively \\
\hline & Outcomes: patients and outcome data included in another trial \\
\hline
\end{tabular}

Allocation: randomised

Participants: head and neck cancer patients

Interventions: 2 doses of arginine (high and medium)

\begin{tabular}{ll}
\hline De Luis 2013 & Allocation: not randomised \\
\hline De Luis 2015 & Allocation: randomised \\
& Participants: head and neck cancer patients \\
& Interventions: 3 different doses of arginine (low, medium, high) but no standard polymeric feed as \\
& a comparison \\
\hline Palma-Milla 2016 & Allocation: randomised \\
& Participants: head and neck cancer patients \\
& $\begin{array}{l}\text { Interventions: "new immunomodulatory formula or that commonly used in clinical practice" (i.e. } \\
\text { both groups received immunonutrition) }\end{array}$ \\
\hline Reis 2016 & Allocation: not randomised (systematic review - not head and neck cancer patients) \\
\hline
\end{tabular}

Characteristics of ongoing studies [ordered by study ID]

\section{NCT03261180}

Trial name or title 'Nestle Impact Advanced Recovery in improving surgery recovery in patients with head and neck cancer (official title "Perioperative nutritional optimization in head and neck cancer patients")

Methods

Non-blinded, parallel-group randomised controlled trial with 5 days pre- and 5 days postoperative duration of treatment and 30 days duration of follow-up 


\section{Inclusion criteria:}

Quote:

- "Members of all races and ethnic groups will be included

- Patients must be diagnosed with cancer of the head and neck and must be surgical candidates

- Patients must be indicated for major head and neck surgery, defined as surgeries with an anticipated post-surgical hospital stay of 4 or more days; examples of major surgeries include, but are not limited to, total laryngectomy, large oral cavity, oropharyngeal, salivary gland, or soft tissue resections requiring free flap or major regional flap (e.g. pectoralis major flap), and large skull base procedures requiring extensive skull base reconstruction

- Patients must have cross-sectional body imaging (positron emission tomography [PET]-computed tomography [CT] or equivalent) performed within 4 weeks of study enrollment and available for review

- Patient must be willing to receive Nestle IMPACT Advance Recovery for five days prior to planned surgery as well as for 5 days after surgery

- Ability to understand and the willingness to sign a written informed consent document"

\section{Exclusion criteria:}

Quote:

- "Patients with known distant metastases or other malignancies

- Patients unable to tolerate oral intake by mouth or per enteral feeding tube

- Patients with galactosemia

- Patients who have received any investigational medication within 6 weeks of enrollment, or who are scheduled to receive an investigational drug during the course of the study

- Patients currently taking IMPACT or other immunonutrition products (arginine-containing supplements) will be excluded; other forms of nutritional supplementation, such as caloric supplementation, tube feeding, or other dietary supplements are allowed on study

- Patients currently taking anabolic steroids will be excluded; patients taking corticosteroids are allowed on study

- Psychiatric illness/social situations that would limit compliance with study requirements

- Excluded patients will be allowed to participate in the trial on an observational basis only"

Interventions

Intervention group: Nestlé Impact AR (Group I). Patients receive Nestlé Impact AR for 5 days before and after surgery in addition to regular diet.

Comparator group: regular diet (Group II). Patients receive regular diet.

$\begin{array}{ll}\text { Putcomes } & \text { Primary outcome: } \\ \text { Quote: "Primary: Rate of post-operative wound complications" (within } 30 \text { days after major head } \\ \text { and neck surgery) }\end{array}$

\section{Secondary outcomes:}

Rate of other postoperative complications (within 30 days after surgery) and sarcopenia (within 30 days after major head and neck surgery)

Other:

Sarcopenia-related gene expression (up to 30 days post-surgery)

\begin{tabular}{ll}
\hline Starting date & Estimated: 30 April 2018 \\
\hline Contact information & Daniel R. Clayburgh (503-494-5355), OHSU Knight Cancer Institute \\
\hline Notes & Study not yet recruiting (https://clinicaltrials.gov/ct2/show/NCT03261180 accessed 9 May 2018) \\
\hline
\end{tabular}


DATA AND ANALYSES

Comparison 1. Immunonutrition versus standard care

\begin{tabular}{|c|c|c|c|c|}
\hline Outcome or subgroup title & No. of studies & $\begin{array}{l}\text { No. of partici- } \\
\text { pants }\end{array}$ & Statistical method & Effect size \\
\hline $\begin{array}{l}1 \text { Postoperative length of hos- } \\
\text { pital stay }\end{array}$ & 10 & 757 & $\begin{array}{l}\text { Mean Difference (IV, Random, 95\% } \\
\mathrm{CI})\end{array}$ & $-2.50[-5.11,0.12]$ \\
\hline $\begin{array}{l}1.1 \text { Pre-operative and postop- } \\
\text { erative feeding }\end{array}$ & 4 & 403 & $\begin{array}{l}\text { Mean Difference (IV, Random, 95\% } \\
\mathrm{CI})\end{array}$ & $-0.30[-2.82,2.21]$ \\
\hline 1.2 Postoperative feeding only & 6 & 354 & $\begin{array}{l}\text { Mean Difference (IV, Random, 95\% } \\
\mathrm{CI})\end{array}$ & $-4.47[-8.46,-0.48]$ \\
\hline 2 Wound infection & 12 & 812 & Risk Ratio (M-H, Random, 95\% Cl) & $0.94[0.70,1.26]$ \\
\hline $\begin{array}{l}2.1 \text { Pre-operative and postop- } \\
\text { erative feeding }\end{array}$ & 6 & 458 & Risk Ratio (M-H, Random, 95\% Cl) & $0.98[0.72,1.33]$ \\
\hline 2.2 Postoperative feeding only & 6 & 354 & Risk Ratio (M-H, Random, 95\% Cl) & $0.55[0.19,1.59]$ \\
\hline 3 Fistula formation & 10 & 747 & Risk Ratio (M-H, Random, 95\% Cl) & $0.48[0.27,0.85]$ \\
\hline $\begin{array}{l}3.1 \text { Pre-operative and postop- } \\
\text { erative feeding }\end{array}$ & 4 & 393 & Risk Ratio (M-H, Random, 95\% Cl) & $0.72[0.33,1.62]$ \\
\hline 3.2 Postoperative feeding only & 6 & 354 & Risk Ratio (M-H, Random, 95\% Cl) & $0.31[0.14,0.71]$ \\
\hline 4 Adverse events & 9 & 719 & Risk Ratio (M-H, Random, 95\% Cl) & $1.33[0.86,2.06]$ \\
\hline $\begin{array}{l}4.1 \text { Pre-operative and postop- } \\
\text { erative feeding }\end{array}$ & 2 & 325 & Risk Ratio (M-H, Random, 95\% Cl) & $0.87[0.30,2.50]$ \\
\hline 4.2 Postoperative feeding only & 7 & 394 & Risk Ratio (M-H, Random, 95\% Cl) & $1.42[0.82,2.46]$ \\
\hline 5 All-cause mortality & 14 & 776 & Risk Ratio (M-H, Random, 95\% Cl) & $1.33[0.48,3.66]$ \\
\hline $\begin{array}{l}5.1 \text { Pre-operative and postop- } \\
\text { erative feeding }\end{array}$ & 6 & 357 & Risk Ratio (M-H, Random, 95\% Cl) & $1.13[0.28,4.60]$ \\
\hline 5.2 Postoperative feeding only & 8 & 419 & Risk Ratio (M-H, Random, 95\% Cl) & $1.57[0.29,8.53]$ \\
\hline
\end{tabular}

\section{Analysis 1.1. Comparison 1 Immunonutrition versus standard care, Outcome 1 Postoperative length of hospital stay.}

\begin{tabular}{|c|c|c|c|c|c|c|c|c|}
\hline \multirow[t]{2}{*}{ Study or subgroup } & \multicolumn{2}{|c|}{ Immunonutrition } & \multicolumn{2}{|c|}{ Standard care } & & \multirow{2}{*}{$\begin{array}{l}\text { Mean Difference } \\
\text { Random, } 95 \% \mathrm{Cl}\end{array}$} & \multirow[t]{2}{*}{ Weight } & \multirow{2}{*}{$\begin{array}{l}\text { Mean Difference } \\
\text { Random, } 95 \% \mathrm{CI}\end{array}$} \\
\hline & $\mathbf{N}$ & $\operatorname{Mean}(S D)$ & $\mathbf{N}$ & Mean(SD) & & & & \\
\hline \multicolumn{9}{|c|}{ 1.1.1 Pre-operative and postoperative feeding } \\
\hline
\end{tabular}




\begin{tabular}{|c|c|c|c|c|c|c|c|}
\hline \multirow{3}{*}{$\begin{array}{l}\text { Study or subgroup } \\
\text { Ghosh } 2012\end{array}$} & \multicolumn{2}{|c|}{ Immunonutrition } & \multicolumn{2}{|c|}{ Standard care } & \multirow{2}{*}{$\begin{array}{l}\text { Mean Difference } \\
\text { Random, } 95 \% \mathrm{Cl}\end{array}$} & \multirow[t]{2}{*}{ Weight } & \multirow{2}{*}{$\begin{array}{l}\text { Mean Difference } \\
\text { Random, } 95 \% \mathrm{Cl}\end{array}$} \\
\hline & $\mathbf{N}$ & Mean(SD) & $\mathbf{N}$ & Mean(SD) & & & \\
\hline & 28 & $31.1(20.5)$ & 29 & $35.3(32.6)$ & \begin{tabular}{l|l}
1 & \\
\end{tabular} & $3.15 \%$ & $-4.2[-18.29,9.89]$ \\
\hline Turnock 2013 & 4 & $18(16.7)$ & 4 & $18.5(7.7)$ & & $1.99 \%$ & $-0.5[-18.52,17.52]$ \\
\hline Falewee 2014 & 105 & $23.6(13.7)$ & 104 & $22.3(11.5)$ & + & $22.58 \%$ & $1.3[-2 \cdot 13,4.73]$ \\
\hline 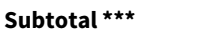 & 219 & & 184 & & & $47.84 \%$ & $-0.3[-2.82,2.21]$ \\
\hline \multicolumn{8}{|c|}{ Heterogeneity: $\operatorname{Tau}^{2}=0 ; \mathrm{Chi}^{2}=1.94, \mathrm{df}=3(\mathrm{P}=0.59) ; \mathrm{I}^{2}=0 \%$} \\
\hline \multicolumn{8}{|c|}{ Test for overall effect: $Z=0.24(P=0.81)$} \\
\hline \multicolumn{8}{|c|}{ 1.1.2 Postoperative feeding only } \\
\hline Riso 2000 & 23 & $25(11.6)$ & 21 & $28(12.6)$ & *- & $9.76 \%$ & $-3[-10.18,4.18]$ \\
\hline De Luis 2002 & 23 & $22.8(11.5)$ & 24 & $31.2(19.1)$ & & $6.91 \%$ & $-8.4[-17.37,0.57]$ \\
\hline De Luis 2004 & 45 & $25.8(15)$ & 45 & $35(24.6)$ & 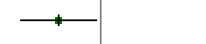 & $7.65 \%$ & $-9.2[-17.62,-0.78]$ \\
\hline De Luis 2007 & 35 & $27.9(21)$ & 37 & $28.2(12)$ & $\longrightarrow$ & $8.35 \%$ & $-0.3[-8.26,7.66]$ \\
\hline Casas-Rodera 2008 & 14 & $18.6(7.8)$ & 15 & $18.3(7.5)$ & + & $13.83 \%$ & $0.3[-5.26,5.86]$ \\
\hline De Luis 2009 & 38 & $24.3(14)$ & 34 & $36.1(27)$ & 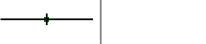 & $5.66 \%$ & $-11.8[-21.91,-1.69]$ \\
\hline 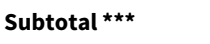 & 178 & & 176 & & & $52.16 \%$ & $-4.47[-8.46,-0.48]$ \\
\hline \multicolumn{8}{|c|}{ Heterogeneity: $\operatorname{Tau}^{2}=8.96 ; \mathrm{Chi}^{2}=7.87, \mathrm{df}=5(\mathrm{P}=0.16) ; \mathrm{I}^{2}=36.49 \%$} \\
\hline \multicolumn{8}{|c|}{ Test for overall effect: $Z=2.19(P=0.03)$} \\
\hline Total $\star \star \star ~$ & 397 & & 360 & & 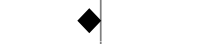 & $100 \%$ & $-2.5[-5.11,0.12]$ \\
\hline \multicolumn{8}{|c|}{ Heterogeneity: $\mathrm{Tau}^{2}=4.82 ; \mathrm{Chi}^{2}=12.89, \mathrm{df}=9(\mathrm{P}=0.17) ; \mathrm{I}^{2}=30.17 \%$} \\
\hline \multicolumn{8}{|c|}{ Test for overall effect: $Z=1.87(P=0.06)$} \\
\hline Test for subgroup dif & $99, \mathrm{df}=$ & $P=0.08), 1^{2}=66$ & & & & & \\
\hline
\end{tabular}

Analysis 1.2. Comparison 1 Immunonutrition versus standard care, Outcome 2 Wound infection.

\begin{tabular}{|c|c|c|c|c|c|}
\hline Study or subgroup & $\begin{array}{c}\text { Immunonu- } \\
\text { trition } \\
\mathbf{n} / \mathbf{N} \\
\end{array}$ & $\begin{array}{c}\text { Standard care } \\
\mathbf{n} / \mathbf{N} \\
\end{array}$ & $\begin{array}{c}\text { Risk Ratio } \\
\text { M-H, Random, 95\% CI }\end{array}$ & Weight & $\begin{array}{c}\text { Risk Ratio } \\
\text { M-H, Random, } 95 \% \mathrm{Cl}\end{array}$ \\
\hline \multicolumn{6}{|c|}{ 1.2.1 Pre-operative and postoperative feeding } \\
\hline Falewee 2014 & $23 / 105$ & $28 / 104$ & - & $38.01 \%$ & $0.81[0.5,1.32]$ \\
\hline Felekis 2010 & $1 / 20$ & $0 / 20$ & & $0.89 \%$ & $3[0.13,69.52]$ \\
\hline Ghosh 2012 & $17 / 28$ & $17 / 29$ & & $48.1 \%$ & $1.04[0.68,1.59]$ \\
\hline Sorensen 2009 & $2 / 8$ & $0 / 7$ & & $1.05 \%$ & $4.44[0.25,79.42]$ \\
\hline Turnock 2013 & $1 / 4$ & $0 / 4$ & & $1.01 \%$ & $3[0.16,57.36]$ \\
\hline Subtotal $(95 \% \mathrm{Cl})$ & 247 & 211 & & $92.25 \%$ & $0.98[0.72,1.33]$ \\
\hline \multicolumn{6}{|c|}{ Total events: 48 (Immunonutrition), 47 (Standard care) } \\
\hline \multicolumn{6}{|c|}{ Heterogeneity: $\operatorname{Tau}^{2}=0 ; \mathrm{Chi}^{2}=2.78, \mathrm{df}=5(\mathrm{P}=0.73) ; \mathrm{I}^{2}=0 \%$} \\
\hline \multicolumn{6}{|c|}{ Test for overall effect: $Z=0.14(P=0.89)$} \\
\hline \multicolumn{6}{|c|}{ 1.2.2 Postoperative feeding only } \\
\hline Casas-Rodera 2008 & $1 / 14$ & $2 / 15$ & & $1.68 \%$ & $0.54[0.05,5.28]$ \\
\hline De Luis 2002 & $1 / 23$ & $3 / 24$ & - & $1.83 \%$ & $0.35[0.04,3.11]$ \\
\hline De Luis 2004 & $0 / 45$ & $0 / 45$ & & & Not estimable \\
\hline De Luis 2007 & $0 / 35$ & $0 / 37$ & & & Not estimable \\
\hline De Luis 2009 & $1 / 38$ & $1 / 34$ & & $1.17 \%$ & $0.89[0.06,13.76]$ \\
\hline Riso 2000 & $2 / 23$ & $3 / 21$ & - & $3.08 \%$ & $0.61[0.11,3.29]$ \\
\hline Subtotal $(95 \% \mathrm{CI})$ & 178 & 176 & & $7.75 \%$ & $0.55[0.19,1.59]$ \\
\hline
\end{tabular}

$\begin{array}{lllllll}\text { Favours immunonutrition } & 0.001 & 0.1 & 1 & 10 & 1000 & \text { Favours standard care }\end{array}$ 


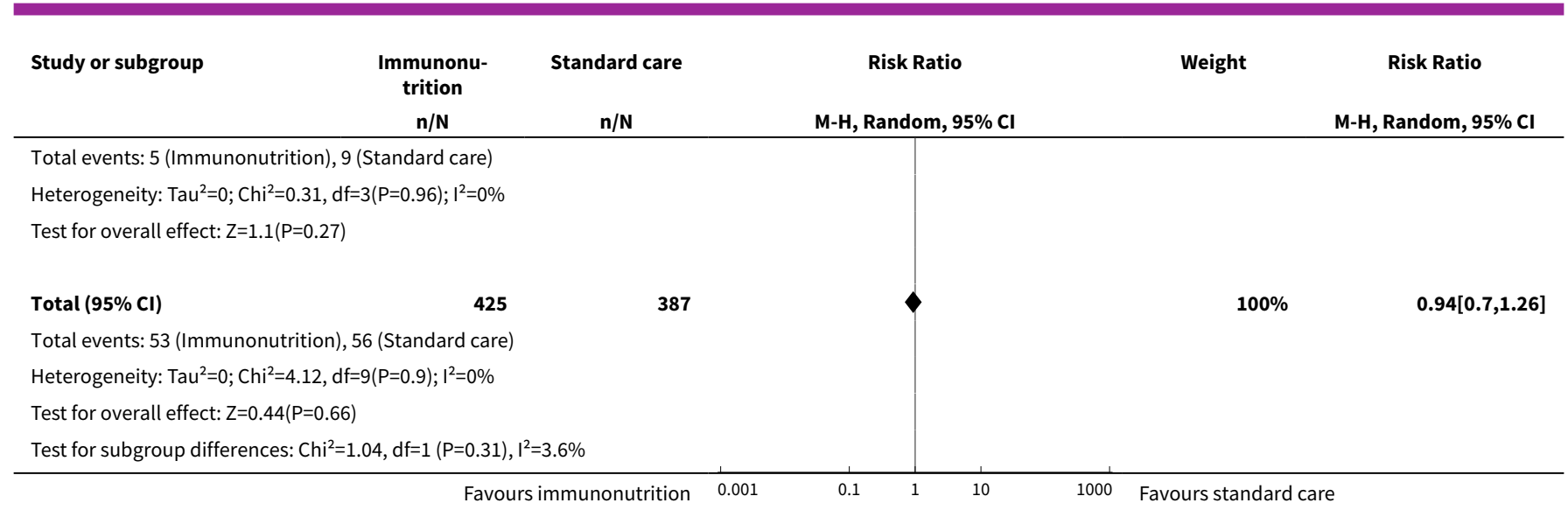

Analysis 1.3. Comparison 1 Immunonutrition versus standard care, Outcome 3 Fistula formation.

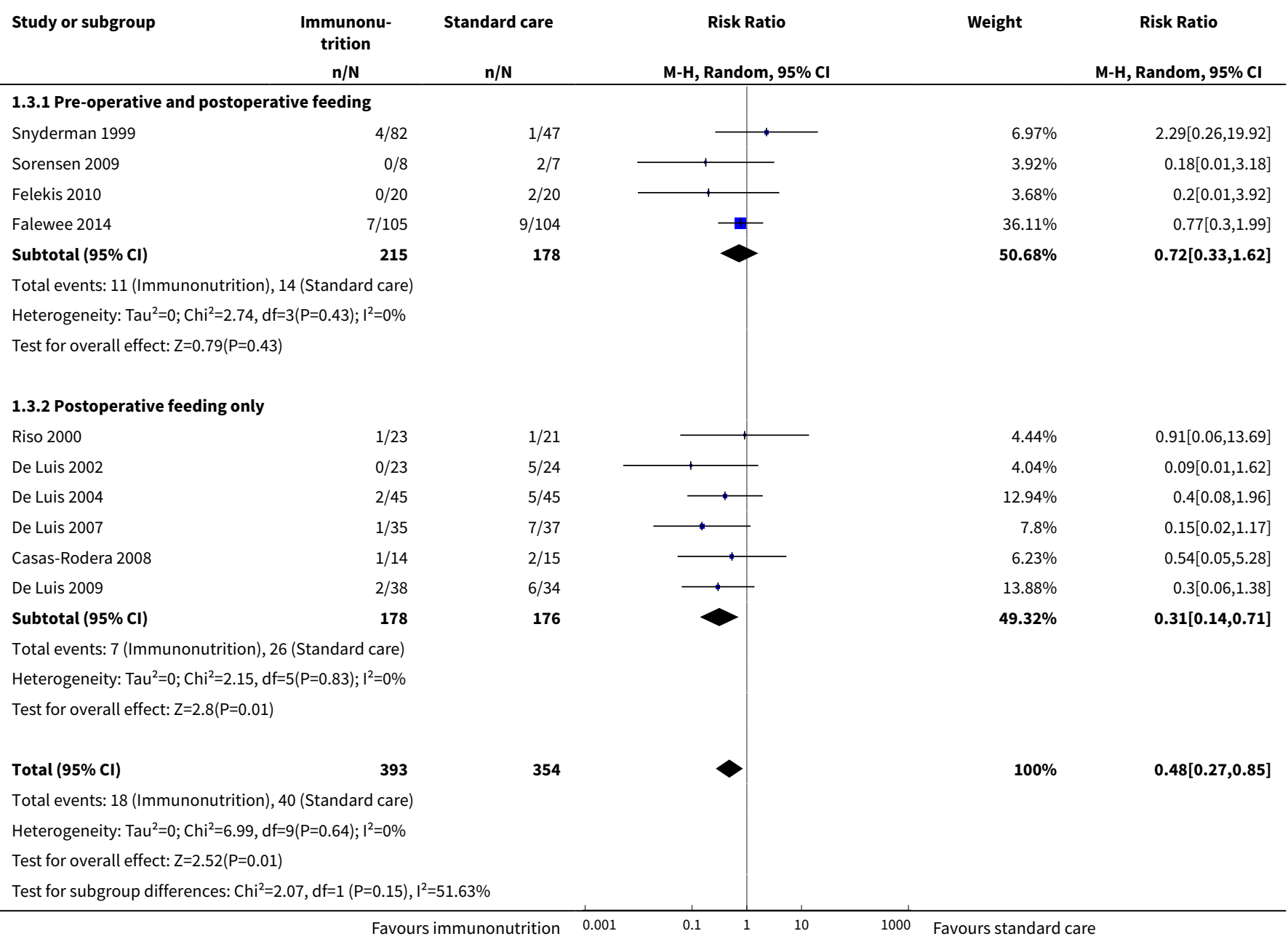


Analysis 1.4. Comparison 1 Immunonutrition versus standard care, Outcome 4 Adverse events.

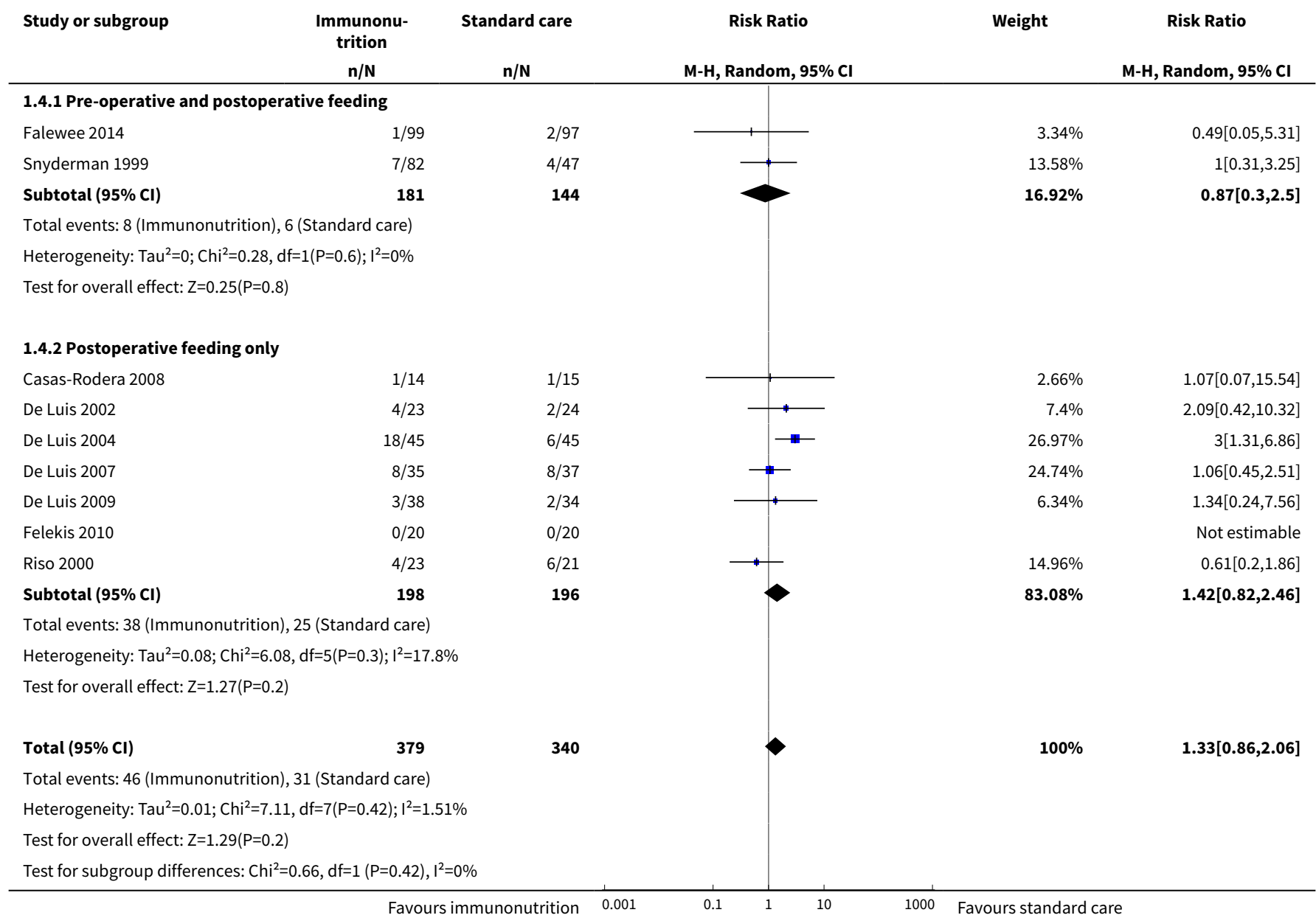

Analysis 1.5. Comparison 1 Immunonutrition versus standard care, Outcome 5 All-cause mortality.

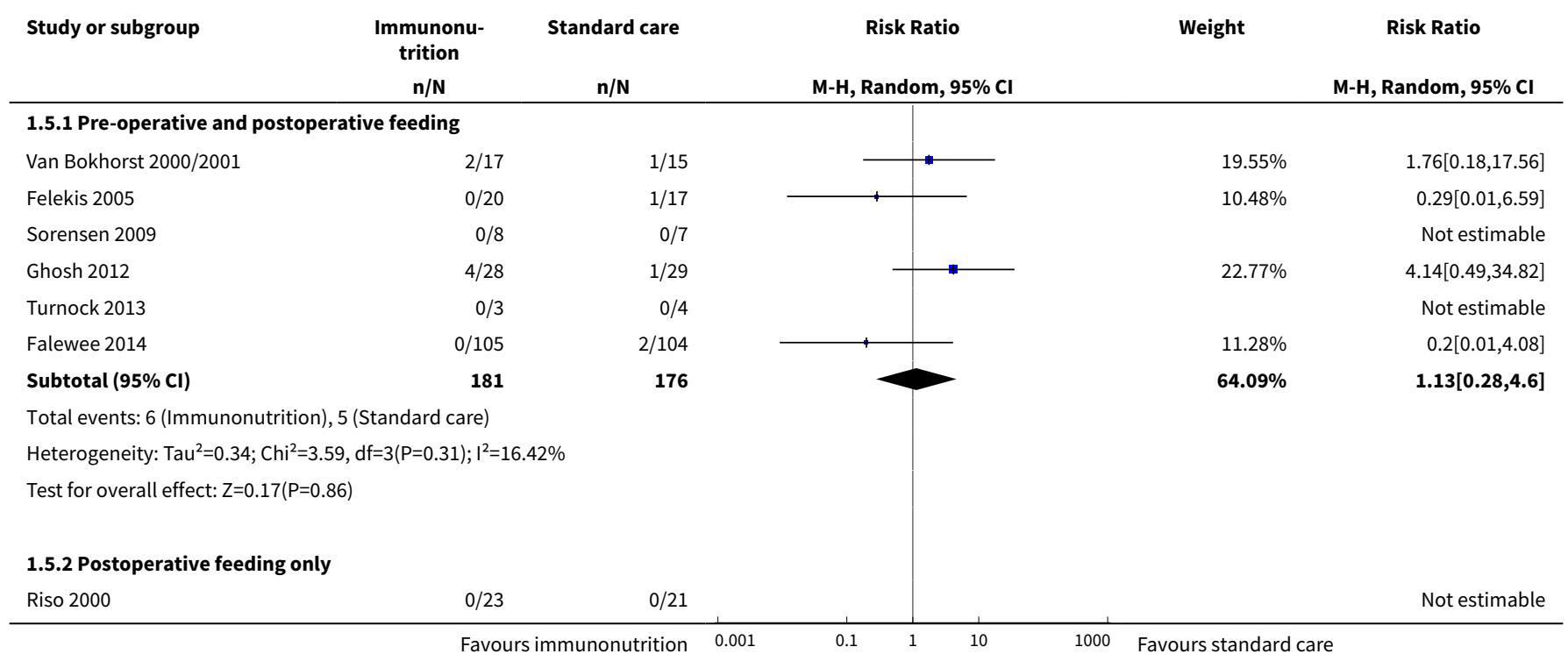




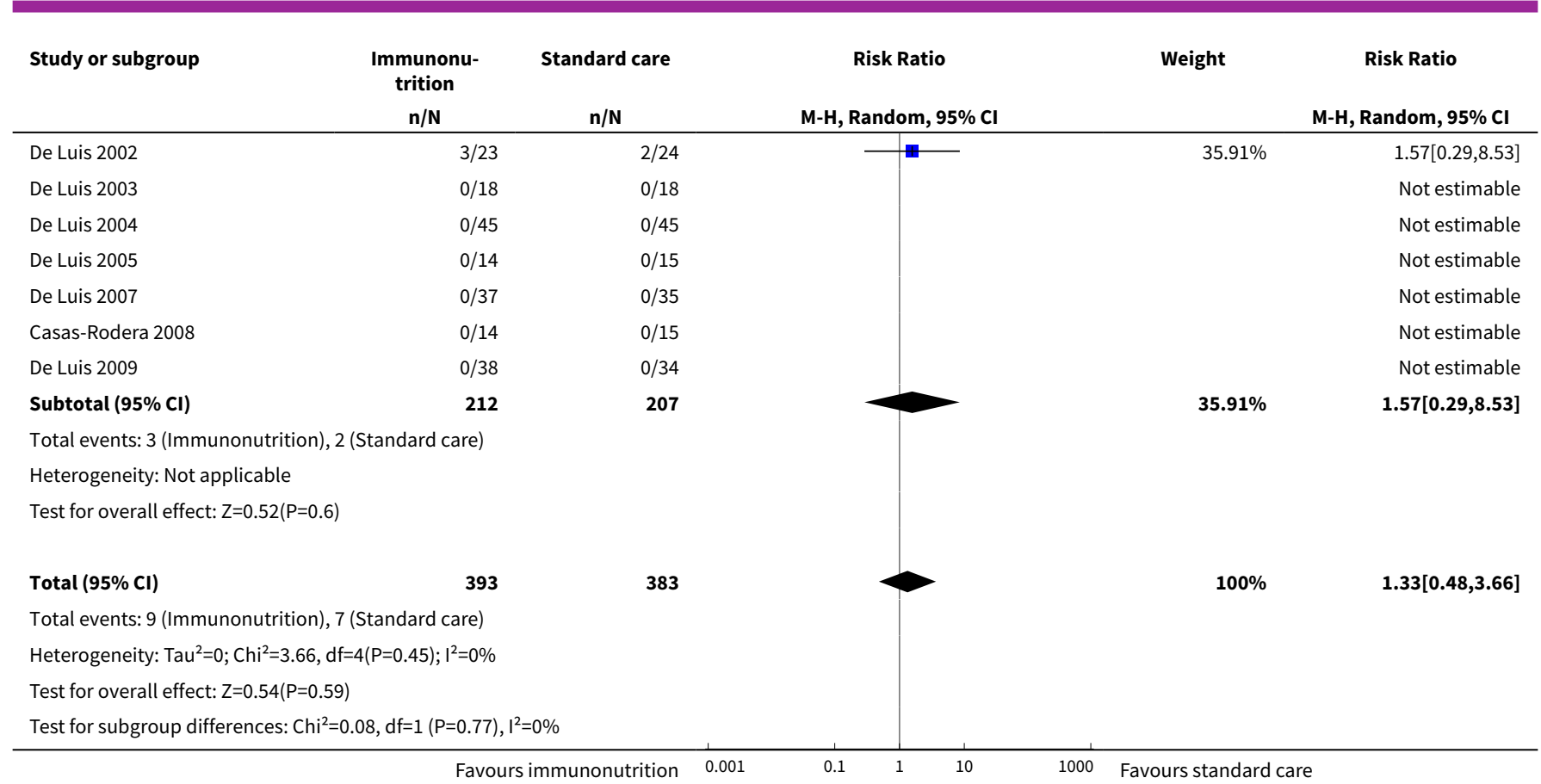




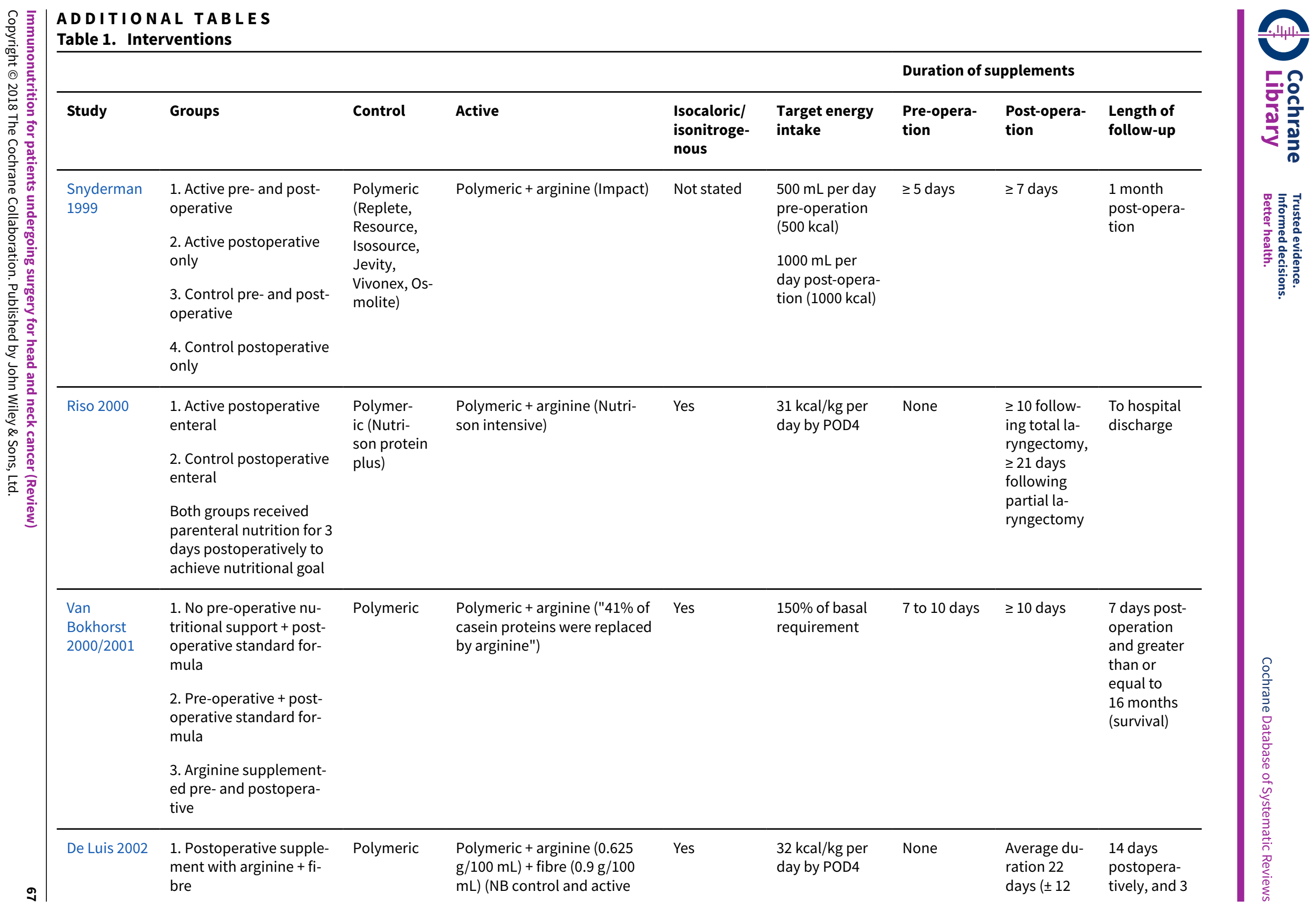




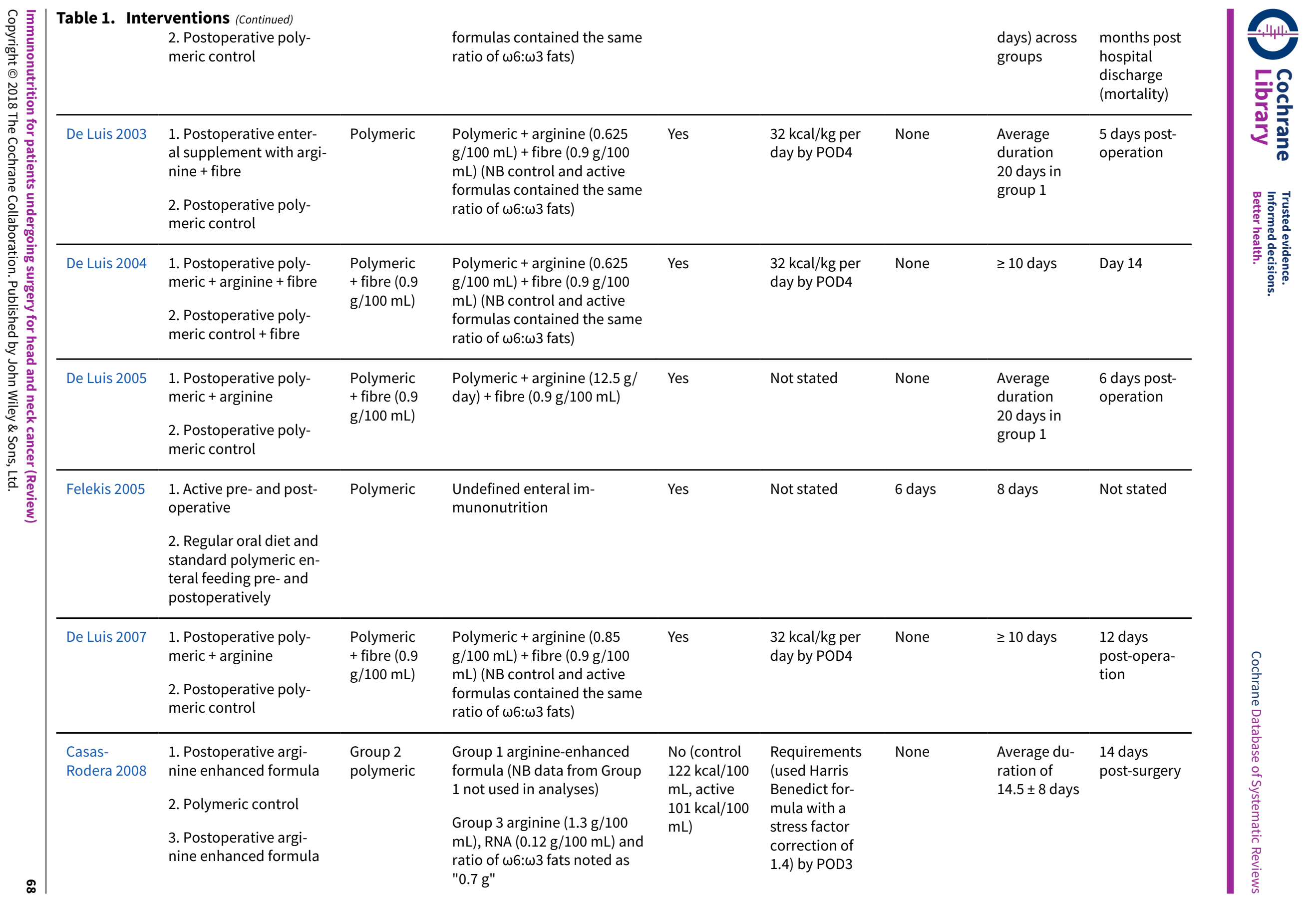




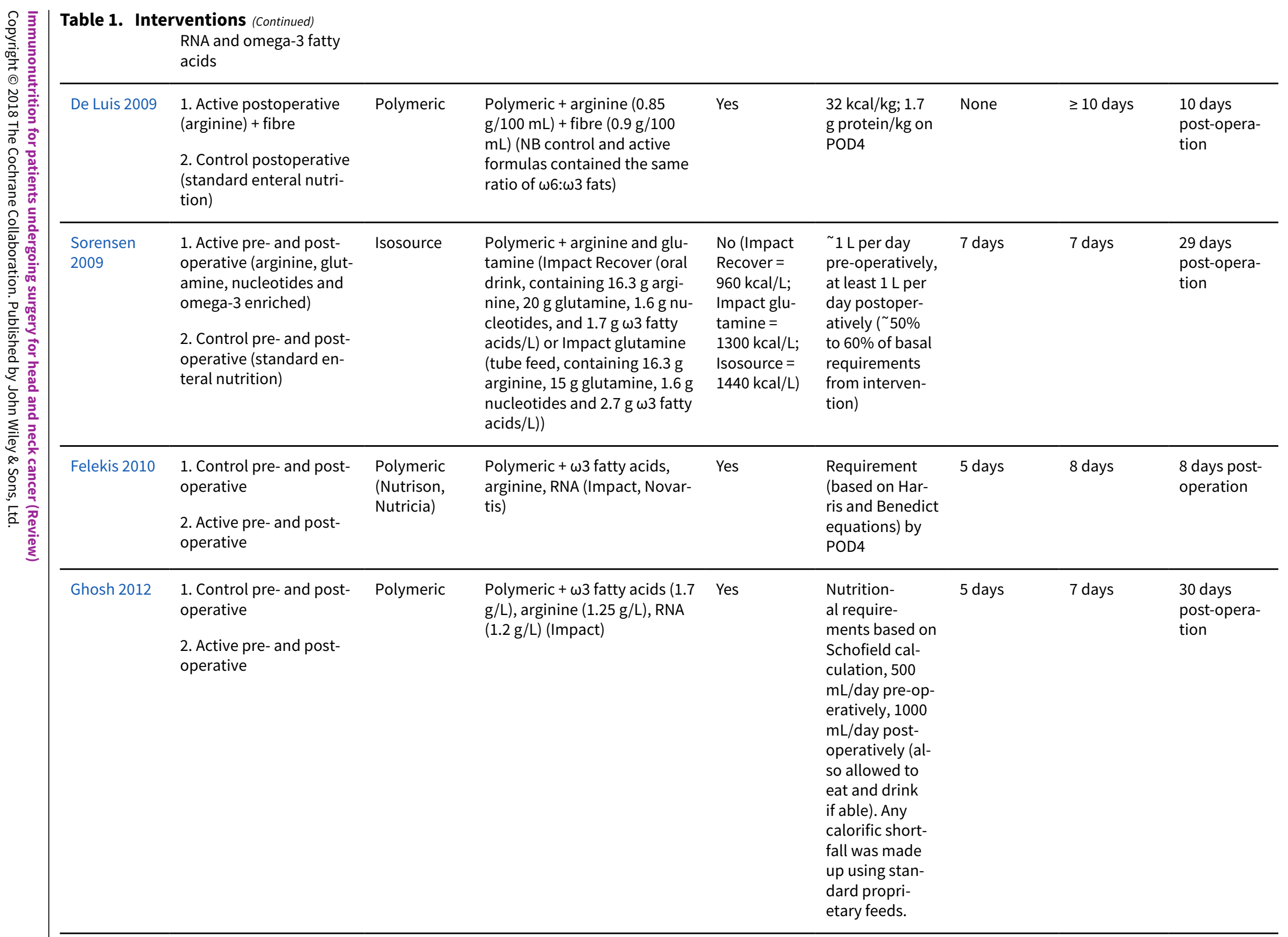


Table 1. Interventions (Continued)

Turnock 1. Control-no supple2013 ments pre-operation postoperative standard supplements standard

(postopera-

tive only)

2. Active - pre- (oral) and postoperative (enteral then oral to day 5) supplements

De Luis 2014 1. Active postoperative

2. Control postoperative

\section{Polymeric}

Polymeric + arginine $(8 \mathrm{~g} / \mathrm{L}$, $20 \mathrm{~g} /$ day) (NB control and active formulas contained the same ratio of $\omega 6: \omega 3$ fats and the same amount of fibre 13.8 $\mathrm{g} / \mathrm{L})$

Polymeric $+\omega 3$ fatty acids $(3.3$ and $1.7 \mathrm{~g} / \mathrm{L}$ EPA and DHA for oral and enteral products, respectively), arginine (12.6 and

$12.5 \mathrm{~g} / \mathrm{L}$ for oral and enteral products), RNA (1.3 and 1.2 $\mathrm{g} / \mathrm{L}$ for oral and enteral products) (Impact)
No (oral/en- Requirements teral Impact $1000 \mathrm{kcal} /$ L; Isosource

standard $1200 \mathrm{kcal} / \mathrm{L}$ )

(25 to $30 \mathrm{kcal} /$ $\mathrm{kg})$
5 days

$\geq 5$ days

Hospital discharge

\begin{tabular}{|c|c|c|c|c|c|c|c|c|}
\hline De Luis 2014 & $\begin{array}{l}\text { 1. Active postoperative } \\
\text { 2. Control postoperative }\end{array}$ & Polymeric & $\begin{array}{l}\text { Polymeric + arginine }(8 \mathrm{~g} / \mathrm{L} \text {, } \\
20 \mathrm{~g} / \text { day) (NB control and ac- } \\
\text { tive formulas contained the } \\
\text { same ratio of } \omega 6: \omega 3 \text { fats and } \\
\text { the same amount of fibre } 13.8 \\
\mathrm{~g} / \mathrm{L} \text { ) }\end{array}$ & $\begin{array}{l}\text { No (control } \\
1.118 \mathrm{kcal} / \mathrm{L} \text {, } \\
\text { active } 1.020 \\
\mathrm{kcal} / \mathrm{L} \text { ) }\end{array}$ & $\begin{array}{l}\text { Requirements } \\
\text { ( } 35 \mathrm{kcal} / \mathrm{kg}, 1.7 \\
\text { g protein } / \mathrm{kg} \text { ) }\end{array}$ & None & $\begin{array}{l}\text { Minimal of } \\
15 \text { days }\end{array}$ & $\begin{array}{l}10 \text { days } \\
\text { post-surgery }\end{array}$ \\
\hline $\begin{array}{l}\text { Falewee } \\
2014\end{array}$ & $\begin{array}{l}\text { 1. Pre- and postopera- } \\
\text { tive control } \\
\text { 2. Pre-operative active, } \\
\text { postoperative control } \\
\text { 3. Pre- and postopera- } \\
\text { tive active }\end{array}$ & $\begin{array}{l}\text { Impact } \\
\text { without im- } \\
\text { munonutri- } \\
\text { ents }\end{array}$ & $\begin{array}{l}\text { Polymeric + } \omega 3 \text { fatty acids ( } 1.0 \\
\text { g per sachet (oral) and } 1.65 \\
\text { g/500 mL (enteral)), arginine } \\
\text { (3.8 g per sachet (oral) and } 6.5 \\
\text { g/500 mL (enteral)), RNA ( } 0.45 \\
\text { g per sachet (oral) and } 0.65 \\
\text { g/500 mL (enteral)) (Oral Im- } \\
\text { pact preoperatively and En- } \\
\text { teral Impact postoperatively) }\end{array}$ & Yes & $\begin{array}{l}\text { Requirements } \\
\text { (calculated } \\
\text { using SFNEP } \\
\text { French recom- } \\
\text { mendations) }\end{array}$ & 7 days & 7 to 15 days & $\begin{array}{l}90 \text { days } \\
\text { post-surgery }\end{array}$ \\
\hline Azman 2015 & $\begin{array}{l}\text { 1. Postoperative active } \\
\text { 2. Postoperative no in- } \\
\text { tervention }\end{array}$ & None & $\begin{array}{l}\text { Glutamine powder ( } 30 \mathrm{~g} / \text { day) } \\
\text { (Glutamine Plus, Fresenius } \\
\text { Kabi) }\end{array}$ & $\begin{array}{l}\text { No control } \\
\text { intervention }\end{array}$ & $\begin{array}{l}30 \text { to } 40 \mathrm{kcal} / \\
\mathrm{kg} / \text { day }\end{array}$ & None & 4 weeks & $\begin{array}{l}4 \text { weeks } \\
\text { post-opera- } \\
\text { tion }\end{array}$ \\
\hline Hanai 2018 & $\begin{array}{l}\text { 1. Pre- and postopera- } \\
\text { tive active } \\
\text { 2. Pre-and postoperative } \\
\text { no intervention }\end{array}$ & None & $\begin{array}{l}\text { Prosure (an eicosapentaenoic } \\
\text { acid (EPA) enriched oral nutri- } \\
\text { tional supplement) at a dose } \\
\text { of } 2 \text { packs per day ( } 480 \mathrm{~mL} \text { ) }\end{array}$ & $\begin{array}{l}\text { No control } \\
\text { intervention }\end{array}$ & $\begin{array}{l}\text { Prosure was ad- } \\
\text { ministered in } \\
\text { addition to a } \\
\text { normal diet (or } \\
\text { in lieu of part } \\
\text { of a normal di- } \\
\text { et). Quote: "The } \\
\text { dietary intake } \\
\text { was not limit- } \\
\text { ed" }\end{array}$ & 14 days & 14 days & $\begin{array}{l}14 \text { days } \\
\text { post-opera- } \\
\text { tion }\end{array}$ \\
\hline
\end{tabular}




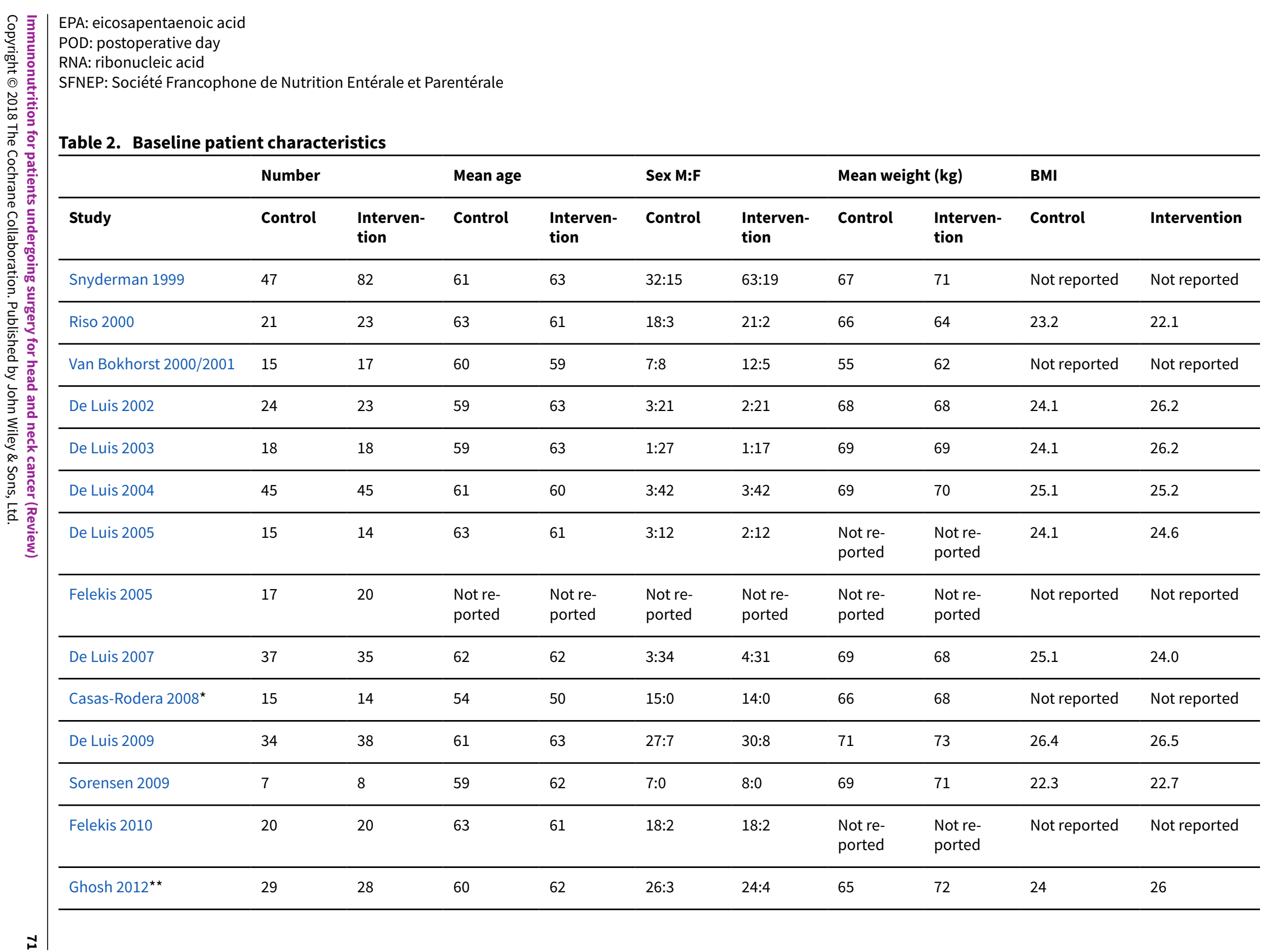




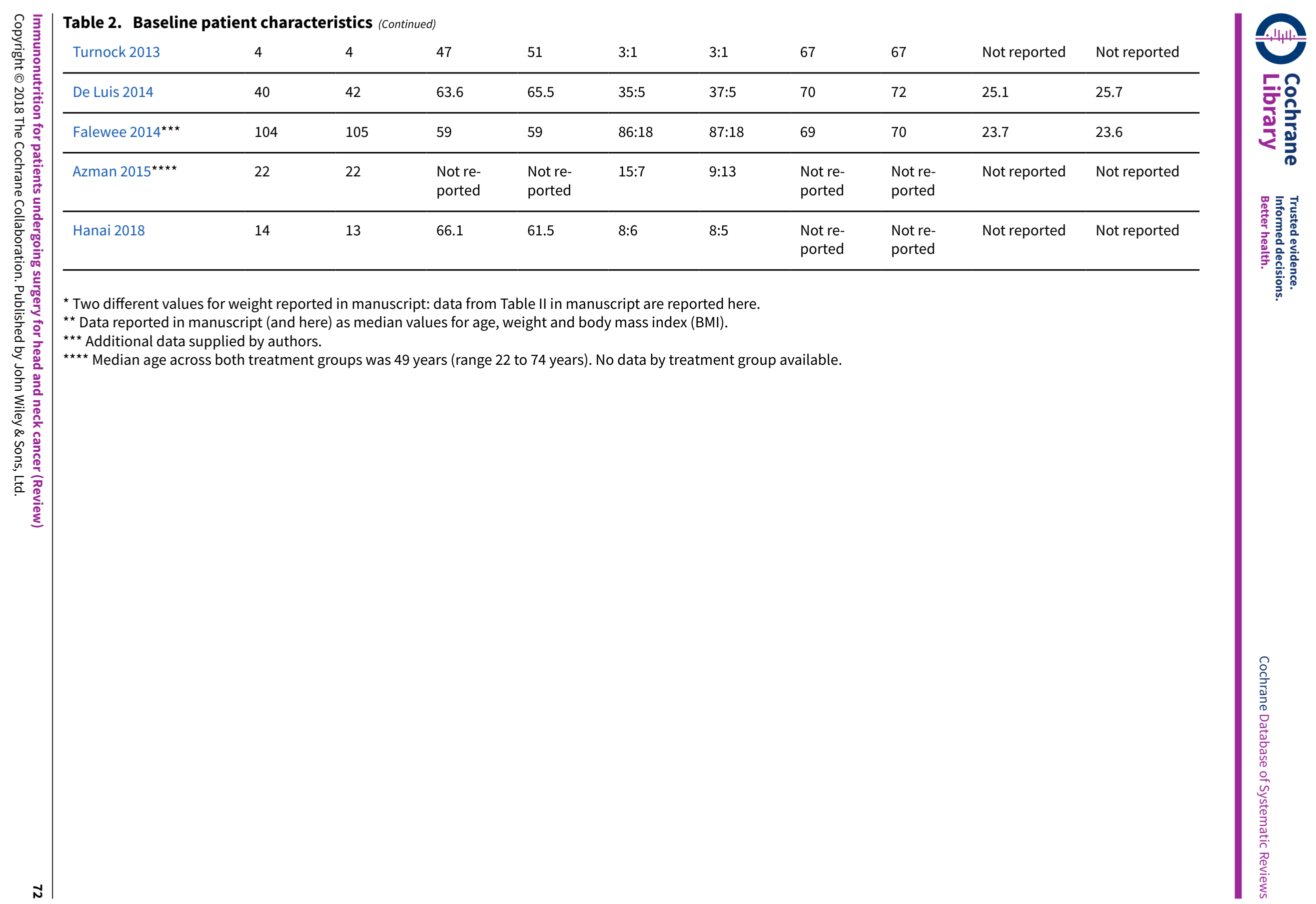


Table 3. Methodological quality of trials

\begin{tabular}{|c|c|c|c|c|c|c|}
\hline Study & $\begin{array}{l}\text { Generation of } \\
\text { allocation se- } \\
\text { quence }\end{array}$ & $\begin{array}{l}\text { Allocation con- } \\
\text { cealment }\end{array}$ & $\begin{array}{l}\text { Power cal- } \\
\text { culations }\end{array}$ & $\begin{array}{l}\text { Patients blind- } \\
\text { ed }\end{array}$ & $\begin{array}{l}\text { Assessors } \\
\text { blinded }\end{array}$ & $\begin{array}{l}\text { Analysed as inten- } \\
\text { tion-to-treat (ITT) }\end{array}$ \\
\hline $\begin{array}{l}\text { Snyderman } \\
1999\end{array}$ & Tables & Not stated & Not stated & $\begin{array}{l}\text { Unclear which } \\
\text { treatment } \\
\text { groups were } \\
\text { blinded }\end{array}$ & $\begin{array}{l}\text { Unclear which } \\
\text { treatment } \\
\text { groups were } \\
\text { blinded }\end{array}$ & Yes - stated ITT \\
\hline Riso 2000 & $\begin{array}{l}\text { Computer-gener- } \\
\text { ated }^{\star}\end{array}$ & $\begin{array}{l}\text { Sealed en- } \\
\text { velopes* (not } \\
\text { defined as } \\
\text { opaque) }\end{array}$ & Not done* & $\begin{array}{l}\text { Stated "dou- } \\
\text { ble-blindly per- } \\
\text { formed" but no } \\
\text { indication as to } \\
\text { who was blind- } \\
\text { ed* }^{*}\end{array}$ & $\begin{array}{l}\text { Stated "dou- } \\
\text { ble-blindly } \\
\text { performed" } \\
\text { but no indica- } \\
\text { tion as to who } \\
\text { was blinded* }\end{array}$ & $\begin{array}{l}\text { Yes - no attrition accord- } \\
\text { ing to number of partici- } \\
\text { pants included in analy- } \\
\text { ses }\end{array}$ \\
\hline $\begin{array}{l}\text { Van } \\
\text { Bokhorst } \\
2000 / 2001\end{array}$ & $\begin{array}{l}\text { Computer-gener- } \\
\text { ated }\end{array}$ & Not stated & Yes & Yes $^{\star \star}$ & Yes $^{\star \star}$ & $\begin{array}{l}\text { Yes - no attrition accord- } \\
\text { ing to number of par- } \\
\text { ticipants included in } \\
\text { analyses for relevant out- } \\
\text { comes }\end{array}$ \\
\hline $\begin{array}{l}\text { De Luis } \\
2002\end{array}$ & Tables ${ }^{\star}$ & $\begin{array}{l}\text { Sealed en- } \\
\text { velopes* (not } \\
\text { defined as } \\
\text { opaque) }\end{array}$ & Yes & Yes & Yes & $\begin{array}{l}\text { Yes - stated "Any drop- } \\
\text { outs were present in the } \\
\text { study" }\end{array}$ \\
\hline $\begin{array}{l}\text { De Luis } \\
2003\end{array}$ & Tables* & $\begin{array}{l}\text { Sealed en- } \\
\text { velopes (not } \\
\text { defined as } \\
\text { opaque) }\end{array}$ & Yes* & Yes & Yes & Yes - stated ITT \\
\hline
\end{tabular}

\begin{tabular}{|c|c|c|c|c|c|c|}
\hline $\begin{array}{l}\text { De Luis } \\
2004\end{array}$ & Tables* & $\begin{array}{l}\text { Sealed en- } \\
\text { velopes }{ }^{\star} \text { (not } \\
\text { defined as } \\
\text { opaque) }\end{array}$ & Yes & $\begin{array}{l}\text { States blinded, } \\
\text { but no indication } \\
\text { as to who was } \\
\text { blinded* }\end{array}$ & $\begin{array}{l}\text { States blind- } \\
\text { ed, but no in- } \\
\text { dication as } \\
\text { to who was } \\
\text { blinded* }\end{array}$ & Yes - stated ITT \\
\hline
\end{tabular}

\begin{tabular}{|c|c|c|c|c|c|c|}
\hline $\begin{array}{l}\text { De Luis } \\
2005\end{array}$ & Tables* & $\begin{array}{l}\text { Sealed en- } \\
\text { velopes (not } \\
\text { defined as } \\
\text { opaque) }\end{array}$ & Yes $^{\star}$ & $\begin{array}{l}\text { Stated "Study } \\
\text { was blinded" but } \\
\text { no indication } \\
\text { as to who was } \\
\text { blinded }\end{array}$ & $\begin{array}{l}\text { Stated "Study } \\
\text { was blinded" } \\
\text { but no indica- } \\
\text { tion as to who } \\
\text { was blinded }\end{array}$ & Yes - stated ITT \\
\hline $\begin{array}{l}\text { Felekis } \\
2005\end{array}$ & Not stated & Not stated & Not stated & Not stated & Not stated & Not stated \\
\hline $\begin{array}{l}\text { De Luis } \\
2007\end{array}$ & Tables* & $\begin{array}{l}\text { Envelopes }{ }^{\star} \\
\text { (not defined as } \\
\text { opaque) }\end{array}$ & Yes & $\begin{array}{l}\text { States blinded, } \\
\text { but no indication } \\
\text { as to who was } \\
\text { blinded* }\end{array}$ & $\begin{array}{l}\text { States blind- } \\
\text { ed, but no in- } \\
\text { dication as } \\
\text { to who was } \\
\text { blinded* }\end{array}$ & Yes - stated ITT \\
\hline
\end{tabular}

\begin{tabular}{|c|c|c|c|c|c|c|}
\hline $\begin{array}{l}\text { Casas- } \\
\text { Rodera } \\
2008\end{array}$ & $\begin{array}{l}\text { Stated "random- } \\
\text { ly allocated" } \\
\text { but no informa- } \\
\text { tion on how se- }\end{array}$ & Not stated & Not stated & Not stated & Not stated & $\begin{array}{l}\text { Yes - stated "no dropouts } \\
\text { were present in the } \\
\text { study" }\end{array}$ \\
\hline
\end{tabular}


Table 3. Methodological quality of trials (Continued)

quence was gen-

erated

\begin{tabular}{|c|c|c|c|c|c|c|}
\hline $\begin{array}{l}\text { De Luis } \\
2009\end{array}$ & $\begin{array}{l}\text { Stated "random- } \\
\text { ly allocated" } \\
\text { but no informa- } \\
\text { tion on how se- } \\
\text { quence was gen- } \\
\text { erated }\end{array}$ & Not stated & Yes & Yes & Yes & Yes - stated ITT \\
\hline $\begin{array}{l}\text { Sorensen } \\
2009\end{array}$ & $\begin{array}{l}\text { Stated as a "ran- } \\
\text { domized design" } \\
\text { but no informa- } \\
\text { tion on how se- } \\
\text { quence was gen- } \\
\text { erated }\end{array}$ & $\begin{array}{l}\text { Envelopes (not } \\
\text { defined as } \\
\text { opaque) }\end{array}$ & Not done & Partial & Partial & $\begin{array}{l}\text { Unclear - no statement } \\
\text { on dropouts }\end{array}$ \\
\hline $\begin{array}{l}\text { Felekis } \\
2010\end{array}$ & $\begin{array}{l}\text { Stated "random- } \\
\text { ization genera- } \\
\text { tor" }\end{array}$ & Not clear & Not done* & $\begin{array}{l}\text { Stated "double } \\
\text { blinded" but no } \\
\text { indication as to } \\
\text { who was blinded }\end{array}$ & $\begin{array}{l}\text { Stated "dou- } \\
\text { ble blinded" } \\
\text { but no indica- } \\
\text { tion as to who } \\
\text { was blinded }\end{array}$ & $\begin{array}{l}\text { Yes - no loss to follow-up } \\
\text { described and stated "no } \\
\text { dropouts occurred due to } \\
\text { intolerance" }\end{array}$ \\
\hline Ghosh 2012 & $\begin{array}{l}\text { "Randomisation } \\
\text { lists" (pharma- } \\
\text { cy clinical trials } \\
\text { unit) }\end{array}$ & $\begin{array}{l}\text { Pharmacy (cen- } \\
\text { tral telephone } \\
\text { assignment) }\end{array}$ & Yes & Yes & Yes & Yes - stated ITT \\
\hline $\begin{array}{l}\text { Turnock } \\
2013\end{array}$ & $\begin{array}{l}\text { Computer-gener- } \\
\text { ated }\end{array}$ & $\begin{array}{l}\text { Opaque, sealed } \\
\text { envelopes }\end{array}$ & Pilot study & No & No & $\begin{array}{l}\text { Yes - no attrition accord- } \\
\text { ing to number of partici- } \\
\text { pants included in analy- } \\
\text { ses }\end{array}$ \\
\hline $\begin{array}{l}\text { De Luis } \\
2014\end{array}$ & Not stated & Not stated & Not stated & Yes & Yes & Yes - no attrition \\
\hline $\begin{array}{l}\text { Falewee } \\
2014\end{array}$ & $\begin{array}{l}\text { Computer-gener- } \\
\text { ated }\end{array}$ & $\begin{array}{l}\text { Pharmacy clini- } \\
\text { cal trials unit }\end{array}$ & Yes & Yes & Yes & Yes $^{\star}$ \\
\hline $\begin{array}{l}\text { Azman } \\
2015\end{array}$ & $\begin{array}{l}\text { Random ballot } \\
\text { picking }\end{array}$ & $\begin{array}{l}\text { Sealed en- } \\
\text { velopes (not } \\
\text { defined as } \\
\text { opaque) }\end{array}$ & Yes & No & No & Yes \\
\hline Hanai 2018 & Not stated & Not stated & Yes & $\begin{array}{l}\text { Not stated, but } \\
\text { assumed non- } \\
\text { blinded as inter- } \\
\text { vention group } \\
\text { received sa- } \\
\text { chets and con- } \\
\text { trol group re- } \\
\text { ceived no inter- } \\
\text { vention }\end{array}$ & Not stated & $\begin{array}{l}\text { Yes - stated ITT (NB: } 1 \text { pa- } \\
\text { tient, quote "Excluded } \\
\text { due to incomplete data") }\end{array}$ \\
\hline
\end{tabular}

${ }^{\star}$ Additional information provided by authors.

${ }^{\star \star}$ Groups 2 and 3 included in analyses; authors stated that these groups were blinded. 


\begin{tabular}{|c|c|c|c|c|c|c|c|c|c|}
\hline & \multicolumn{2}{|l|}{ Number } & \multirow[t]{2}{*}{ Other complications definition } & \multicolumn{2}{|c|}{$\begin{array}{l}\text { Other complications - } \\
\text { total }\end{array}$} & \multicolumn{2}{|c|}{ Pneumonia } & \multicolumn{2}{|c|}{ Urinary tract } \\
\hline Study & Control & $\begin{array}{l}\text { Interven- } \\
\text { tion }\end{array}$ & & Control & $\begin{array}{l}\text { Interven- } \\
\text { tion }\end{array}$ & Control & $\begin{array}{l}\text { Interven- } \\
\text { tion }\end{array}$ & Control & $\begin{array}{l}\text { Interven- } \\
\text { tion }\end{array}$ \\
\hline \multicolumn{10}{|c|}{ Pre- and postoperative feeding } \\
\hline $\begin{array}{l}\text { Snyder- } \\
\text { man } 1999\end{array}$ & 47 & 82 & $\begin{array}{l}\text { "...infectious complications were judged us- } \\
\text { ing CDC criteria and were considered signifi- } \\
\text { cant if antibiotic therapy was instituted" (NB: } \\
\text { total for other complications provided here } \\
\text { include "postoperative infection" butnot } \\
\text { "wound healing problem" or "fistula") }\end{array}$ & 19 & 19 & - & - & - & - \\
\hline $\begin{array}{l}\text { Van } \\
\text { Bokhorst } \\
2000 / 2001\end{array}$ & 15 & 17 & $\begin{array}{l}\text { "Postoperative complications were cate- } \\
\text { gorized as absent, minor (including minor } \\
\text { wound infections, redness and induration of } \\
\text { the wound, pulmonary infections, and urinary } \\
\text { tract infections), or major (including wound } \\
\text { infections requiring surgical drainage, orocu- } \\
\text { taneous or pharyngocutaneous fistula, flap } \\
\text { failure, radiologic signs of anastomotic leak- } \\
\text { age, respiratory insufficiency, cardiac failure, } \\
\text { and septic shock)" (NB: data on individual } \\
\text { complications not given in manuscript so the } \\
\text { total for other complications provided here } \\
\text { may include fistula and wound infection) }\end{array}$ & 7 major & 10 major & - & - & - & - \\
\hline $\begin{array}{l}\text { Felekis } \\
2005\end{array}$ & 17 & 20 & $\begin{array}{l}\text { Reported as major and minor, but otherwise } \\
\text { not defined }\end{array}$ & $\begin{array}{l}9 \text { ( } 6 \text { major, } \\
3 \text { minor })\end{array}$ & $\begin{array}{l}4 \text { ( } 2 \text { major, } \\
2 \text { minor) }\end{array}$ & - & - & - & - \\
\hline $\begin{array}{l}\text { Sorensen } \\
2009\end{array}$ & 7 & 8 & $\begin{array}{l}\text { "Serious wound complications were record- } \\
\text { ed as they occurred and included wound in- } \\
\text { fection, wound dehiscence, and wound fis- } \\
\text { tula. Wound assessments using the ASEPSIS } \\
\text { scoring method were performed daily and } \\
\text { photographic images were taken on sever- } \\
\text { al postoperative days." Authors also noted } \\
\text { that "Patients may have had more than one } \\
\text { complication" (NB: figures provided here in- } \\
\text { clude "wound dehiscence" (classed as major) } \\
\text { and "other" (urinary tract infection and noso- } \\
\text { comial pneumonia combined as one group) }\end{array}$ & $\begin{array}{l}2 \text { (0 major } \\
2 \text { minor) }\end{array}$ & $\begin{array}{l}5 \text { (1 major } \\
\text { - wound } \\
\text { dehis- } \\
\text { cence; } 4 \\
\text { minor) }\end{array}$ & - & - & - & - \\
\hline
\end{tabular}




\begin{tabular}{|c|c|c|c|c|c|c|c|c|c|}
\hline \multirow{3}{*}{ 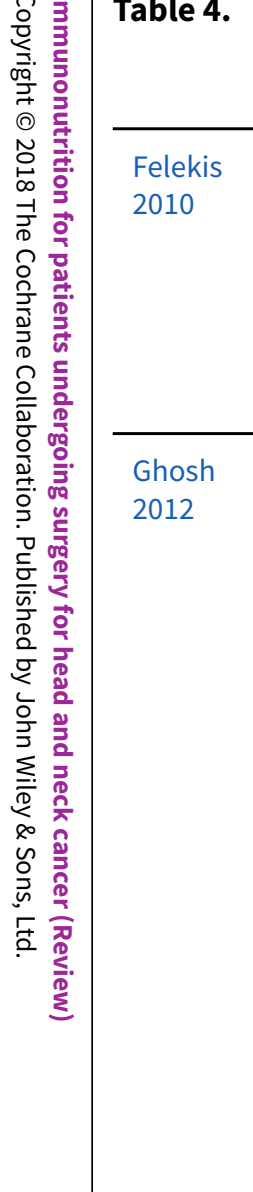 } & \multicolumn{2}{|c|}{ 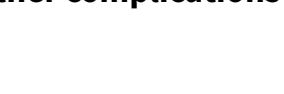 } & \multicolumn{4}{|l|}{$\begin{array}{l}\text { (classed as minor) but exclude "wound fistu- } \\
\text { la" and "wound infection"). }\end{array}$} & \multirow[b]{2}{*}{0} & \multirow[b]{2}{*}{1} & \multirow[b]{2}{*}{0} \\
\hline & 20 & 20 & $\begin{array}{l}\text { Minor described in results as "a slight in- } \\
\text { crease of the temperature }\left(<38^{\circ}\right) \text {, without an } \\
\text { identifiable source of infection". Major de- } \\
\text { scribed in results as including pneumonia, } \\
\text { urinary tract infection, fistula and wound in- } \\
\text { fection. NB: figures provided here do not in- } \\
\text { clude fistula and wound infection. }\end{array}$ & $\begin{array}{l}6 \text { ( } 3 \text { minor, } \\
3 \text { major - } \\
2 \text { pneumo- } \\
\text { nia, } 1 \text { UTI) }\end{array}$ & $\begin{array}{l}2 \text { (2 minor, } \\
0 \text { major) }\end{array}$ & 2 & & & \\
\hline & 29 & 28 & $\begin{array}{l}\text { "The primary outcome event was defined as } \\
\text { any patient with an infection of the lower res- } \\
\text { piratory tract, gastro-intestinal tract, urinary } \\
\text { tract or blood which required antibiotic treat- } \\
\text { ment and occurred at any time, up to the 30th } \\
\text { post-operative day." } \\
\text { "Secondary outcome measures included in- } \\
\text { fections of primary surgical site, neck wound, } \\
\text { PEG site, tracheostomy, free-flap or split skin } \\
\text { graft donor site." } \\
\text { "...the surgical site/wound infections were de- } \\
\text { fined according to CDC Definitions of Noso- } \\
\text { comial Surgical Site infections, } 1992 \text { and the } \\
\text { ASEPSIS wound score. The diagnosis of the } \\
\text { non-wound infection was as stipulated in the } \\
\text { Trial Antibiotic Policy, which also governed } \\
\text { how any infective complication diagnosed } \\
\text { throughout the trial was to be treated." }\end{array}$ & $\begin{array}{l}8 \text { with } \\
\text { chest, } \\
\text { urinary, } \\
\text { gastroin- } \\
\text { testinal or } \\
\text { blood in- } \\
\text { fection } \\
17 \text { with } \\
\text { neck, pri- } \\
\text { mary site, } \\
\text { donor site, } \\
\text { or PEG site } \\
\text { infection }\end{array}$ & $\begin{array}{l}12 \text { with } \\
\text { chest, } \\
\text { urinary, } \\
\text { gastroin- } \\
\text { testinal or } \\
\text { blood in- } \\
\text { fection } \\
17 \text { with } \\
\text { neck, pri- } \\
\text { mary site, } \\
\text { donor site, } \\
\text { or PEG site } \\
\text { infection }\end{array}$ & 4 & 9 & 1 & 2 \\
\hline $\begin{array}{l}\text { Turnock } \\
2013\end{array}$ & 4 & 4 & $\begin{array}{l}\text { "General infections (urinary tract infection, } \\
\text { respiratory tract infection), flap anastomo- } \\
\text { sis complications (venous or arterial), and } \\
\text { wound complications (dehiscence, tissue } \\
\text { necrosis, haematoma, chyle leak, salivary fis- } \\
\text { tula or wound infection) were recorded. Infec- } \\
\text { tious complications were judged using CDC } \\
\text { criteria and were considered significant if an- } \\
\text { tibiotic therapy was instituted." (NB: figures } \\
\text { provided here do not include wound infec- } \\
\text { tion). }\end{array}$ & $\begin{array}{l}2 \text { (infec- } \\
\text { tious) }\end{array}$ & 0 & - & - & - & - \\
\hline $\begin{array}{l}\text { Falewee } \\
2014^{*}\end{array}$ & 104 & 105 & $\begin{array}{l}\text { Infectious complications: "systemic infection } \\
\text { requiring antibiotic treatment (septicaemia, }\end{array}$ & - & - & - & - & - & - \\
\hline
\end{tabular}




\begin{tabular}{|c|c|c|c|c|c|c|c|c|c|}
\hline & & & $\begin{array}{l}\text { bacteraemia), surgical site infection (accord- } \\
\text { ing to CDC Definitions of Nosocomial Surgi- } \\
\text { cal Site infections), documented nosocomial } \\
\text { pneumopathy, up to the 30th post-operative } \\
\text { day." } \\
\text { Surgical site infections (SSI): "primary surgi- } \\
\text { cal site, neck wound, free-flap or split skin } \\
\text { graft donor site, and tracheotomy" }\end{array}$ & & & & & & \\
\hline $\begin{array}{l}\text { Hanai } \\
2018\end{array}$ & 14 & 13 & $\begin{array}{l}\text { Clinical complications presented as numbers } \\
\text { of patients with "wound complications" clas- } \\
\text { sified according to Clavien-Dindo system }\end{array}$ & 7 & 4 & - & - & - & - \\
\hline \multicolumn{10}{|c|}{ Postoperative feeding only } \\
\hline Riso 2000 & 21 & 23 & $\begin{array}{l}\text { "Post-operative complications were recorded } \\
\text { as none, minor (urinary tract infection; respi- } \\
\text { ratory tract infection: abnormal chest X-ray), } \\
\text { and major (fistula; wound infection; sponta- } \\
\text { neous or surgical purulent drainage and flap } \\
\text { necrosis; anastomotic leakage)." (NB: figures } \\
\text { provided here exclude reported fistula). }\end{array}$ & $\begin{array}{l}4 \text { major } \\
\text { (1 flap } \\
\text { necrosis, } \\
3 \text { purulent } \\
\text { drainage) } \\
1 \text { minor } \\
\text { (respirato- } \\
\text { ry tract) }\end{array}$ & $\begin{array}{l}2 \text { (pu- } \\
\text { rulent } \\
\text { drainage) }\end{array}$ & $\begin{array}{l}1 \text { (respira- } \\
\text { tory tract) }\end{array}$ & 0 & 0 & 0 \\
\hline $\begin{array}{l}\text { De Luis } \\
2002\end{array}$ & 24 & 23 & $\begin{array}{l}\text { "Postoperative complications were record- } \\
\text { ed as none, general infections (respiratory } \\
\text { tract infection was diagnosed when the chest } \\
\text { radiographic examination showed new or } \\
\text { progressive unfiltration, temperature above } \\
38.5^{\circ} \mathrm{C} \text { and isolation of pathogens from the } \\
\text { sputum or blood culture and/or urinary tract } \\
\text { infection was diagnosed if the urine culture } \\
\text { showed at least } 10^{5} \text { colonies of a pathogen) } \\
\text { and local complications such as fistula and/or } \\
\text { wound infection, assessing all complications } \\
\text { using standard methods and the same inves- } \\
\text { tigator." (NB: figures provided here exclude } \\
\text { reported fistula). }\end{array}$ & 4 & 5 & - & - & - & - \\
\hline $\begin{array}{l}\text { De Luis } \\
2003\end{array}$ & 18 & 18 & Not collected & - & - & - & - & - & - \\
\hline
\end{tabular}




\begin{tabular}{|c|c|c|c|c|c|c|c|c|c|}
\hline $\begin{array}{l}\text { De Luis } \\
2004\end{array}$ & 45 & 45 & $\begin{array}{l}\text { "Postoperative complications were record- } \\
\text { ed as none, general infections (respiratory } \\
\text { tract infection was diagnosed when the chest } \\
\text { radiographic examination showed new or } \\
\text { progressive unfiltration, temperature above } \\
38.5^{\circ} \mathrm{C} \text { and isolation of pathogens from the } \\
\text { sputum or blood culture and/or urinary tract } \\
\text { infection was diagnosed if the urine culture } \\
\text { showed at least } 10^{5} \text { colonies of a pathogen) } \\
\text { and local complications such as fistula and/or } \\
\text { wound infection. All complications were as- } \\
\text { sessed with standard methods by the same } \\
\text { investigator." (NB: figures provided here ex- } \\
\text { clude reported fistula). }\end{array}$ & 4 & 2 & - & - & - & - \\
\hline $\begin{array}{l}\text { De Luis } \\
2005\end{array}$ & 15 & 14 & Not collected & - & - & - & - & - & - \\
\hline $\begin{array}{l}\text { De Luis } \\
2007\end{array}$ & 37 & 35 & $\begin{array}{l}\text { "Postoperative complications were record- } \\
\text { ed as none; general infections (respiratory } \\
\text { tract infection was diagnosed when the chest } \\
\text { radiographic examination showed new or } \\
\text { progressive unfiltration, temperature above } \\
38.5^{\circ} \mathrm{C} \text { and isolation of pathogens from the } \\
\text { sputum or blood culture and/or urinary tract } \\
\text { infection was diagnosed if the urine culture } \\
\text { showed at least } 10^{5} \text { colonies of a pathogen) } \\
\text { and wound complications, such as fistula } \\
\text { and/or wound infection, assessed all compli- } \\
\text { cations with standard methods by the same } \\
\text { investigator surgeon." (NB: figures provided } \\
\text { here exclude reported fistula). }\end{array}$ & 2 & 2 & - & - & - & - \\
\hline $\begin{array}{l}\text { Casas- } \\
\text { Rodera } \\
2008\end{array}$ & 15 & 14 & $\begin{array}{l}\text { "Postoperative complications were record- } \\
\text { ed as none, general infections (respiratory } \\
\text { tract infection was diagnosed when the chest } \\
\text { radiographic examination showed new or } \\
\text { progressive unfiltration, temperature above } \\
38.5^{\circ} \mathrm{C} \text { and isolation of pathogens from the } \\
\text { sputum or blood culture and/or urinary tract } \\
\text { infection was diagnosed if the urine culture } \\
\text { showed at least } 10^{5} \text { colonies of a pathogen), } \\
\text { and wound complications such as fistula and/ } \\
\text { or wound infection. All complications were }\end{array}$ & 1 & 0 & 1 & 0 & 0 & 0 \\
\hline
\end{tabular}




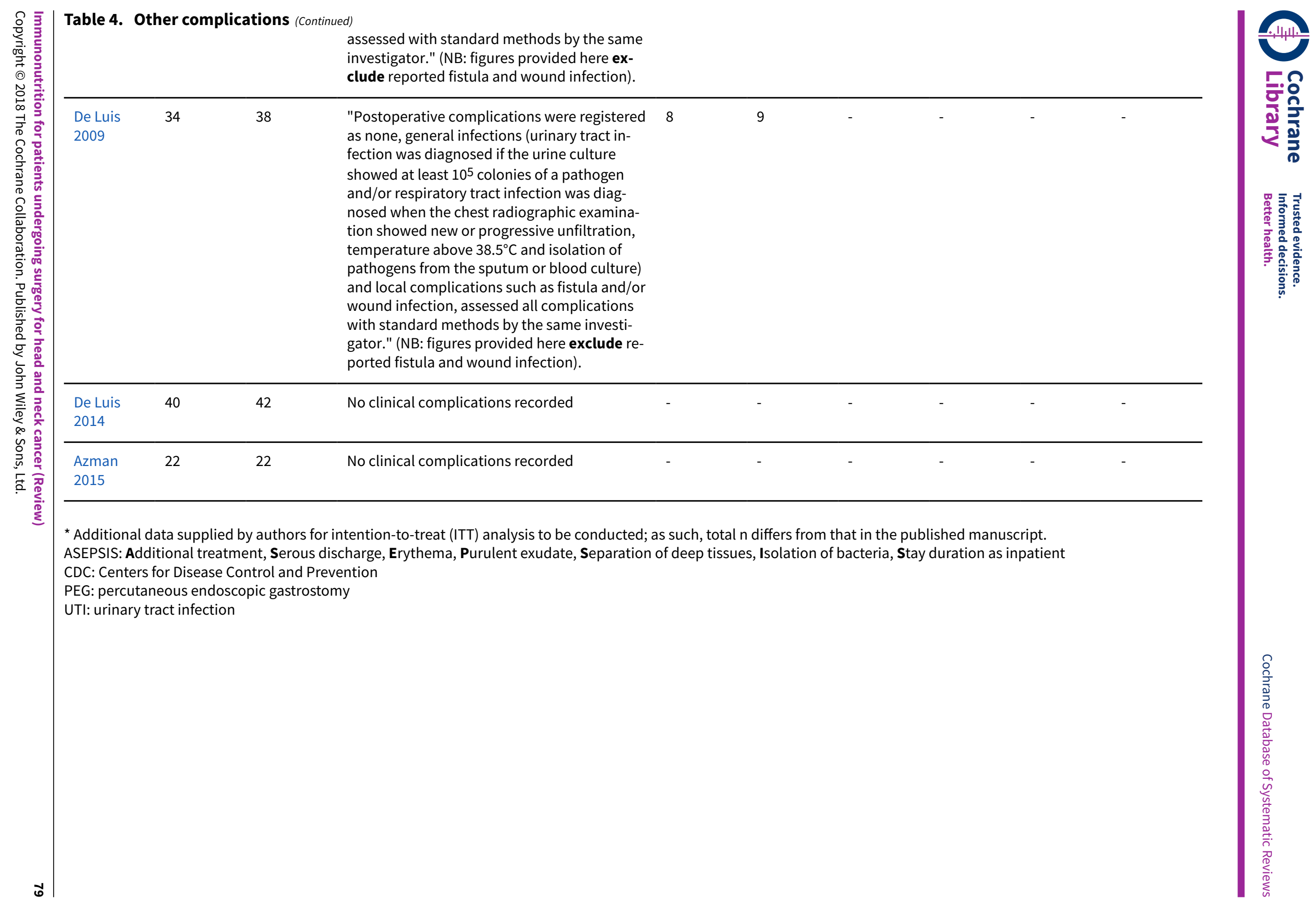




\section{AP PEN DICES}

\section{Appendix 1. Search strategies}

\section{CENTRAL (via Cochrane Register of Studies)}

\section{\#1 MESH DESCRIPTOR Head and Neck Neoplasms EXPLODE ALL TREES WITH QUALIFIERS SU \\ \#2 MESH DESCRIPTOR Otorhinolaryn- gologic Neoplasms EXPLODE ALL TREES WITH QUALIFIERS SU}

\#3 MESH DESCRIPTOR Otorhinolaryngologic Neoplasms EXPLODE ALL TREES

\#4 MESH DESCRIPTOR Head and Neck Neoplasms EXPLODE ALL TREES

\#5 (head near neck):TI,AB,KY

\#6 ((larynx or laryngeal or glottis or glottic or "oral cavity" or nasopharynx or nasopharyngeal or hypopharynx or hypopharyngeal or pharynx or pharyngeal or parapharyngeal or mouth)):TI,AB,KY

\#7 (face or facial or oesophageal or esophageal or oesophagus or esophagus or thyroid or salivary or paranasal or "aero digestive" or aerodigestive or aerodigestive):TI,AB,KY

\section{\#8 \#5 OR \#6 OR \#7}

\#9 ((cancer ${ }^{\star}$ or carcinoma* or neoplasm $^{\star}$ or tumor ${ }^{\star}$ or tumour ${ }^{\star}$ or metas$\left.\left.\operatorname{tas}^{\star}\right)\right): T I, A B, K Y$

\#10 MESH DESCRIPTOR Neoplasms EXPLODE ALL TREES

\#11 \#9 OR \#10

\#12 \#8 AND \#11

\section{\#13 \#3 OR \#4 OR \#12}

\#14 MESH DESCRIPTOR Surgical Procedures, Operative EXPLODE ALL TREES

\#15 ((surg* or resect $^{\star}$ or reconstruc$\left.\left.\mathrm{t}^{\star}\right)\right): \mathrm{TI}, \mathrm{AB}, \mathrm{KY}$

\#16 ((pharyngectomy or laryngopharyngectomy or laryngectomy or mandibulectomy or commando or esophagectomy or oesophagectomy)):TI,AB,KY

\#17 ((neck and dissect $\left.\left.{ }^{\star}\right)\right): T I, A B, K Y$

\section{EMBASE (Ovid)}

\section{\#1 ("Head and Neck Neo- plasms/surgery"[Mesh])}

\#2 "Otorhinolaryngologic Neoplasms/surgery"[Mesh]

\#3 ("Head and Neck Neoplasms"[Mesh])

\#4 "Otorhinolaryngologic Neoplasms"[Mesh]

\#5 ("head neck" OR head-neck OR "head and neck" OR head-and-neck[Title/Abstract])

\#6 (larynx or laryngeal or glottis or glottic or "oral cavity" or nasopharynx or nasopharyngeal or hypopharynx or hypopharyngeal or pharynx or pharyngeal or parapharyngeal or mouth[Title/Abstract])

\#7 (face or facial or oesophageal or esophageal or oesophagus or esophagus or thyroid or salivary or paranasal or "aero digestive" or aerodigestive or aero-digestive[ $\mathrm{Ti}$ tle/Abstract])

\section{\#8 (\#5 OR \#6 OR \#7)}

\#9 (cancer* or carcinoma* or neoplasm* or tumor ${ }^{\star}$ or tumour* or metastas* [Title/Abstract])

\#10 "Neoplasms"[Mesh]

\#11 (\#9 OR \#10)

\#12 (\#8 AND \#11)

\section{\#13 (\#3 OR \#4 OR \#12)}

\#14 "Surgical Procedures, Operative"[Mesh]

\#15 (surg* or resect* or reconstruct* ${ }^{\star}[$ Title/Abstract])

\#16 (pharyngectomy or laryngopharyngectomy or laryngectomy or mandibulectomy or commando or esophagectomy or oesophagectomy[Title/Abstract])

\#17 (neck and dissect*[Title/Abstract])

\#18 "Neck Dissection"[Mesh]

\#19 ((free or myocutaneous[Title/Abstract])) AND flap[Title/Abstract]
1 exp "head and neck tumor"/su [Surgery]

2 exp *"head and neck tumor"/

3 (head adj3 neck).tw.

4 (larynx or laryngeal or glottis or glottic or "oral cavity" or nasopharynx or nasopharyngeal or hypopharynx or hypopharyngeal or pharynx or pharyngeal or parapharyngeal or mouth).tw.

5 (face or facial or oesophageal or esophageal or oesophagus or esophagus or thyroid or salivary or paranasal or "aero digestive" or aerodigestive or aero-digestive).tw.

63 or 4 or 5

7 (cancer $^{\star}$ or carcinoma* or neoplasm * or tumor ${ }^{\star}$ or tumour ${ }^{\star}$ or metas$\left.\operatorname{tas}^{\star}\right)$.tw.

8 exp *neoplasm/

97 or 8

106 and 9

112 or 10

12 exp surgery/

13 (surg $^{\star}$ or resect ${ }^{\star}$ or reconstruc$\left.t^{\star}\right) . t w$.

14 (pharyngectomy or laryngopharyngectomy or laryngectomy or mandibulectomy or commando or esophagectomy or oesophagectomy).tw.

15 (neck and dissect*).tw.

16 exp neck dissection/

17 ((free or myocutaneous) and flap).tw.

1812 or 13 or 14 or 15 or 16 or 17

1911 and 18 
(Continued)

\#18 MESH DESCRIPTOR Neck Dissection EXPLODE ALL TREES

\#19 (((free or myocutaneous) and flap)):TI,AB,KY

\#20 \#14 OR \#15 OR \#16 OR \#17 OR \#18 OR \#19

\section{\#21 \#13 AND \#20}

\#22 \#1 OR \#2 OR \#21

\#23 MESH DESCRIPTOR Arginine EXPLODE ALL TREES

\#24 (immuno or arginine* or glutamine* or nucleotide* or omega-3 or omega3 or omega- 6 or omega 6 or " $\omega-3$ " or nucleoside $^{\star}$ or fibre* or fiber ${ }^{\star}$ or IMP1000 or IMP500 or immunostimulat* or immuno-stimulat $\left.{ }^{\star}\right): T I, A B, K Y$

\#25 MESH DESCRIPTOR Fatty Acids, Omega-3 EXPLODE ALL TREES

\#26 MESH DESCRIPTOR Fatty Acids, Omega-6 EXPLODE ALL TREES

\#27 MESH DESCRIPTOR Glutamine EXPLODE ALL TREES

\#28 MESH DESCRIPTOR Nucleotides EXPLODE ALL TREES

\#29 MESH DESCRIPTOR Dietary Fiber EXPLODE ALL TREES

\#30 (Argininosuccinic* or Benzoylarginine* or Homoarginine* or Nitroarginine $^{\star}$ or Tosylarginine ${ }^{\star}$ or Methylarginine $^{\star}$ or NO2Arg or NOARG or L-NMMA or D-NMMA or TAME or Proglumide* or Xylamide* or Xilamide or Milid or PUFA* $^{*}$ or "n-3 fatty acid" or Docosahexaen* or Neuroprostane* or Icosapentaenoic* or Timnodonic or Linoleic* or Linolenic* or Octadecadienoic* or Linoleate* or Linoelaidic or "n-6 fatty acid $^{*}$ or Eicosapentaenoic or EPA or O-3FA ${ }^{\star}$ or $\left.0-6 \mathrm{FA}^{\star}\right): \mathrm{TI}, \mathrm{AB}, \mathrm{KY}$

\#31 \#23 OR \#24 OR \#25 OR \#26 OR \#27 OR \#28 OR \#29 OR \#30

\#32 (enteral or polymeric* or Parenteral or diet ${ }^{\star}$ or feed ${ }^{\star}$ or food ${ }^{\star}$ or supplement ${ }^{\star}$ or nutri* or formul* or tpn or enteric or Nutraceutical ${ }^{\star}$ or tube* or pn or SEN or "Ensure Liquid*"):TI,AB,KY

\#33 MESH DESCRIPTOR Nutrition Therapy EXPLODE ALL TREES
\#20 (\#14 OR \#15 OR \#16 OR \#17 OR \#18 OR
\#19)

\#21 (\#13 AND \#20)

\#22 (\#1 OR \#2 OR \#21)

\#23 "Arginine"[Mesh]

\#24 (immuno or arginine* or glutamine* or nucleotide* or omega-3 or omega 3 or omega- 6 or omega 6 or " $\omega-3$ " or nucleoside* or fibre ${ }^{\star}$ or fiber ${ }^{\star}$ or IMP1000 or IMP500 or immunostimulat ${ }^{\star}$ or immuno-stimulat ${ }^{\star}[\mathrm{Ti}$ tle/Abstract])

\#25 ("Fatty Acids, Omega-3"[Mesh] OR "Fatty Acids, Omega-6"[Mesh])

\#26 "Glutamine"[Mesh]

\#27 "Nucleotides"[Mesh]

\#28 "Dietary Fiber"[Mesh]

\#29 (Argininosuccinic* or Benzoylarginine* or Homoarginine ${ }^{\star}$ or Nitroarginine ${ }^{\star}$ or Tosylarginine* or Methylarginine* or NO2Arg or NOARG or L-NMMA or D-NMMA or TAME or Proglumide* or Xylamide* or Xilamide or Milid or PUFA* or "n-3 fatty acid" en ${ }^{*}$ or Neuroprostane* or Icosapentaenoic* or Timnodonic or Linoleic ${ }^{\star}$ or Linolenic* or Octadecadienoic ${ }^{\star}$ or Linoleate* or Linoelaidic or "n-6 fatty acid*" or Eicosapentaenoic or EPA or 0-3FA* or 0-6FA* [Title/Abstract])

\section{\#30 (\#23 OR \#24 OR \#25 OR \#26 OR \#27 OR \#28 OR \#29)}

\#31 (enteral or polymeric* or Parenteral or diet* or feed ${ }^{\star}$ or food ${ }^{\star}$ or supplement ${ }^{\star}$ or nutri ${ }^{*}$ or formul* or tpn or enteric or Nutraceutical* or tube* or pn or SEN or "Ensure Liquid*"[Title/Abstract])

$$
\begin{aligned}
& \text { \#32 "Nutrition Therapy"[Mesh] } \\
& \text { \#33 "Nutritional Support"[Mesh] } \\
& \text { \#34 "Dietary Supplements"[Mesh] } \\
& \text { \#35 "Food, Formulated"[Mesh] }
\end{aligned}
$$$$
\text { \#36 (\#31 OR \#32 OR \#33 OR \#34 OR \#35) }
$$

\#37 (\#30 AND \#36)

\#38 (immunonutri* or immunoenhanc ${ }^{\star}$ or imn or ied or Pharmaconutri ${ }^{\star}$ or immune-modulat ${ }^{*}$ or immunomodulat* or IMEN or immunoenteral or IEEN or ien or immunodiet $^{\star}$ or immunoenrich* or ief or ieef[Title/Abstract])
201 or 19

21 exp arginine/

22 exp omega 3 fatty acid/ or exp omega 6 fatty acid/

23 exp glutamine/

24 exp nucleotide/

25 exp dietary fiber/

26 (Argininosuccinic ${ }^{\star}$ or Benzoylarginine* or Homoarginine* or Nitroarginine $^{\star}$ or Tosylarginine* or Methylarginine ${ }^{\star}$ or NO2Arg or NOARG or L-NMMA or D-NMMA or TAME or Proglumide* or Xylamide* or Xilamide or Milid or PU$F^{*}$ or "n-3 fatty acid*" or Docosahexaen* or Neuroprostane* or Icosapentaenoic* or Timnodonic or Linoleic* or Linolenic ${ }^{*}$ or Octadecadienoic ${ }^{*}$ or Linoleate* or Linoelaidic or "n-6 fatty acid $^{*}$ or Eicosapentaenoic or EPA or 0-3FA* or 0-6FA*).tw.

\section{1 or 22 or 23 or 24 or 25 or 26}

28 (enteral or polymeric ${ }^{\star}$ or Parenteral or diet* or feed ${ }^{\star}$ or food* or supplement $^{\star}$ or nutri ${ }^{\star}$ or formul ${ }^{\star}$ or tpn or enteric or Nutraceutical ${ }^{\star}$ or tube ${ }^{\star}$ or pn or SEN or "Ensure Liquid*").tw.

29 diet therapy/ or diet supplementation/ or nutritional support/

30 exp elemental diet/

3128 or 29 or 30

\section{7 and 31}

33 (immunonutri* or immunoenhanc* or imn or ied or Pharmaconutri ${ }^{\star}$ or immune-modulat ${ }^{\star}$ or immunomodulat ${ }^{*}$ or IMEN or immunoenteral or IEEN or ien or immunodiet* or ((immune ${ }^{\star}$ or immuno*) adj6 (enhanc* or enrich $\left.{ }^{\star}\right)$ ) or immunoenrich* or ief or ieef).tw.

34 (isosource or jevity or vivonex or osmolite or nutrison or "oral impact" or replete or alitraQ or immun-aid or optimental or perative or pivot or stresson or immunaid or nutrisource or Oxepa or immunex or cubitan or dipeptiven or omegaven or Reconvan or anom or oligopeptic or prosure* or Prem-8 or racol or RAC or rakol or ((impact or crucial) and (nestle or novartis))).tw.

3532 or 33 or 34 
(Continued)

\#34 MESH DESCRIPTOR Nutritional Support EXPLODE ALL TREES

\#35 MESH DESCRIPTOR Dietary Supplements EXPLODE ALL TREES

\#36 MESH DESCRIPTOR Food, Formulated EXPLODE ALL TREES

\section{\#37 \#32 OR \#33 OR \#34 OR \#35 OR \#36}

\section{\#38 \#31 AND \#37}

\#39 (immunonutri* or immunoenhanc* or imn or ied or Pharmaconutri ${ }^{\star}$ or immune-modulat* or immunomodulat* or IMEN or immunoenteral or IEEN or ien or immunodiet ${ }^{\star}$ or ((immune ${ }^{\star}$ or immuno*) near (enhanc ${ }^{\star}$ or enrich $\left.{ }^{\star}\right)$ ) or immunoenrich* $^{*}$ or ief or ieef):TI,AB, KY

\#40 (isosource or jevity or vivonex or osmolite or nutrison or rna or Ribonucleic or "oral impact" or replete or alitraQ or immun-aid or optimental or perative or pivot or stresson or immunaid or nutrisource or Oxepa or immunex or cubitan or dipeptiven or omegaven or Reconvan or anom or oligopeptic or prosure* or Prem-8 or racol or RAC or rakol or ((impact or crucial) and (nestle or novartis)))

\#41 \#38 OR \#39 OR \#40

\#42 \#22 AND \#41
\#39 (immune $^{\star}$ enhanc $^{\star}$ or immune enrich $^{\star}$ or immuno* enhanc ${ }^{\star}$ or immuno* enrich* ${ }^{\star}[\mathrm{Ti}$ tle/Abstract])

\#40 (isosource or jevity or vivonex or osmolite or nutrison or "oral impact" or replete or alitraQ or immun-aid or optimental or perative or pivot or stresson or immunaid or nutrisource or Oxepa or immunex or cubitan or dipeptiven or omegaven or Reconvan or anom or oligopeptic or prosure ${ }^{\star}$ or Prem-8 or racol or RAC or rakol[Title/Abstract])

\#41 ((impact or crucial[Title/Abstract])) AND (nestle or novartis[Title/Abstract])

\#42 (\#37 OR \#38 OR \#39 OR \#40 OR \#41)

\#43 (\#22 AND \#42)

\section{Web of Science (Web of Knowledge)}

\#1 TOPIC: (larynx or laryngeal or glottis or glottic or "oral cavity" or nasopharynx or nasopharyngeal or hypopharynx or hypopharyngeal or pharynx or pharyngeal or parapharyngeal or mouth or face or facial or oesophageal or esophageal or oesophagus or esophagus or thyroid or salivary or paranasal or "aero digestive" or aerodigestive or aero-digestive or (head near/3 neck))

\#2 TOPIC: (cancer* or carcinoma* or neoplasm $^{\star}$ or tumor ${ }^{\star}$ or tumour ${ }^{\star}$ or metastas $\left.^{\star}\right)$

\#3 TOPIC: (surg* or resect* or reconstruct $^{\star}$ or pharyngectomy or laryngopharyngectomy or laryngectomy or mandibulectomy or commando or esophagectomy or oesophagectomy or (neck and dissect ${ }^{\star}$ ) OR ((free or myocutaneous) and flap))

\#4 \#3 AND \#2 AND \#1
CINAHL (EBSCO)

S40 S22 AND S39

\section{S39 S36 OR S37 OR S38}

S38 TX isosource or jevity or vivonex or osmolite or nutrison or "oral impact" or replete or alitraQ or immun-aid or optimental or perative or pivot or stresson or immunaid or nutrisource or Oxepa or immunex or cubitan or dipeptiven or omegaven or Reconvan or anom or oligopeptic or prosure* or Prem-8 or racol or RAC or rakol or ((impact or crucial) and (nestle or novartis))

S37 TX immunonutri* or immunoenhanc* or imn or ied or Pharmaconutri* or immune-modulat ${ }^{\star}$ or immunomodulat* or IMEN or immunoenteral or IEEN or ien or immunodiet $^{\star}$ or ((immune* or immuno*) N6 (enhanc $^{\star}$ or enrich $\left.{ }^{\star}\right)$ ) or immunoenrich ${ }^{\star}$ or ief or ieef

\section{S36 S30 AND S35}

\section{S35 S31 OR S32 OR S33 OR S34}

\section{Trial Registries}

\section{ICTRP}

immunonutri* AND head AND neck or immunoenhanc* AND head AND neck or Pharmaconutri ${ }^{\star}$ AND head AND neck or immune-modulat* AND head AND neck or immunomodulat* AND head AND neck or immunoenteral AND head AND neck or immunodiet* AND head AND neck or immunoenrich*AND head AND neck or immune ${ }^{*}$ AND enhanc* AND head AND neck OR immune AND

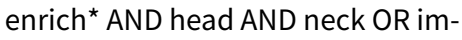
muno* AND enhance* AND head AND neck OR immuno* AND enrich* AND head AND neck

\section{ClinicalTrials.gov (via clinicaltrial- s.gov)}

immunonutrition OR immunoenhanced OR Pharmaconutrition OR immunomodulated OR immunomodulating OR immunoenteral OR immunodiet OR immunoenriched OR ((immuno OR 
(Continued)

\#5 TOPIC: (Argininosuccinic* or Benzoylarginine* or Homoarginine ${ }^{\star}$ or Nitroarginine $^{\star}$ or Tosylarginine* or Methylarginine* or NO2Arg or NOARG or L-NMMA or D-NMMA or TAME or Proglumide* or Xylamide* or Xilamide or Milid or PUFA* or "n-3 fatty acid*" or Docosahexaen* or Neuroprostane* or Icosapentaenoic * or Timnodonic or Linoleic* or Linolenic * or Octadecadienoic ${ }^{\star}$ or Linoleate* or Linoelaidic or "n-6 fatty acid*" or Eicosapentaenoic or EPA or 0-3FA* or 0-6FA ${ }^{\star}$ )

\#6 (enteral or polymeric* or Parenteral or diet $^{\star}$ or feed ${ }^{\star}$ or food ${ }^{\star}$ or supplement ${ }^{\star}$ or nutri $^{\star}$ or formul ${ }^{\star}$ or tpn or enteric or Nutraceutical ${ }^{\star}$ or tube* or pn or SEN or "Ensure Liquid $\left.{ }^{\star \prime \prime}\right)$

\#7 \#6 AND \#5

\#8 TOPIC: (immunonutri* or immunoenhanc* or imn or ied or Pharmaconutri ${ }^{\star}$ or immune-modulat* or immunomodulat* or IMEN or immunoenteral or IEEN or ien or immunodiet ${ }^{*}$ or ((immune ${ }^{\star}$ or immuno ${ }^{\star}$ ) near $/ 6$ (enhanc ${ }^{\star}$ or enrich $\left.{ }^{\star}\right)$ ) or immunoenrich* or ief or ieef)

\#9 TOPIC: (isosource or jevity or vivonex or osmolite or nutrison or "oral impact" or replete or alitraQ or immun-aid or optimental or perative or pivot or stresson or immunaid or nutrisource or $\mathrm{Ox}$ epa or immunex or cubitan or dipeptiven or omegaven or Reconvan or anom or oligopeptic or prosure* or Prem-8 or racol or RAC or rakol or ((impact or crucial) and (nestle or novartis)))

\#10 \#9 OR \#8 OR \#7

\#11 \#10 AND \#4

\section{S34 (MH "Food, Formulated+")}

S33 (MH "Dietary Supplements+")

\section{S32 (MH "Nutritional Support+")}

S31 TX enteral or polymeric* or Parenteral or diet $^{\star}$ or feed ${ }^{\star}$ or food ${ }^{\star}$ or supplement ${ }^{\star}$ or nutri $^{*}$ or formul ${ }^{\star}$ or tpn or enteric or Nutraceutical $^{*}$ or tube* or pn or SEN or "Ensure Liquid*"

\section{S30 S23 OR S24 OR S25 OR S26 OR S27 OR S28 OR S29}

S29 TX Argininosuccinic* or Benzoylarginine* or Homoarginine* or Nitroarginine* or Tosylarginine* or Methylarginine* or NO2Arg or NOARG or L-NMMA or D-NMMA or TAME or Proglumide ${ }^{\star}$ or Xylamide* or Xilamide or Milid or PUFA* or "n-3 fatty acid*" or Docosahexaen $^{\star}$ or Neuroprostane* or Icosapentaenoic* or Timnodonic or Linoleic ${ }^{\star}$ or Linolenic ${ }^{\star}$ or Octadecadienoic* or Linoleate* or Linoelaidic or "n-6 fatty acid*" or Eicosapentaenoic or EPA or $0-3 \mathrm{FA}^{*}$ or $0-6 \mathrm{FA}^{*}$

\section{S28 (MH "Dietary Fiber")}

S27 (MH "Nucleotides+")

S26 (MH "Glutamine")

S25 (MH "Fatty Acids, Omega-6+") OR (MH "Fatty Acids, Omega-3+")

S24 TX immuno or arginine* or glutamine* or nucleotide* or omega-3 or omega 3 or omega- 6 or omega 6 or " $\omega-3$ " or nucleoside* or fibre* or fiber ${ }^{\star}$ or IMP1000 or IMP500 or immunostimulat* or immuno-stimulat*

S23 (MH "Arginine")

S22 S1 OR S2 OR S21

S21 S13 AND S20

S20 S14 OR S15 OR S16 OR S17 OR S18 OR S19

S19 (MH "Neck Dissection")

S18 TX (free or myocutaneous) and flap

S17 TX neck and dissect*

S16 TX pharyngectomy or laryngopharyngectomy or laryngectomy or mandibulectomy or commando or esophagectomy or oesophagectomy

S15 TX surg* or resect* or reconstruct*

S14 (MH "Surgery, Operative+")

S13 S3 OR S4 OR S12 immune) AND (enhanced OR enriched OR enhancing OR enriching)) OR immune-modulating OR immune-modulated OR imn OR ied OR IMEN OR IEEN OR ien OR ief OR ieef

Condition: head and neck

\section{ClinicalTrials.gov (Cochrane ENT Register)}

1 (immuno or arginine* or glutamine* or nucleotide* or omega-3 or omega3 or omega- 6 or omega 6 or " $\omega-3$ " or nucleoside* or fibre* or fiber ${ }^{\star}$ or IMP1000 or IMP500 or immunostimulat* or immuno-stimulat $\left.{ }^{\star}\right): A B, E H, K W, K Y, M-$ C,MH,TI,TO AND INSEGMENT

2 (Argininosuccinic ${ }^{*}$ or Benzoylarginine ${ }^{\star}$ or Homoarginine* or Nitroarginine* or Tosylarginine ${ }^{\star}$ or Methylarginine* or NO2Arg or NOARG or L-NMMA or D-NMMA or TAME or Proglumide* or Xylamide* or Xilamide or Milid or PU$\mathrm{FA}^{*}$ or "n-3 fatty acid*" or Docosahexaen ${ }^{\star}$ or Neuroprostane* or Icosapentaenoic ${ }^{*}$ or Timnodonic or Linoleic* or Linolenic ${ }^{*}$ or Octadecadienoic ${ }^{*}$ or Linoleate* or Linoelaidic or "n-6 fatty acid*" or Eicosapentaenoic or EPA or O-3FA* or O-6FA $\left.{ }^{\star}\right): A B, E H, K W, K Y, M-$ $\mathrm{C}, \mathrm{MH}, \mathrm{TI}, \mathrm{TO}$ AND INSEGMENT

\section{3 \#1 OR \#2 AND INSEGMENT}

4 (enteral or polymeric* or Parenteral or diet* or feed ${ }^{\star}$ or food ${ }^{\star}$ or supplement $^{\star}$ or nutri* or formul* or tpn or enteric or Nutraceutical ${ }^{\star}$ or tube ${ }^{\star}$ or pn or SEN or "Ensure Liquid*"):AB,EH,KW,KY,MC,MH,TI,TO AND INSEGMENT

\section{5 \#3 AND \#4}

6 (immunonutri* or immunoenhanc * or imn or ied or Pharmaconutri* or immune-modulat* or immunomodulat* or IMEN or immunoenteral or IEEN or ien or immunodiet* or immunoenrich* or ief or ieef): $A B, E H, K W, K Y, M-$ C,MH,TI,TO AND INSEGMENT

7 ((immune* or immuno*) near (enhanc* or enrich*)):AB,EH,KW,KY,MC,MH,TI,TO AND INSEGMENT

8 (isosource or jevity or vivonex or osmolite or nutrison or rna or Ribonucleic or "oral impact" or replete or alitraQ or immun-aid or optimental or pera- 
(Continued)

\section{S12 S8 AND S11}

S11 S9 OR S10

S10 (MH "Neoplasms+")

S9 TX cancer* or carcinoma* or neoplasm* or tumor $^{\star}$ or tumour ${ }^{\star}$ or metastas*

\section{S8 S5 OR S6 OR S7}

S7 TX face or facial or oesophageal or esophageal or oesophagus or esophagus or thyroid or salivary or paranasal or "aero digestive" or aerodigestive or aero-digestive

S6 TX larynx or laryngeal or glottis or glottic or "oral cavity" or nasopharynx or nasopharyngeal or hypopharynx or hypopharyngeal or pharynx or pharyngeal or parapharyngeal or mouth

S5 TX head N3 neck

S4 (MH "Otorhinolaryngologic Neoplasms+")

S3 (MH "Head and Neck Neoplasms+")

S2 (MH "Otorhinolaryngologic Neoplasms+/

SU")

S1 (MH "Head and Neck Neoplasms+/SU") tive or pivot or stresson or immunaid or nutrisource or Oxepa or immunex or cubitan or dipeptiven or omegaven or Reconvan or anom or oligopeptic or prosure* or Prem-8 or racol or RAC or rakol):AB,EH, KW,KY,MC,MH,TI,TO AND INSEGMENT

9 ((impact or crucial) and (nestle or novartis)):AB,EH,KW, KY,MC,MH,TI,TO AND INSEGMENT

10 \#5 OR \#7 OR \#6 OR \#8 OR \#9

11 (nct*):AU AND INSEGMENT

12 \#10 AND \#11

\section{CONTRIBUTIONS OF AUTHORS}

Noah Howes (NH), Charlotte Atkinson (CA), Steven Thomas (ST), Stephen J Lewis (SJL).

- Conceiving the review: NH, SJL and ST

- Designing the review: NH, SJL and ST

- Co-ordinating the review: $\mathrm{NH}$ and $\mathrm{CA}$

- Undertaking manual searches: NH and SJL

- Screening search results: NH, CA, SJL and ST

- Organising retrieval of papers: SJL

- Screening retrieved papers against inclusion criteria: $\mathrm{NH}, \mathrm{CA}, \mathrm{SJL}$ and ST

- Appraising quality of papers: $\mathrm{NH}, \mathrm{CA}, \mathrm{SJL}$ and ST

- Abstracting data from papers: NH, CA, SJL and ST

- Writing to authors of papers for additional information: SJL

- Obtaining and screening data on unpublished studies: SJL

- Data management for the review: NH, CA and SJL

- Entering data into Review Manager (RevMan 5.3): NH and SJL

- RevMan statistical data: NH, CA, SJL and ST

- Other statistical analysis not using RevMan: $\mathrm{NH}$ and ST

- Double entry of data: (data entered by person one: $\mathrm{NH}$; data entered by person two: $\mathrm{ST}$ )

- Interpretation of data: NH, CA, SJL and ST

- Writing the review: $\mathrm{NH}, \mathrm{CA}, \mathrm{SJL}$ and ST

- Providing guidance on the review: JB, SJL and ST

- Securing funding for the review: N/A 
- Guarantor for the review (one author): SJL

- Person responsible for reading and checking review before submission: $\mathrm{NH}$

\section{DECLARATIONS OF INTEREST}

Noah Howes: no known conflicts of interest to declare.

Charlotte Atkinson: no known conflicts of interest to declare.

Steven Thomas: Steven Thomas was involved in the design, conduct and publication of a study of postoperative feeding in colorectal surgery (Lidder 2013) - funding support for that study was provided by Nutricia Ltd. He has no pecuniary interest in the product used in any of the studies.

Stephen J Lewis: Stephen J Lewis was involved in the design, conduct and publication of a study of postoperative feeding in colorectal surgery (Lidder 2013) - funding support for that study was provided by Nutricia Ltd. He has no pecuniary interest in the product used in any of the studies.

\section{SOURCES OF SUPPORT}

\section{Internal sources}

- No sources of support supplied

\section{External sources}

- National Institute for Health Research, UK. Infrastructure funding for Cochrane ENT

- National Institute for Health Research Bristol Biomedical Research Centre, UK.

This research was supported by the National Institute for Health Research (NIHR) Bristol Biomedical Research Centre. The views expressed are those of the authors and not necessarily those of the NHS, the NIHR or the Department of Health and Social Care.

\section{DIFFERENCES BETWEEN PROTOCOL AND REVIEW}

We have made the following changes from the protocol (Howes 2014):

- Authorship has changed from: Noah Howes, Stephen J Lewis, Steven Thomas to Noah Howes, Charlotte Atkinson, Steven Thomas, Stephen J Lewis.

- The Background has been reworked and updated.

- The outcome wound infection/fistula has been separated into two separate outcomes.

- We have clarified the measurement of some of the outcomes as follows:

- wound infections "as measured by the proportion of patients in whom any type or degree of wound infection was recorded, at any point postoperatively";

- fistula formation "as measured by the proportion of patients in whom a fistula was recorded at any point postoperatively";

- adverse events/tolerance of feeds "as defined by trial authors: as measured by the proportion of patients in whom adverse events relating to tolerance of feed was recorded, at any point postoperatively";

- all-cause mortality "as measured by the proportion of patients recorded as having died at any point postoperatively";

- postoperative complications as defined by trial authors "as measured by the proportion of patients in whom any type or degree of complication (other than wound infection, fistula formation or relating to tolerance of feed) was recorded, at any point postoperatively".

- We added "tolerance of feeds, as defined by trial authors" to the outcome "Adverse events" so that it now reads "Adverse events/ tolerance of feeds, as defined by trial authors".

- We added the following clarifying statement to Types of outcome measures: "We assessed the following outcomes in the review, but we did not use them as a sole basis for excluding studies".

- We have added a description of the method used to create a 'Summary of findings' table and carry out GRADE quality assessment.

- We did not conduct the planned sensitivity analysis to look at trial influence by sequentially excluding each trial due to the increased potential for obtaining spurious low $P$ values resulting from repeated analyses.

- We did not conduct the planned subgroup analysis of "preoperative immunonutrition versus placebo drink" because only one study (with three treatment groups) gave pre-operative immunonutrition alone in one group (Falewee 2014). However, eight studies gave immunonutrition pre- and postoperatively and the remaining 10 studies gave immunonutrition only postoperatively; we conducted analyses for these subgroups. 
- We removed "Biochemical changes, as defined by trial authors" and "Immunological changes, as defined by trial authors" from the secondary outcomes and have not formally assessed these because very few papers commented on immunological and biochemical parameter changes, and in each paper the markers chosen were different and assessed at differing time intervals. Meta-analysis of the few papers was thus not possible. Given the expected profound influence of the operative inflammatory response on levels of such markers, their interpretation is not straightforward.

\section{N DEX TERMS}

\section{Medical Subject Headings (MeSH)}

${ }^{\star}$ Food, Fortified [adverse effects]; Arginine [administration \& dosage]; Cause of Death; Fatty Acids [administration \& dosage]; Fistula [epidemiology]; Glutamine [administration \& dosage]; Head and Neck Neoplasms [complications] [^surgery]; Length of Stay; Malnutrition [etiology] [*therapy]; Postoperative Complications [epidemiology] [* prevention \& control]; Randomized Controlled Trials as Topic; Surgical Wound Infection [epidemiology]

\section{MeSH check words}

Aged; Humans; Middle Aged 